Portland State University

PDXScholar

1995

\title{
A Study of Special Preparation and Training Needs of Middle School Teachers
}

Marilyn Seger

Portland State University

Follow this and additional works at: https://pdxscholar.library.pdx.edu/open_access_etds

Part of the Junior High, Intermediate, Middle School Education and Teaching Commons Let us know how access to this document benefits you.

\section{Recommended Citation}

Seger, Marilyn, "A Study of Special Preparation and Training Needs of Middle School Teachers" (1995). Dissertations and Theses. Paper 1227.

https://doi.org/10.15760/etd.1226

This Dissertation is brought to you for free and open access. It has been accepted for inclusion in Dissertations and Theses by an authorized administrator of PDXScholar. Please contact us if we can make this document more accessible: pdxscholar@pdx.edu. 


\title{
A STUDY OF SPECIAL PREPARATION AND TRAINING NEEDS \\ OF MIDDLE SCHOOL TEACHERS
}

\author{
by \\ MARILYN SEGER
}

A dissertation submitted in partial fulfillment of the requirements for the degree of

\author{
DOCTOR OF EDUCATION \\ in \\ EDUCATIONAL LEADERSHIP: \\ ADMINISTRATION AND SUPERVISION
}

Portland State University

O.1995 
UMI Number: 9608483

Copyright 1995 by

Seger, Marilyn

All rights reserved.

UMI Microform 9608483

Copyright 1995, by UMI Company. All rights reserved.

This microform edition is protected against unauthorized copying under Title 17, United States Code.

\section{UMI}

300 North Zeeb Road

Ann Arbor, MI 48103 


\section{DISSERTATION APPROVAL}

The abstract and dissertation of Marilyn Seger for the Doctor of Education in Educational Leadership:

Administration and Supervision were presented May 1, 1995, and accepted by the dissertation committee and the doctoral program.

COMMITTEE APPROVALS:

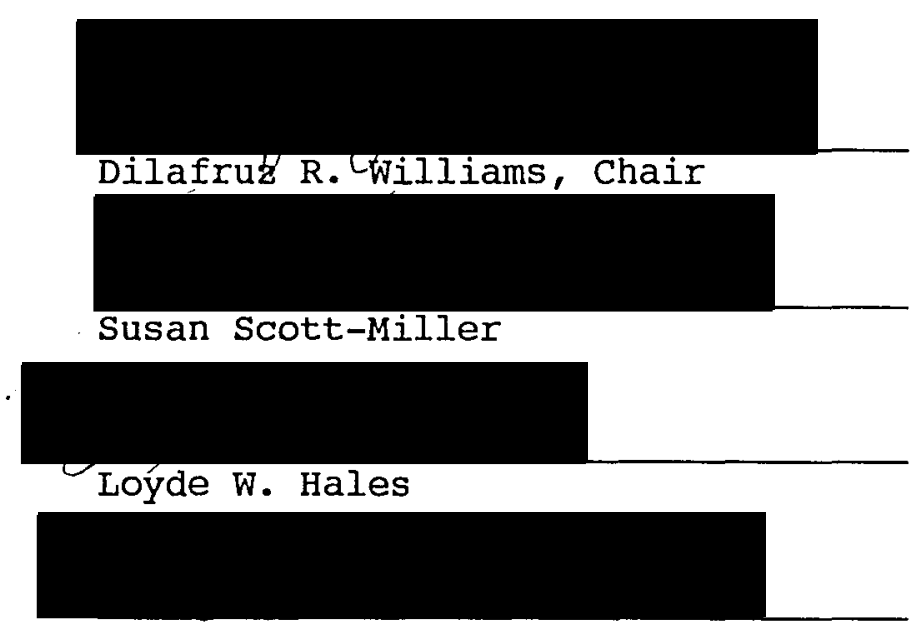

M. Carrol Tama

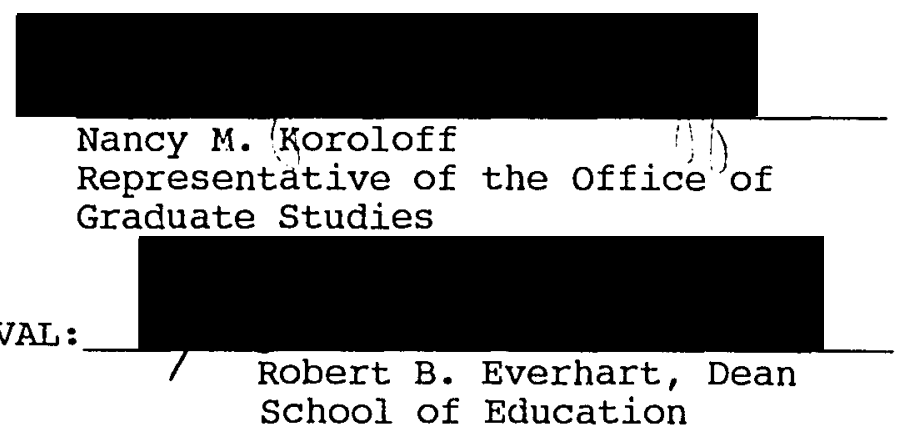

DOCTORAL PROGRAM APPROVAL:

School of Education

ACCEPTED FOR PORTLAND STATE UNIVERSITY BY THE LIBRARY

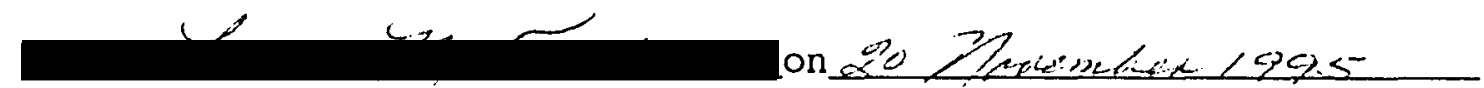


ABSTRACT

An abstract of the dissertation of Marilyn Seger for the Doctor of Education in Educational Leadership: Administration and Supervision presented May 1, 1995.

Title: A Study of Special Preparation and Training Needs of Middle School Teachers

The concept of middle level schooling has existed in the United States since the early 1900s. During the early 1960s, middle level schools were organized to meet the unique developmental needs of early adolescents. Yet, special training, preparation and/or certification for aspiring teachers who wish to work at this level is not available in the majority of states. Many state licensing agencies provide either elementary or secondary certification, which historically was believed to be adequate for middle level teaching.

This study investigates the special preparation and training needs of middle level teachers as perceived by teachers and administrators in a suburban school district which was involved for several years in the implementation of innovative practices for middle schools. Middle level educators in this district had received inservice training 
and were engaged in considerable discussions on research related to effective middie schools. Thirty teachers and 10 administrators were surveyed about their own levels of preparation and their concepts of the elements of model preparation programs for middle school teachers. In a follow-up interview process, including a sample of the survey respondents, interviewees discussed in-depth their district's middle school programs; the impact of a state grant focusing on middle school organizational and instructional issues; and their perceptions about staff development needs of middle school personnel that were not being addressed.

The data obtained through survey responses, interviews, and examination of district documents showed that the majority of the sample personnel received their training in middle school concept areas through formal inservice opportunities and/or on the job experience. Furthermore, a majority of the participants endorsed and expressed a need for the following: a special preparation program for middle school teachers containing field experience at the middle level; training in the unique developmental needs of the early adolescent; and, special training in a variety of instructional strategies. Results also indicated that the sample personnel were not aware of the school district's own studies on middle level schooling and were dissatisfied with the current programs, which they felt had suffered as a result of a lack of effective leadership at the district and building levels. 


\section{ACKNOWLEDGEMENTS}

To my family, who have inspired me, believed in me, and most importantly, supported me through this process, I am eternally grateful.

A very special thank you to my most recent advisor, Dr. Dilafruz williams, for her consistent prodding, her encouragement, and her willingness to take me on as an advisee.

An additional thank you to my first two advisors, Dr. John Lind and Dr. John Heflin, who helped me to begin this long endeavor and who have served as my mentors throughout the Educational Administration Program.

I am very appreciative of the input and the time that the other members of my doctoral committee, Dr. Loyde Hales, Dr. M. Carrol Tama, Dr. Susan Scott-Miller, and Dr. Nancy Koroloff, have given to me and to my effort.

I wanc to acknowledge the support that my school district has given me, both through tuition reimbursement and time to work on my research.

Lastly, I wish to dedicate this dissertation to the memory of my father, Lewis R. Masters, Jr., he always believed in me and his encouragement is sadly missed, and to the other people who are most important in my life--my mother, Eileen Masters, my grandmother, Roberta Floreth, my son, Rian, and my daughter, Erin; but most importantly to the 
iii

one person who is my love, my life, and the essence of my being, my husband of 23 years, Paul . . who is always there for me. 
TABLE OF CONTENTS

PAGE

ACRNOWLEDGEMENTS. .......................... ii

LIST OF TABLES......................... viii

CHAPTER

I INTRODUCTION...................... 1

Statement of the Problem............ 10

Purpose of the study............... 10

Research Questions................ 12

Importance of the study............. 13

Limitations of the study............. 15

Definitions of Terms.............. 16

summary .......................... 18

II REVIEW OF THE LITERATURE.............. 20

Introduction................... 20

Early Adolescent Development.......... 21

Physical Development of Early Adolescents

Intellectual Development of Early Adolescents

Social and Emotional Development of Early Adolescents

Effective Middle Level Schools......... 31

Effective Middle Level Teachers......... 41

Preparation Programs for Middle

Level Teachers................. 47 
The University of Georgia Program The University of Northern Colorado Program NCATE Guidelines for Middle Level Undergraduate Teacher Education

Summary...................... 79

III METHODOLOGY AND PROCEDURE.............. 84

Introduction.................... 84

Design of the Study............... 85

Population and sample............. 89

The Questionnaire................ 91

Interviews.................... 93

Historical Data................. 95

Data Gathering Procedures............ 96

Data Analysis..................... 97

Summary.................... 98

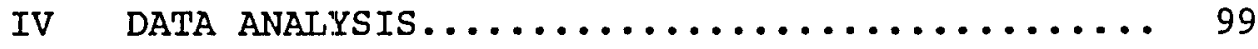

The River's Edge School District........ 100

Development of Middle Schools in the

River's Edge School District.......... 100

The 1980-1981 Middle School Study

The 1990-1991 Middle School Study

The 21st Century Grant School Improvement Grant

Description of Respondents........... 113

Presentation of Survey Data........... 118

Special Preparation of Teachers

special Preparation of Administrators

Training in Middle School Concept Areas The Advisor/Advisee Concept

The Interdisciplinary Teaching Concept

The Intramural Program Concept

The CORE Program Concept

The Activities Program Concept 
The Block Scheduling Concept

Varieties of Teaching Strategies

Exploratory/Elective Program Concept

Perceived Needs of Young

Adolescents

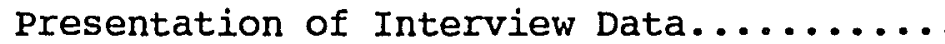

Successful Middle School Programs

Inservice Opportunities

The 21st Century School Improvement Grant

Needs of the Middle School Personnel

in the River's Edge School District

Data Synthesis................. 147

Special Preparation/Certification for

Middle Level Educators.............. 148

Unique Preparation Needs of Middle

Level Educators................. 149

How Should Teacher Preparation Institutions Address the Needs of Middle Level Educators...................... 154

Characteristics/Components of a Model Teacher Preparation Program for Middle School Teachers....................

Why Is Special Training/Preparation in Teaching at the Middle Level Desirable/ Crucial....................... 158

summary.................... 160

V SUMMARY, CONCLUSIONS, AND RECOMMENDATIONS.... 162

Summary....................... 163

Conclusions..................... 171

Recommendations for Further

Research..................... 191

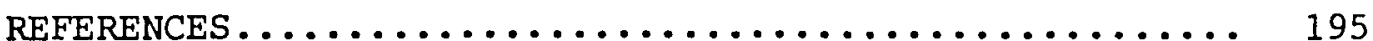


vii

APPENDIX

A MIDDLE SCHOOL STAFF QUESTIONNAIRES......... 202

B DEMOGRAPHIC DATA CHARTS................. 213 


\section{LIST OF TABLES}

\section{TABLE PAGE}

1. Advisor/Advisee Training of Teachers........ 122

2. Advisor/Advisee Training of Administrators................... 122

3. Interdisciplinary Teaching Training of

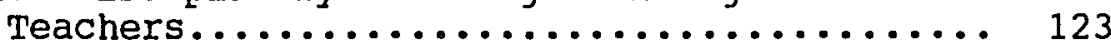

4. Interdisciplinary Teaching Training of Administrators..................... 124

5. Intramural Program Training of

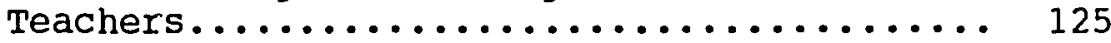

6. Intramural Program Training of

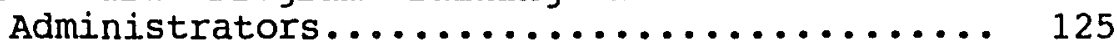

7. CORE Program Training of Teachers.......... 126

8. CORE Program Training of Administrators...... 127

9. Activities Program Training of Teachers...... 128

10. Activities Program Training of Administrators.................... 128

11. Block Scheduling Training of Teachers....... 129

12. Block Scheduling Training of Administrators.................... 130

13. Varieties of Teaching Strategies Training of Teachers....................... 131

14. Varieties of Teaching Strategies Training of Administrators.................. 131

15. Exploratory/Elective Program Training

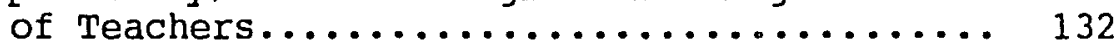

16. Exploratory/Elective Program Training

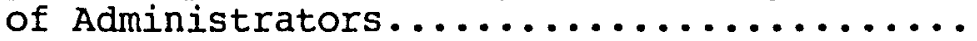


17. Perceived Developmental Needs of Early Adolescents........................ 136

18. Special Preparation/Certification for Middle Level Teachers................ 148 
CHAPTER I

\section{INTRODUCTION}

Separate educational facilities for early adolescents have existed in the United States since the early 1900s. Initially these schools were classified as junior high schools. Junior high schools were created to provide an appropriate educational program for young adolescents. In reality, they became mini high schools. The discontent with the junior high school program led to the birth of the middle school movement in the 1960 s.

Across the nation, reasons for establishing middle schools were numerous and varied. The principal reasons were: (a) to move ninth graders to the high school, (b) to provide a more effective transition between elementary and high school, (c) to correct the weaknesses of the junior high school, (d) to assist in desegregation, (e) to remedy crowded conditions in other schools, (f) to establish a program designed specifically for children in this age group, (g) to utilize new facilities, (h) to allow for more specialization in grades 5 and/or 6 , (i) to experiment with various innovations, and $(j)$ to test successful programs from other school systems (Alexander \& McEwin, 1984). Despite such a variety, the focus for the movement soon became to provide a 
quality educational program that addressed the needs and characteristics of early adolescents.

Although every child and every age level is unique, the time between the ages of 10 and 14 is one of the most trying and demanding that any child will face. During this time, dramatic changes occur in every aspect of one's being. Physically, these children experience the most rapid period of growth since their prenatal existence. Socially, their peers take precedence in their lives as they begin to pull away from their parents, testing their autonomy . Cognitively, they are developing their ability to think abstractly, to speculate about their social context, and to ponder their personal and social values. To complicate the issue, these stages occur at differing times and rates for all individuals, creating the high degree of diversity that is typical of this age group (Lipsitz, 1984). Schools that specifically educate these children have shown a definite increase since their inception in the 1960s. Research on this growth indicates that:

The middle school movement is one of the largest, most comprehensive efforts at educational reorganization in the history of American public schooling . . The middle school is probably the only major, humanistic, educator-inspired national innovation to survive and prosper over the last twenty years. (George \& Oldaker, 1986, p. 80)

Prior to the initiation of the movement in the 1960s, there were approximately 100 middle schools. According to the National Middle School Association (personal communication, November 1994), there are currently 12,384 schools containing grades five through nine. 
Indeed the middle school movement has gained national focus in the last few years with the publishing of the Carnegie Council on Adolescent Development's (1989) report Turning Points: Preparing American Youth for the 21st

Century. The report emphasized the importance of appropriate education for early adolescents.

The early adolescent years are crucial in determining the future success or failure of millions of American youth. All sectors of the society must be mobilized to build a national consensus to make transformation of middle grade schools a reality. (p. 10)

The leading force behind the middle school movement has been the National Middle School Association (NMSA). This association was formed in 1974. Its membership, consisting of teachers, administrators, college professors, and college students, has grown from 988 members in 1976 to 21,000 members in 1994. The primary purpose of the association is the promotion of middle school education. NMSA sponsors an annual conference, several regional and thematic conferences yearly, publishes a monthly journal, two newspaper supplements, an annual research document, a quarterly research journal, and a minimum of one or more monographs annually. "The educational community has come to recognize the Association as a prime source of information regarding the education of the emerging adolescent" (Swaim, 1982, p. 1).

There are definite parameters that have been established by NMSA that delineate the essential elements of an authentic middle school (Lounsbury, 1982). Though they acknowledged 
that other features could be components of middle school programs, the National Middle School Association listed these 10 elements as essential to the existence of a middle school: (a) educators knowledgeable about and committed to transescents, (b) a balanced curriculum based on transescent needs, (c) a range of organizational arrangements, (d) varied instructional strategies, (e) a full exploratory program, (f) comprehensive advising and counseling, (g) continuous progress for students, (h) evaluation procedures compatible with nature of transescents, (i) cooperative planning, and (j) positive school climate.

Thus, educators who work at the middle school level should want to work with early adolescents. Educators need to understand the unique needs and characteristics of this age as well as the human growth and development of these students. Normal for early adolescents is a need for peer communication, emotional ups and downs, challenging authority, and a need for physical movement. Elementary and/or secondary prepared teachers will most likely find these students to be a true enigma. Early adolescents need teachers who are committed to their success (Carnegie Council on Adolescent Development, 1989).

Staffing middle schools with teachers who understand the needs of students is not enough. Equally important is the need to formulate a curriculum that is responsive to the educational needs of these children. An ideal curriculum would balance academic goals with the human development needs of the early adolescent. 
In middle school, the climate for learning and the instructional processes used are nearly as important as the content itself. Both content and the student must be valued. (Lounsbury, 1982, pp. 10-11)

At this level, the process of learning--learning how to learn--is as important as the product of learning. A continued emphasis on basic skills could be mingled with aesthetics and attitudes. An effective curriculum would build upon the learning that occurred at the elementary level, yet be intellectually stimulating and rich in options and exploratory experiences (Sale, 1979). "Rather than being fixed and rigid in nature, it should be flexible, varied, and responsive to the continuously changing needs of middle school students" (Sale, 1979, p. 185).

This curriculum can be delivered through various organizational arrangements. Some ways to organize for instruction in a middle school are: interdisciplinary teams, block scheduling, core classes, multi-age grouping, developmental age grouping, alternate schedules, and/or a school-within-a-school arrangement. An effective middle school will employ several of these strategies, even have different arrangements at each grade level. The key is to experiment, or to have the flexibility to do so, until the pattern that best enhances the learning experiences of the students is found.

Within the established organizational arrangement, each teacher must develop a repertoire of effective and appropriate instructional strategies. Middle level teachers enter classrooms where skills and achievement levels are 
distributed across a broad continuum. Their students do not learn in uniform progression, rather they experience plateaus, rapid progress, and regression while being in varying stages of readiness. In addition to this variety of cognitive abilities, these students are generally very social in nature and are at the same time experiencing physical growth spurts. In general, teachers at the middle level should provide an activity and/or laboratory approach as opposed to a presentation and/or telling approach, although variety is really the answer. Some strategies that are effective are: cooperative learning for employing the social skills they value, short lectures for transmitting information, simulations for explaining complex systems, discussion for reinforcing and clarifying concepts, demonstrations and laboratories for making abstract theories more concrete, and meaningful practice for encouraging the refinement of new skills (Arth, Johnston, Lounsbury, \& Toepfer, 1985).

Middle school students are curious and enjoy investigating many things. One means of channeling this curiosity through the curriculum is through an exploratory program. The exploratory approach may be addressed in various ways such as through mini courses, exploratory courses, service clubs, special interest activities, and independent study projects. All of these options allow for an opportunity to experience brief, yet intense, interestbased activities (Lounsbury, 1982). 
One of the most difficult programs to establish, yet one of the most essential elements of a successful middle school, is an advisor/advisee program. Advisory programs provide students with a regular opportunity to meet with a small group of peers and a caring adult. Advisors have a special responsibility for their advisees, for their individual academic and personal welfare. As advisors get to know their advisees, they become advocates for those students. Advisors can provide insights for the other staff members about how to best assist those students in progressing at their own rates throughout the middle school years.

Teachers must understand that continuous progress for students is dependent upon careful assessment of learning styles, along with an increasing degree of student involvement in goal setting, determining methods of learning, and self-evaluation. To enable students to see that they are progressing, the evaluation and reporting procedures that are being used should be helpful in enabling these children to discover and understand strengths, weaknesses, values, and interests that they possess. The fragile nature of the young adolescent's self-esteem suggests that this process should focus on objective performance. The information should be as personal, reflecting individual uniqueness, as possible. Evaluation should be viewed as an integral part of the entire learning process (Lounsbury, 1982).

Effective middle schools are created and maintained through cooperative school wide planning. All staff-teachers, administrators, paraprofessionals, specialists-- 
must contribute to, believe in, and work toward the goals and vision of the school if it is to be successful. This cooperation and belief in the program leads to a positive school climate. Successful middle schools are places where a striking level of caring is pervasive. These schools could be viewed as a family where warmth, caring, and respect are as apparent in the halls, lunchroom, and offices, as in the classroom. This positive atmosphere:

which we all need and flourish under, is especially important for a vulnerable age group as they take the shaky first steps toward emotional independence. (Lipsitz, 1984, p. 181)

Effective middle schools also recognize and acknowledge the importance of parent participation in their program. "Families and middle grades schools must be allied through trust and respect if young adolescents are to succeed in school" (Carnegie Council on Adolescent Development, 1989, p. 69). The trend in parent involvement has traditionally spiraled downward as students move from elementary school to middle school. Parents tend to believe that their involvement at this level is discouraged by their children. These young adolescents are trying on their wings of independence often causing parents to believe that involvement on their part is not necessary any longer; however, these children really do want their parents to be involved. Opportunities for middle grades schools to provide avenues for parent participation could include: playing governance roles on school site councils, offering parents the means to support the learning process at school and at 
home, and maintaining open and effective communication processes (Carnegie Council on Adolescent Development, 1989). If these schools are to deliver effective education to the children that they serve, then the teachers that work in them might best be prepared through proper training from middle level teacher preparation and/or certification programs. Studies conducted by the National Middle School Association strongly endorse special preparation for teachers working at this level. NMSA (1986) created a Professional Preparation and Certification Committee to address this issue. This committee presented a proposal to the National Council for Accreditation of Teacher Education (NCATE). The proposal became the basis for the guidelines for middle level undergraduate teacher education. These guidelines were used by NCATE to evaluate programs beginning the spring of 1992 .

It appears that teacher training institutions are attempting to address the issue of special preparation because an increasing number are adopting such programs. In 1968, only two states reported some form of middle level teacher certification. By 1975, the number had increased to 15; and by 1987 the number had grown to 28 , with nine other states reporting that certification was under study (Alexander \& McEwin, 1988). However, teacher education institutions in the state of Oregon are not offering such special preparation programs. 
Statement of the Problem

Unlike many transitory reform efforts, the middle school movement, initiated almost 30 years ago, has proved to be a lasting phenomenon. It continues to grow and become more accepted as time passes. The rapid growth of middle schools far overshadows the increase of 38 in the past five years of institutions that now offer some form of middle level teacher education programs. In what ways, then, can institutions of higher education which provide teacher education training programs address the need for specialized training for prospective educators at this level? The training received in elementary and secondary teacher education programs may not be designed to prepare teachers to work effectively with middle school aged students. Thus, the need for special preparation and middle school inservice training by local school districts should be addressed.

\section{Purpose of the Study}

The primary purpose of this study was to determine the extent to which middle level educators believe that special preparation is necessary, in order to become effective middle school teachers. River's Edge, a suburban school district in the state of Oregon, was used for this case study, since River's Edge had been particularly innovative and vigorous in its attempt to address the special preparation needs of middle level teachers and administrators. The rationale for using River's Edge as a case was the belief that in order to understand the special preparation needs of middle level 
educators, historically, the educators should have had a thorough grounding in the research and issues of implementation of the middle level. It appeared that this information would be a prerequisite for understanding this need. Moreover, the investigator had been associated with River's Edge School District for a number of years and hence had a historical and contextual understanding of the efforts and issues associated with these special needs. River's Edge School District was used for this case study, specifically, to investigate what types of preparation middle level educators had received and what kinds of classes and/or training they would include in a model specialized preparation program for middle level teachers. A secondary purpose was to determine whether these educators believed that a separate certification should be required for middle school teachers, and what their rationale was for such certification. Finally, the study traced how the River's Edge School District began the implementation of a middle school program and how that program has evolved over a 10-year period.

To accomplish these purposes, the case study, investigated whether the unique nature of middle schooling necessitates a specialized preparation program for those aspiring educators who are planning to work in middle level schools. A survey and follow-up interviews were conducted as a means of gathering data. The data were analyzed and then parallels were drawn between the results of this study with those that had previously been done. Two such programs, at 
the University of Georgia and at the University of Northern Colorado, were used because they were ranked by NMSA as being most successful.

Parallels from the case study data were also sought with the guidelines for preparation programs developed by the National Council for Accreditation of Teacher Education. Based on the results of the study, several recommendations are made.

\section{Research Questions}

The study was designed to answer the following research questions :

1. Do the teachers and administrators of the River's Edge School District believe that there should be special preparation/certification for middle level educators incorporated into the teacher education program in the state of Oregon? For what reasons?

2. How did the River's Edge School District, with three schools containing students ages 10 to 14 , implement a middle school program? How did the district involve staff and parents in this process? How could the district assess the effectiveness of its progress toward this endeavor?

3. What are the unique preparation needs of aspiring middle level teachers as perceived by teachers and administrators of the River's Edge School District?

4. How should these needs be addressed by teacher preparation institutions? How can the River's Edge School 
District address the needs for inservice and staff development initiatives?

5. What do the teachers and administrators of the River's Edge School District recognize as the characteristics or components of a model teacher preparation program for middle school teachers?

\section{Importance of the Study}

The need for special preparation for middle level educators has been addressed by NMSA and NCATE through their guidelines for middle level undergraduate teacher education. It has been called for in the plans for action in Turning points, a report of the Carnegie Council on Adolescent Development (1989) that stated:

We ask leaders in higher education to focus immediately on changes needed in the preparation of middle grade teachers and in ways of collaborating with middle schools to support their reform. (p. 10)

The middle school phenomenon has reached oregon; however, the concept of specialized teacher preparation and/or certification (licensure) at the middle level is not an option in this state. The professional courses required for the two basic licensure programs (elementary and secondary) offered by Oregon state System of Higher Education institutions may not be providing adequate preparation for aspiring teachers considering working with students in middle level schools. The licensure programs in Oregon are not addressing the uniqueness of the educational program that exists at the middle level. They are not specialized enough 
to provide proper training for middle level instruction. Teachers at the middle level with elementary certification cannot expect to maintain order and present lessons in the relatively unnegotiated manner of the elementary school classroom. Early adolescents do not automatically acquiesce to the wishes of adults. They are:

impulsive, self-absorbed, antagonistic to and dependent on adult authority, alternatively energetic and enervated, vociferously independent and slavishly conformist. (Lipsitz, 1984, p. 180)

Furthermore, those educators who have been trained to teach at the secondary level--with the majority of their training being in a specific subject area--have very little background in child development. They have not been prepared to deal with the typical ups and downs of working with those students, with:

the bad days when young adolescents go for the jugular . . to . . the good times when they are most enthusiastic, creative, and appreciative students one can teach. (p. 186)

Effective teachers of middle level students are knowledgeable about emerging adolescents, use varied instructional strategies, use hands-on methods and materials, are attentive to differences in learning styles, and view the school and the classroom as social systems. It is likely that the only training middle level educators in oregon can expect to receive is either on the job training or inservice training, neither of which is a preservice option, since the state licensing agency does not require special preparation for middle school educators. 
The results of this case study provide important information for shaping the middle level teacher preparation policies, programs, and practices at the state and local levels (districts); as well as for defining staff development and organizational plans for the River's Edge School District.

\section{Limitations of the Study}

This study is limited by three factors. First, being a case study of the River's Edge School District, a suburban school district, the results of the sampling of teachers and administrators cannot be generalized to other suburban districts or to urban or rural districts, because it is not possible to know what is idiosyncratic to the district or what might suggest a trend. Additionally, using a school district that had a reputation of having a strong middle school orientation may have had a limiting influence on the study. This initial level of expertise could have had an impact on the participants of the study. Second, the investigator had been historically associated with River's Edge. While this can be a strong asset in terms of the historical and contextual understanding of data, there is also the potential of some bias. Third, in examining specialized preparation programs only two were selected--the program at the University of Georgia and the program at the University of Northern Colorado. While these two programs were chosen because the National Middle School Association ranks them as two of the most successful in the country, neither of these programs address suburban needs per se; 
therefore, in looking for parallels with the case study results, there are some Iimitations.

$$
\text { Definitions of Terms }
$$

Advisor/Advisee Program: in an advisor/advisee program an advisor (teacher, administrator, specialist) meets regularly (daily is optimum, once a week minimum) with a group of students. The smaller the advisee group, the better, since the effectiveness decreases with over 20 students as advisees. An advisee group could be cross-graded $(6,7,8)$ or grade specific $(6$ or 7 or 8$)$. The advisor serves as an advocate for each advisee in both academic and personal welfare.

Block Scheduling: in block scheduling, a block of time is set aside for instruction of basic subjects. Interdisciplinary teams of teachers of math, science, social studies, language arts, and/or reading schedule their students during a block of time. This allows for flexibility in scheduling, one day math could be 40 minutes, the next 90 minutes. It also allows teachers to have control over their own schedules.

Certification: the licensing procedure that enables school personnel to work in the public school system. The literature uses the term certification; however, in Oregon, the procedure is now termed licensure.

CORE Program: a manner of scheduling where a number of subjects (usually Language Arts, Literature, and Social 
Studies) are taught by the same teacher to a common group of students.

Endorsements: additional specific requirements for receiving certification.

Exploratory Program: the time during middle school students' schedules when they are able to explore classes other than the basics. Some examples of exploratory classes would be: band, computers, chorus, drama, journalism, art, foreign language. Some exploratory programs include physical education and health as two of the options. An exploratory class is usually limited in scope and typically lasts 6-18 weeks •

Interdisciplinary Teams: a combination of teachers who teach basic subjects (language arts, reading, math, science, social studies) to a particular group of students. The team may consist of two to five members. The team shares common planning time.

Intramural program: an opportunity for activity, generally of an athletic nature, between two groups of students. The groups are not established by ability. The purpose of the activity is neither competitive nor interscholastic in nature.

Middle School: an educational organization that generally encompasses grades șix through eight. It serves an emerging adolescent population (ages 10-14) by providing a comprehensive program (physical, social, emotional, intellectual, moral) that is balanced and success oriented (continuous progress). 
NCATE: (National Council for Accreditation of Teacher Education) the primary accreditation agency for teacher education institutions in the United States.

NMSA: (National Middle School Association) a national association of teachers, administrators, college professors, and college students that promotes and investigates middle school education.

Transescent: a term created by Eichhorn (1966) describing an early adolescent:

the stage of development which begins prior to the onset of puberty and extends through the early stages of adolescence. Since puberty does not occur for all precisely at the same chronological age in human development, the transescent designation is based on the many physical, social, emotional, and intellectual changes in body chemistry that appear prior to the puberty cycle to the time in which the body gains a practical degree of stabilization over those complex pubescent changes. (p. viii)

TSPC: (Teacher Standards and Practices Commission) the state licensing and regulation agency for school personnel in Oregon.

\section{Summary}

This chapter introduced the concept of a unique educational process, the middle school, from its inception to its rapid growth and national focus over the last few years. It discussed the importance of realizing that this level of schooling is as viable as that of the elementary and secondary systems and should be acknowledged as such by the professional education community. 
The influence of the National Middle School Association on this educational level is outlined. Because this program merits special recognition, it should also require having professionals who would be solely trained to work in middle level schools and with middle level students.

The chapter also stated the problem the study would investigate, the study's purpose, the research questions to be answered, and the importance of such research. It also outlined the limitations of the study and defined key terms used in the investigation. 
CHAPTER II

REVIEW OF RELATED LITERATURE

\section{Introduction}

The main focus of this study is the need for specialized teacher preparation for middle level teachers. A review of the literature includes the following areas of research:

(a) current findings on adolescent development, (b) effective middle level schools, (c) effective middle level teachers, (d) preparation programs for middle level teachers, and (e) NCATE guidelines for schools and colleges of education in designing middle level undergraduate teacher education programs.

Each area of research covered in this chapter relates to quality educational experiences for middle level children. To work effectively with middle level students, it is important to understand their nature, how they develop, and the forces that impact their development. There has been an increased interest from the scientific community in the study of adolescence:

as reflected in the establishment of the society of Research on Adolescence in 1985 and in the increased number of scientific journals, meetings, and books on adolescence research. (Epstein \& Petersen, cited in Maclver \& Epstein, 1991, p. 520)

Numerous studies have been conducted evaluating what the essential organizational, instructional, and curricular elements of an effective middle school program are, and 
Consensus has been reached among experts in the field of early adolescent education.

Similar studies have investigated the characteristics of effective middle level teachers and the skills that are required for being successful in working with transescents. More recently, a focus of middle level educational research has been the investigation of established preparation programs for middle school teachers. The results of this research prompted the advisory committee for teacher preparation of NMSA to work closely with NCATE to establish the guidelines for middle level teacher education. An examination of the four areas of research, along with the NCATE guidelines, seems to indicate that there may be a relationship between the uniqueness of middle level schooling and the need for specialized training for people who elect to work in an educational setting with the transescent learner.

Early Adolescent Development

Life for early adolescents is significantly different from what it was for their parents or grandparents. In 1990, a report of the National Commission on the Role of the School and the Community in Improving Adolescent Health, which is a joint effort of the American Medical Association and the National Association of State Boards of Education, found that "for the first time in the history of this country, young people, are less healthy and less prepared to take their places in society than were their parents" (Scales, 1991, p. 23). This is a critical time in a young adolescent's life 
cycle, a time for leaving childhood behind and facing the complicated world of adulthood. This concept was reinforced in the research of Eccles, Midgley, Wigfield, Buchanan, Reuman, Flanagan, and MacIver (1993):

Few developmental periods are characterized by so many changes at so many different levels--changes due to pubertal development, social role definitions, cognitive development, school transitions, and the emergence of sexuality. (p. 90)

The U.S. Bureau of Census estimates that during the 1990s more than 65 million children will become early adolescents between the ages of 10 and 15 (Scales, 1991, p. 2). From rural communities to urban, young adolescents struggle with a changing society:

with the concomitant loss of family networks of support, role models, communities of shared values, and opportunities to be meaningfully involved in life; changes in family structure (for example, blended, single parent, and both parents working), leading to a decrease in meaningful dialogue, interaction, and support; and the advent of television with its wide range of potential and often "foreign" models and values. (Whisler, 1990, pp. 3-4)

Numerous studies on early adolescence pinpoint this stage as the last opportunity to save our nation's children, to prevent the youth problems that plague our country. Today's adolescents are at risk of becoming delinquent, failing at school, dropping out of school, abusing drugs and alcohol, and/or becoming an adolescent parent (Scales, 1991). This is a time in their lives when these children initiate the "formation of behavioral patterns that have lifelong consequences for the educational performance and health 
status that will shape their future" (Hamburg, 1993, p. 466). This is when young students are very impressionable, malleable, and easily open to influence.

\section{Physical Development of Early} Adolescents

Physical growth for early adolescents is characterized as dramatic and accelerated. Indeed it is the time in a person's life when more rapid growth is experienced than any other time in the development process other than fetal and neonatal growth. Females tend to mature more rapidly than males. According to studies by Van Hoose and Strahan in 1988, the average gain in height is two to four inches a year while the average gain in weight is 8 to 10 pounds a year. This means that during the early adolescent years (10 to 15) a middle level student could experience a gain of 10 to 20 inches in height and 40 to 50 pounds in weight.

Many of the disturbing behaviors that students exhibit at the middle school level can be attributed to their physical development. Preadolescent boys tend to delight in roughness and aggressive play. The need for this activity correlates with physiological changes (muscle size and strength increase). This rapid muscular growth is also demonstrated by the restless energy that is ever present in the middle school classroom (George \& Lawrence, 1982).

This growth process occurs at different rates for each individual, but common responses to these phenomena are evident among students. Early adolescents are preoccupied with their body image and the awakening of sexual interests. 
These states of temporary disproportion can create a feeling of awkwardness and some students experience trouble with coordination. This preoccupation with body changes often influences the ability to concentrate and generally results in a short attention span (George \& Lawrence, 1982). Children in middle school continually compare themselves to all the other students they encounter throughout their school day. They feel that they are constantly on display. They experience what some experts refer to as an imaginary audience:

The typical adolescent believes that her story or his story is so unique and his/her troubles so great and different that no one, especially adults, can appreciate his/her needs, interests or concerns. (Van Hoose \& Strahan, 1988, p. 8)

In general, early adolescents do not possess the knowledge or the information to understand that what they are experiencing is a normal process:

Young adolescent girls and boys need to know some basic facts about the ranges for the events of puberty and some basic facts about these sexual developments. (p. 10)

our society places a tremendous emphasis on sexuality. Advertising, television, and movies promote sexual activity. The young adolescent's life is further complicated by the onset of puberty, another major physiological occurrence. The Planned Parenthood Federation conducted polls in 1986 and 1988 to discover the proportion of adolescents experiencing their first sexual intercourse before age 15. The results showed that "298 of adolescents had had sexual intercourse by age 15, and $20 \%$ by age 14" (Scales, 1991, p. 26) in 1986, and 
by 1988 the numbers showed that "33\% of boys and $27 \%$ of girls had had sexual intercourse by age 15" (p. 26). Further disturbing evidence shows that between 1973 and 1985 the pregnancy rates of adolescents under the age of 15 increased by $23 \%$ while the abortion rates of the same age group increased by $63 \%$. In addition:

young people who are both academically poor students and living in poverty are three to five times more likely to become adolescent parents than their peers who are good students and live above the poverty line. (p. 27)

Another health issue related to increased sexual activity is the spread of the AIDS (Acquired Immune Deficiency Syndrome) virus among adolescents. "From 1988 to 1991, AIDS cases among 13- to 19-year-olds increased more than 100\%" (Scales, 1991, p. 28). Studies also show that as more adolescents are experiencing problems related to early sexual experiences and poor emotional health, fewer opportunities will be available to them for physical and mental health services. Only about $25 \%$ of the students in Scales' study were exposed to health education in their schools. This exposure amounted to less than one year of study. The other 758 of the students received an even shorter amount of time in health education classes.

Intellectual Development of Early Adolescents

Early adolescents also experience cognitive development as well as physical.

Functional intelligence is not fixed at birth or any other age, and it is profoundly influenced by individual experience, especially the experience 
that comes under the influence of significant persons in a child's life. (George \& Lawrence, 1982 , p. 43)

This developmental process in children's thinking seems to change in a gradual and continuous manner. Although it was suggested by some researchers that this is the time in children's lives when they transition from Piaget's (1972) concrete operational stage to the formal operational stage, cognitive development for the early adolescent is not easily summarized. The correlation between age and cognitive development is not perfectly established.

In Piaget's (1972) concrete operational stage, a student's thinking is tied to their concrete, personal experience. In the formal operational level a person has the ability to reason beyond personal experience to perform logical operations concerned with the possible, not just the actual. The process of moving from the concrete level to formal operational level cannot be taught. It develops through the experiences of life. This process is a complicated one and is as uneven as the physical growth of young adolescents. In fact, students may even be able to think abstractly in one subject area but not in another (George \& Lawrence, 1982).

There is no doubt that a large majority of ten-tofourteen-year-old students operate at the level of concrete thinking and need further development of the structures of concrete thought before they will reach formal operations . . . Formal operational thinking, in contrast, does not develop in all people. Some experiments suggest that perhaps onethird of American adults never fully achieve formal operational thinking. (p. 46) 
Concrete thought also involves the concept of egocentrism that is evident in the 10- to 14-year-old. Egocentric early adolescents exist in a world where everything develops meaning in relation to their own needs and interests. The principal factor in influencing the transition from egocentric to a sociocentric perspective is social interaction with peers (George \& Lawrence, 1982). A number of different studies have investigated this issue (Adelson/Adelson, Green, \& O'Neil/Flavell/Thornburg, all cited in Scales, 1991). One interesting study was conducted by Adelson, Green, and O'Neil. These researchers asked 10to 15-year-olds to resolve hypothetical dilemmas that juxtaposed community-oriented solutions with individuallyoriented ones:

The study suggests that the 10-to-11-year-old is characterized more by the predominance of concrete thinking, an ego-centric perspective, a focus on "right now," and on fairly rigid standards of right and wrong. The 14-and-15-year-old is characterized by more abstract thinking, the ability to consider possibilities and not just realities, to see things from another person's point of view, to allow perceived consequences of behavior to temper the desire for immediate gratification of wants, and to consider exceptions to the rules. (Scales, 1991, p. 12)

Social and Emotional Development of Early Adolescents

As with other developmental processes young adolescents experience social and emotional change. Adults who have limited exposure to children from ages 10 to 14 often describe the middle school years as a time of storm and 
stress. This view is exaggerated and generally a distortion of the facts.

These mood and behavior swings are not unusual and may be associated with hormonal activity, with adjusting to the varying expectations of others, or with confusion and ambivalent feelings about the changes that are taking place in their bodies. (Dorman, 1984, p, 5)

They are minor incidents that come and go very quickly and are more easily forgotten during this time period. It further complicates the issue because if the people who live and work with these children expect them to be irresponsible and to demonstrate bizarre behavior then they will communicate messages to these children that could diminish their self-esteem.

One of the most prevalent changes is the growing importance of the peer group. A sense of acceptance in this peer group is a key element in early adolescents' self-worth. Everything they do and all of the people they encounter tend to influence how they view themselves.

It is through trial and error with peers that youth learn and practice socially acceptable behavior and begin to establish a sense of who they are as young men and women. (Dorman, 1984, p. 4)

This process of forming friendships is an important sign of social and emotional growth that is essential in the journey toward healthy adulthood. To the other extreme, some young adolescents cling to the security of their peer group and may actually yield their own individuality and act in ways that are contrary to how they really think and/or feel 
just to remain a part of the group (Van Hoose \& Strahan, 1988 )

Friendships that children experience prior to the onset of adolescence are generally based upon shared activities and interests, not on strong emotional ties. Young adolescents' friendships affect males and females in different ways. The physicality of males, their penchant for horseplay, is prevalent in their demonstrations of friendship.

To girls especially, the peer group is crucial in developing the capacity for intimate caring and trust, for it is within the peer group that girls first begin mutually to share deep feelings, concerns, and hopes. (Dorman, 1984, p. 4)

Emotionally healthy young adolescents maintain close relationships with their families and their peer groups. (They) report that they look to the peer group for association and companionship and to their families for affection, identification, values, and help in solving large problems - . . Young adolescents do want freedom to choose their hair styles, clothes, and entertainment, and to be like their friends in these areas, but they are likely to retain their parents' social and moral values. (Dorman, 1984, p. 4)

Another major factor influencing the lives of early adolescents is the way they view themselves and feel about themselves. Again a disparity between genders arises. One study involving 6,000 adolescents in 10 countries showed that boys generally had higher levels of self-esteem than girls.

Despite recent gender role changes in industrialized nations, these researchers concluded that there is still more power and prestige associated with young males' life options than with the life options of young women in these countries. Young women in early adolescence begin to discover this power and prestige disparity for the first time. (Scales, 1991, p. 10) 
Other studies have indicated that in general early maturing girls have lower self-esteem than their female peers, while the opposite holds true for early maturing boys who tend to have higher self-esteem than late maturing males. Some research also reports that as a result of gender role socialization early adolescent girls more generally demonstrate lower self-esteem than boys of the same age. "Carol Gilligan's latest case studies of young adolescent girls suggest that the confident 11-year-old often becomes confused and quiet by age $16^{\prime \prime}(\mathrm{p}, 10)$.

Not only gender but age is a factor in social and emotional development. Early adolescents experience more difficulties with self-image than they did when they were 8- to 11-year-olds. As 12- to 14-year-olds, they tend to have less positive and/or stable opinions about themselves. These young adolescents also tend to believe that other people have negative opinions about them.

This instability of self-image and diminished selfesteem usually declines in later adolescence as young people adjust to the changes that have taken place in their bodies and begin to develop a more stable sense of identity. (Dorman, 1984, p. 5)

One societal institution that is capable of directing and molding young adolescents is the school. Schools that serve middle level students are pivotal establishments in their lives. Problems may arise because the world around these early adolescents is continually changing, but the schools that they attend are usually not changing at a commensurate rate. 
Effective Middle Level Schools

Effective middle level schools are not junior or mini high schools. Their programs do not mimic a secondary or high school structure. They are unique to the students they serve, to the developmental needs of the early adolescent. Eichhorn (1987), one of the first authors to describe the middle school phenomena, believed that the nature of transescence lends itself to a learning environment that allows for flexibility. It is an environment where close relationships between students and staff members are integral. These trusted adults are people who assist the transescents in understanding the strange and rapid growth processes they are experiencing. It is an environment that encourages social involvement, which is helpful to students' mental growth. It provides them with the opportunity to be involved in making decisions relating to school life. The middle school climate must emphasize physical movement rather than inactive proceedings. Students should be grouped irrespective of chronological ages or grade levels. They should be given the opportunity to understand and be active participants in change (Eichhorn, 1966).

Eichhorn's book, entitled The Middle School, was first published in 1966. It has been described as being 30 years ahead of its time. It was reprinted in 1987 and Eichhorn added a foreword entitled, "The Middle School: Reflection and Challenge." In this foreword Eichhorn described the middle school as "One of the few innovations that has survived the 
test of time" (p. vii). He described the growth of the middle level concept as dramatic and added that:

if middle level education is to continue to develop as it should, educators must focus their attention on the basic idea that middle level students differ significantly from those at elementary and high school levels. (pp. viii-ix)

One of the next major studies conducted on middle schools was done by Lipsitz (1984), director of the Center for Early Adolescence at the University of North Carolina at Chapel Hill. In 1980-1981, Lipsitz worked as a research associate for the National Institute of Education investigating effective middle grade schools that foster healthy development. A product of her research is the book entitled, Successful Schools for Young Adolescents. This book is a descriptive and interpretive study of four exemplary middle schools: Western Middle School in Alamance County, North Carolina; Region 7 Middle School (The Dorothy I. Fisher Magnet Middle School) in Detroit, Michigan; Noe Middle School in Louisville, Kentucky; and, Shoreham-Wading River Middle School in Shoreham, Long Island. Each school was successful and each was unique, with its own distinctive school community.

Lipsitz (1984) found some recurrent themes existing in these successful middle schools.

The most striking feature of the four schools is their willingness and ability to adapt all school practices to the individual differences in intellectual biological, and social maturation of their students. (p. 167) 
These concepts were addressed in one school through offering mini courses, providing responsible choice to its students and an opportunity to pursue personal interests. In two schools, schools-within-a-school programs operated to allow small groups of students to be known by small groups of teachers who regulated the daily schedule based on their needs. The fourth school achieved this goal by operating an advisor-advisee program that gave all of the students daily contact with an adult who took time to listen to and comfort them. Each of these schools was a positive environment for early adolescent personal and social development. It was believed that the positive environment contributed to academic achievement. The central goal for all four schools was an emphasis on academics, and this goal was understood by all staff members.

Everyone in each school, staff and students alike, believed that their school was special; that their school was the best. As Lipsitz (1984) explained:
Made to feel like chosen people, staff and students have banded together in their specialness and achieved accordingly. The sense of definition that comes from the exclusivity felt by each school is important in keeping staff morale high and retaining parent support. Most important, though, is the sense of purpuse it gives the young adolescents. It helps bind them to the school. It is incumbent upon adults to articulate something that a school stands for and that students can be defined by and stand with. (p. 172)
The principals of all four schools had a vision of what appropriate schooling for early adolescents was and each transmitted this perspective to the school's staff. These 
instructional leaders believed in empowering their teachers. They demanded commitment from their faculty and in turn provided professional and personal support to their teachers. These ideologies also secured and protected the autonomy of their schools in their districts. Since they administered such effective schools, the central office administration trusted their judgment, and they were afforded a large degree of latitude in leading their schools (Lipsitz, 1984).

A strong belief that was pervasive in all four schools was the notion that their schools were not secondary institutions. These were schools where caring is a dominant force. The staffs believed that:

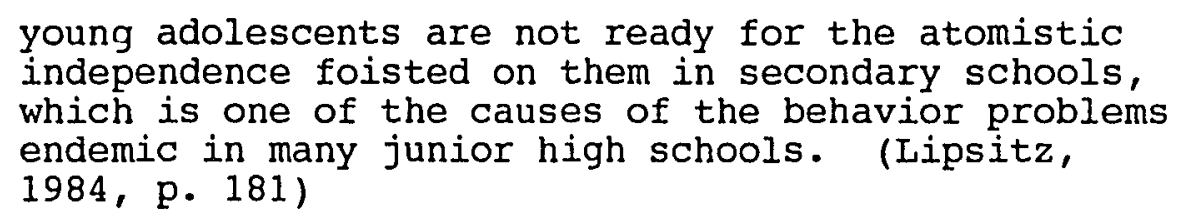
endemic in many junior high schools. (Lipsitz, 1984 , p. 181)

These schools allowed their students to gradually gain more independence, while continually being supported by adults and their peers in special groups (houses, teams, advisory groups). Students in the four schools reported that they knew they are cared for and liked. "Antisocial behavior that results from the randomness and brevity of student groupings in most secondary schools is substantially reduced in these schools" (p. 182).

As mentioned previously, the teachers in all four schools were empowered to make important decisions. They were the curriculum builders, budget preparers, schedulers, and student advisors of their particular schools. Their process of decision making was collegial and their basis for 
decision making was the academic and social well-being of the particular group of students with whom they worked. The atmosphere in which they work was one replete with collegiality. Opportunities to work together were encouraged through common planning and lunch periods, team meetings, and team teaching. A majority of these teachers believed that they could do a great deal to see that all of their students achieved at a high level. They were described by their students as caring, involved and "with it" (Lipsitz, 1984). Each of the four schools was organized in a different way. Each was organized to enhance communication, personalization, continuity in relationships, and individual choice. The school philosophy, influenced by sensitivity to the age group, shaped the organizational design. The organizational structure had evolved over time in response to the staff's evaluations of the students' needs. These schools were responsive to the particular social contexts of the communities that they served; yet, all four had adopted some form of house or team structure, believing that this allowed for more of a community feeling for their schools (Lipsitz, 1984).

Using research on effective schools and the unique nature of early adolescents, the National Middle School Association published a monograph in 1988 entitled, Developing Effective Middle Schools Through Faculty Participation (Merenbloom, 1988). Eleven characteristics of an effective middle school were enlisted in the monograph as follows : 
(1) Features a program that responds to the physical, intellectual, social-emotional and moral needs of early adolescents.

(2) Has a set of documents to guide all aspects of the program.

(3) Possesses a definite curriculum plan that includes organized knowledge, skills, and personal development activities.

(4) Has a clearly established program of studies based upon the concept of exploration and provides opportunities for student growth.

(5) Builds on the strengths of elementary education and prepares students for success in high school.

(6) Employs teachers who focus on the learning needs of pupils by using appropriate teaching strategies.

(7) Creates teaching teams using blocks of time to best deliver the instructional program.

(8) Emphasizes the guidance and counseling function of staff members by providing for a home-base program, stressing the importance of self-concept, and providing a positive climate.

(9) Promotes flexibility in implementing the daily, weekly, and monthly schedule to meet the varying needs of students.

(10) Actively involves parents in various aspects of the school experience.

(11) Evaluates the program on a regular basis and makes changes that enhance the learning. (pp. 5-9)

A recent study, and perhaps the one receiving the most attention, is that of the Carnegie Council on Adolescent Development (1989). The Carnegie Corporation of New York established this council in 1986. The council then created the Task Force on Education of Young Adolescents. David W. Hornbeck, former Superintendent of Schools in Maryland, was 
selected to chair the task force. Other members of the task force were chosen from education, research, government, health, and the nonprofit and philanthropic sectors.

The Task Force commissioned papers, interviewed experts in relevant fields, and met with teachers, principals, health professionals, and leaders of youth serving community organizations. It examined, first-hand, promising new approaches to fostering the education and healthy development of young adolescents. (p. 13)

The product of this task force was the report, Turning Points: Preparing American Youth for the 21st Century (Carnegie Council on Adolescent Development, 1989). People at all levels of our American society were challenged to address its recommendations: the President and the Congress; officials of state and local governments; members of boards of education, superintendents, administrators, principals, and teachers; health professionals and leaders of youthserving and community organizations; and parents and students (p. 18). The report provided eight recommendations to guide middle schools. The task force considered these recommendations to be essential if our middle schools were to create 15-year-olds who are intellectually reflective, en route to a lifetime of meaningful work, good citizens, caring and ethical, and healthy.

The recommendations were designed to improve the educational experiences of all middle school students, providing most benefit to those who are at risk. They can be summarized in the three areas of early adolescence discussed previously: physical, intellectual, social, and emotional. 
The one recommendation that focused primarily on the physical development of young adolescents reinforced the importance of healthy students if opportunities for achievement were to be optimal. The report suggested that we:

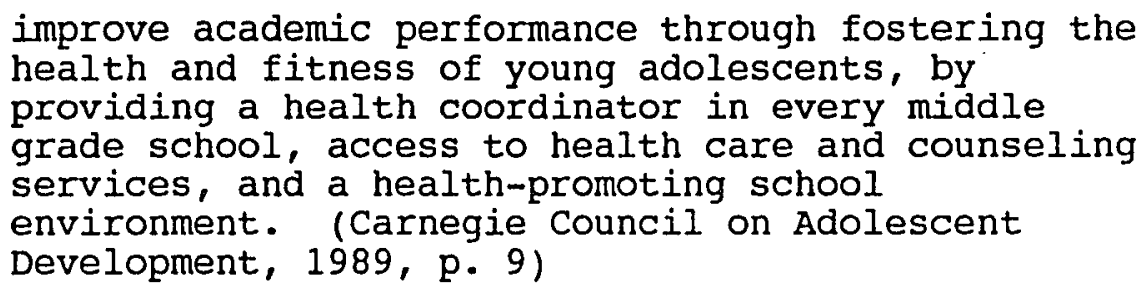

A better understanding of the importance of good health on their development is also an important component.

Three of the task force's recommendations were related to the social and emotional development of the middle level student. These ideas discussed the significance of interpersonal relations as well as the concepts of parental and community involvement in the educational experience of the 10- to 14-year-old. One recommendation centered around the concept of smaller groups of students and adults working together in schools.

Create small communities for learning where stable, close, mutually respectful relationships with adults and peers are considered fundamental for intellectual development and personal growth. (Schools-within-schools, houses, teams). (Carnegie Council on Adolescent Development, 1989, p. 9)

Middle schoolers count on opportunities for social interaction with their peers and they rely on that special adult that they can trust and turn to when they need some extra support and understanding. 
Another recommendation telis about the importance of parents' participation in their children's education. It advised schools to:

reengage families in the education of young adolescents by giving families meaningful roles in school governance, communicating with families about the school program and students' progress, and offering families opportunities to support the learning process at home and at the school. (Carnegie Council on Adolescent Development, 1989, 1989, p. 9)

The report continued by widening the circle of influence in a middle schooler's life by incorporating the community in the educational process. It proposed that we:

connect schools with communities, which together share responsibility for each middle grade student's success, through identifying service opportunities in the community, establishing partnerships and collaborations to ensure students' access to health and social services, and using community resources to enrich the instructional program and opportunities for constructive afterschool activities. (pp. 9-10)

The intellectual developmental needs of the early adolescent were also addressed by several recommendations in Turning Points (Carnegie Council on Adolescent Development, 1989). Two of these recommendations related directly to the middle school student while the third detailed options for educators who work with these children. The first recommendation related to the academic program for the preadolescent. It promoted a:

core academic program that results in students who are literate, including in the sciences, and who know how to think critically, lead a healthy life, behave ethically, and assume the responsibilities of citizenship in a pluralistic society. (p. 9) 
In addition, the report asked that schools

ensure success for all students through elimination of tracking by achievement level and promotion of cooperative learning, flexibility in arranging instructional time, and adequate resources ( $t i m e$, space, equipment, and materials) for teachers. (p. 9)

Teachers and administrators need to understand the developmental needs of early adolescents as they plan appropriate programs for them. These are the people, the majority of whom, have chosen to work with these students and they must be afforded the opportunity to plan relevant experiences. Turning Points (Carnegie Council on Adolescent Development, 1989) suggested that we:

Empower teachers and administrators to make decisions about the experiences of middle grade students through creative control by teachers over the instructional program linked to greater responsibilities for students' performance, governance committees that assist the principal in designing and coordinating school-wide programs, and autonomy and leadership within sub-schools or houses to create environments tailored to enhance the intellectual and emotional development of all youth. (p. 9)

Effective middle level schools are unique educational institutions that meet the developmental needs of the early adolescents they serve. Their organization, curriculum, and instruction are distinct in nature from both primary and secondary schools. The people who work in these schools should also be willing and able to work with the preadolescent they will face every day in their classrooms. Turning Point's (Carnegie Council on Adolescent Development, 1989) final recommendation provided insight about how to 
achieve this concept. The reports suggested that we "staff middle grade schools with teachers who are expert at teaching young adolescents and who have been specially prepared for assignment to the middle grades" (p. 9).

Effective Middle Level Teachers

Teachers who work with middle schoolers need to understand the physical, social, psychological, and intellectual needs of their students. They need to become experts in their field.

Teachers must begin to see themselves as middle grades experts as well as subject-matter specialists. As middle grades experts, teachers need to believe that their subject matter knowledge has educational value only as it becomes integrated with the whole student. Middle grades experts will reinvent instruction to address the personal, social, and physical needs of young adolescents as inseparable from their intellectual development. For example, it must become normal for teachers to personalize their teaching--responding to and drawing on students' experiences at home and with peers instead of ignoring these important out-ofschool domains of adolescents' lives. Young adolescents' intense focus on their peers should be a normal part of classroom activity as students interact with and learn from one another in cooperative groups. Even the often-irritating adolescent physicality can become a normal part of lessons where students are expected to "do" things as well as learn about them. (Oakes, HunterQuartz, Gong, Guiton, \& Lipton, 1993, p. 470)

Numerous studies have been conducted to evaluate the competencies of effective middle level teachers. In their monograph, What Research Says to the Middle Level

Practitioner, Johnston and Markle (1986) included a section on teacher behavior that summarized what researchers 
concluded to be the characteristics and practices of effective middle school teachers. This monograph is an accumulation of research synopses that have appeared in the Middle School Journal since 1979 in a column entitled "What Research Says to the Practitioner." The research reviewed was both descriptive and comparative in nature. In examining this research, they discovered that the most relevant findings were those that addressed clusters of related behaviors, not single, isolated behaviors. All teachers need to model important behaviors to their students, since early adolescents are in the process of developing their selfconcepts. Effective middle school teachers are strong models because they have positive self-concepts themselves. They feel good about themselves and about what they do. Activities in their classrooms do not have to focus on them at all times. They demonstrate warmth as they interact with their students. These teachers seek contact with their students both inside the classroom and in other non-academic settings. They are optimistic. Their classrooms exude a positive, pleasant atmosphere. They are encouraging to all students and demonstrate their optimism in their assessments of individual student capabilities.

Flexibility is an extremely important characteristic for middle level teachers. They must be able to change the focus of their lesson if they see that their students are becoming bored or disinterested. A routine daily schedule is not the way of life for a middle school teacher. The ability to readily and easily adjust to changes in plans, time 
schedules, and student behavior is second nature to an effective middle level educator. In fact, they are able to capitalize on the unexpected in their classrooms (Johnston \& Markle, 1986).

Effective middle school teachers are aware of the developmental changes that their students are experiencing. The tasks that they assign to their students are appropriate to the students' ability. If, as their students are working through a task, they become confused or uncertain, the teacher will adjust the task to fit the students' needs. These teachers are not likely to push students into activities for which they are not ready. Tied to this awareness of developmental levels, is an extensive knowledge of the subject matter that they teach (Johnston \& Markle, 1986).

A repertoire of effective instructional strategies (short lectures, discussions, cooperative learning activities, simulations, demonstrations, laboratories) and materials is essential for the successful middle school teacher. Effective middle school teachers understand the need of the early adolescent learner to attend to the manipulation of concrete images before moving on to formal operations. They are able to organize instruction so that within a class session several different strategies are employed. This technique conforms to the varying attention spans of the early adolescents with whom they are working. Effective teachers "capitalize on students' natural activity levels and integrate physical activity and hands-on 
instruction into the classroom procedures" [National Association of Secondary School Principals (NASSP), 1985, p. 10]. Because the transescent learner is so social by nature, the more group interaction activities employed, the more successful these strategies are apt to be. These group activities stimulate creative problem solving and productive thinking. This variety of instructional strategies should be coupled with the use of a variety of questioning strategies, using both higher order and knowledge, recall questions.

These effective teachers understand that they will encourage greater pupil performance by organizing and planning their instruction.

They tend to review previous lessons, outlining main topics of planned lessons, signaling the beginnings and endings of lessons, underscoring important points and summarizing. (Johnston \& Markle, 1986, p. 17)

In addition to planning and organizing lessons to improve student performance, effective teachers monitor their students' learning by carefully and expediently checking test papers and student work.

Diagnosing individual learning needs and prescribing individual instruction is also an important competency that Johnston and Markle (1986) listed. As effective middle level teachers are monitoring students' learning, they recognize the various learning rates and provide for adequate time to complete assigned tasks. Their lessons are centered on the interests of their students. They define expectations on an individual basis. "They also demonstrate less of a tendency 
to teach an entire class the same lesson and to grade on a group standard" (p. 17).

Other researchers have a more extensive list of competencies for middle school teachers. The Essential

Middle School listed 61 competencies compiled by Marshall and Holmes in 1977 (Wiles \& Bondi, 1986a). Those competencies not addressed by Johnston and Markle (1986) are employed by a middle school teacher who:

-Works effectively in close collaboration with fellow teachers in cooperative planning and team teaching.

-Has an open mind toward innovation and change. -Provides opportunities and guidance to help students become independent learners (define own goals and problems, identify resources and evaluate outcomes).

-Accepts responsibility of multi-disciplinary instruction: plans thematic and coordinated studies with other teachers and assists them in teaching subjects outside of their own area of specialization.

-Is able to help students clarify values, consider alternative values, and develop a personal and workable valuing system. (Wiles \& Bondi, 1986a, pp. 50-56)

In effective middle schools, teachers model the appropriateness of cooperation as they work with their colleagues to provide relevant, challenging curriculum for their students through thematic instruction. Working together in teams with common students allows middle school teachers to better understand the students they all work with as they share their strategies and techniques. Knowing the developmental needs of their students, these teachers provide 
opportunities for early adolescents to participate in their instructional program by setting goals and objectives for themselves as well as indicating their interests and possible sources of information. "Recent studies suggest that the psychological environment of the classroom may have a strong influence on the goals that students adopt" (Andermand \& Maehr, 1994, p. 296).

Thus, special preparation for middle school teachers should focus on early adolescent psychology, curriculum, instructional organization, and teaching methods.

The transitional nature of adolescence demands a transition in the role of the teacher from being primarily a dispenser of knowledge to being a coordinator of many sources of knowledge, with significant emphasis upon the function of diagnosis, prescription, planning, decision making, utilization of human and material resources, and evaluation. (Sale, 1979, p. 5)

Teachers of adolescents must understand their students' behavior, their needs, and the effective ways of promoting learning. They must have knowledge of each student's potential. They must know the strategies to reach their students and to stimulate the desire to learn.

The teacher is the critical factor for a successful learning environment at the middle school level. It is imperative that prospective teachers possess the desire and the appropriate skills to work at this level. As George, Stevenson, Thomason, and Beane (1992) argued in The Middle School and Beyond:

Even the post-Sputnik national urgency for reforming the preparation of science and mathematics teachers pales in the light of the need for expert middle level educators who are prepared 
for and committed to helping youngsters who are experiencing the life threatening exigencies of contemporary adolescence. (p. 18)

Effective middle level teachers are not born. They need to be developed through successful preparation programs that are specially designed. Such programs would provide opportunities to explore: a variety of instructional strategies, the process of thematic studies, the logistics of collaboration with colleagues in teaming situations, the nature of the preadolescent, as well as other concepts mentioned previously.

\section{Preparation Programs for Middle} Level Teachers

As the number of middle schools increases across our nation, so do the number of specialized preparation programs for middle level teachers; however, the increase in middle schools far exceeds the increase in special preparation programs, thereby creating a need for the preparation of teachers to work in middle grade schools. Preparation for elementary and secondary classrooms is inadequate for a teacher who is going to work with early adolescents (Lounsbury, 1984).

The recognition of this need for the special preparation of middle level teachers is not a recent phenomenon. Sources as far back as the late 1920 s and early 1930 s recognized its importance. Along with the development of the junior high school, came the recognition that specially trained teachers would be needed if the movement to improve instructional 
programs for these young adolescents was to be successful (Lounsbury, 1984). This belief continues to be paramount in the minds of middle school researchers today. Clark and Jones (cited in Alexander \& McEwin, 1988) conducted a study of middle level preparation in which they concluded:

the uniqueness of the early adolescent and the specialized functions of the developmentally responsive middle level school call for more comprehensive preparation programs. (p. 3)

This preparation problem has been addressed in numerous districts across the country by providing inservice courses for teachers working at the middle level. The most prominent researchers in the field of special middle level teacher preparation, Alexander and McEwin (1984), believed this to be an insult to quality educational experiences for early adolescents.

Inservice education is useful for continuing education, but is inadequate for initial preparation. Full-term preparation programs which focus specifically on the unique characteristics and needs of early adolescents are prerequisite to successful middle level teaching. Effective programs containing well-developed courses and practica emphasizing program design, teaching strategies, and other related areas are essential. Only when these kinds of programs are widely available and required for middle level teaching will the potential to significantly improve middle level education be fully realized. (cited in Lounsbury, 1984, p. 118)

A recent article entitled, "Staff Training Gets a second Look" (Holland, 1994) discussed typical problems with staff development efforts:

Good staff development . . . supports a school's goals, aims to change behaviors and includes longterm support... studies show that teachers forget 90 percent of what they learn in one-shot 
workshops. It takes about 20 follow-up sessions to ensure that teachers can apply their new skills in the classroom . - The challenge for the nation is enormous. About 75 percent of all teachers have been on the job 10 years or more, meaning that staff development is about the only way to pass on new research and strategies. (p. 6)

The article cited the recent national standards on staff development produced by the National Staff Development Council in collaboration with seven other national associations. The council's first set of standards released in 1994 was the middle level edition. "The standards call on districts to commit to continuous staff development, and to develop programs that are grounded in research . . " (p. 6). In 1978, Gillan, a graduate student at Northwestern State University of Louisiana, completed a dissertation entitled A National Assessment of the Effects of Middle School Teacher Certification. In this study, Gillan investigated:

what significant differences exist between certified middle school teachers and those of middle school teachers certified at another level in the areas of: (1) attitudes toward the middle school, (2) educational concept emphasis in the middle school, (3) job satisfaction with the middle school, and (4) professional recommendations for middle school teacher preparation and certification. (p. $x$ )

Gillan (1978) created a questionnaire and surveyed 288 teachers, randomly selected from 20 school faculties. Ten of the schools were from states with specific middle school teacher certification and 10 schools were from states that do not require specific certification. Gillan had a response rate of $84 \%$ to his questionnaire, $47 \%$ of the certified middle 
school teachers and $53 \%$ of the non-certified teachers. Some significant findings were revealed in Gillan's study:

-Certified middle school teachers strongly support undergraduate middle school teacher education programs, options, and special certification at the middle school.

-Middle school teacher certification promotes positive attitudes, concepts, and opinions toward the middle school program.

-Certified middle school teachers place greater emphasis on concepts of "Team Teaching" and "Student Planning in Scheduling."

-Certified middle school teachers show significant preference in the following areas over other middle school teachers: choice of middle school employment, employment stability, and job satisfaction.

- Certified middle school teachers are more satisfied with their subject area preparation than other middle school teachers. (p. xii-xiii)

In another study, Youngblood (1989) collected data from superintendents, directors of staff development, or directors of middle level education in 298 school districts in another northwest state, the state of washington. In addition, a random sample of principals, vice-principals, counselors, and teachers in the 300 middle schools and junior high schools in the state participated. The respondents in Youngblood's study stated that they could benefit from further information on the emotional development of the young adolescent student, teaching methods for the young adolescent learner, social development of the young adolescent, intellectual development of the young adolescent, and discipline techniques. 
A more recent study conducted in 1992, by Judith Smith, a doctoral candidate at Portland State University, Oregon, produced a dissertation entitled, Effective Middle School Teaching: Factors that promote and Maintain It. In her study, Smith researched the concept of the "expert" teacher that arose from the Carnegie Council on Adolescent Development's (1989) Turning Points: Preparing Youth for the 21st Century. Smith stated:

Once one knows what an "expert" teacher is, the major question that is raised is what factors promote and maintain such "experts?" Paying attention to these factors should increase the numbers of effective middle school teachers and therefore help meet the challenge issued by Turning points. The purpose of this study was to learn what these factors are by listening to the "experts." knowing these factors, their hierarchy of importance, and their potential for replication have serious implications for pre-teacher and staff training programs, hiring practices, and district policy making. (p. 2)

Smith (1992) surveyed and interviewed "self-reported effective middle school teachers to share their perceptions on what they believe are the most significant factors that enable them to be better teachers" (p. 8). These were teachers from 17 middle schools in an urban school district. Smith received 307 valid questionnaires to analyze and then followed through with 19 interviews of respondents who were the top scoring teachers from the questionnaires (p. 2). Smith's (1992) study included information on teacher training at the middle school level. Her research led her to the conclusion that:

The demand for middle school teachers to be both a specialist in two or more subject areas as well as a child-centered generalist and advisor to students 
during the most tumultuous and vulnerable period in their lives, suggests that teachers at the middle level have to be even more capable, knowledgeable, and expert than teachers at other levels. (p. 124)

The teachers who participated in Smith's (1992) study agreed that teacher training institutions must make some adaptations if they are to produce qualified middle level educators. They concurred that:

(1) There must be a way of screening teacher applicants to find out which ones are most dispositionally suited for and have the desire to teach early adolescents.

(2) Trainees must be completely immersed in middle school pedagogy and curricular strategies which are in direct response to early adolescent needs and development.

(3) Training institutions must require much more exposure and experience with early adolescents. (pp. 123-124)

Additional studies supporting specialized training by researchers and practitioners have been conducted. MCEwin (1983) surveyed over 400 middle level principals throughout the nation and found that over $80 \%$ of the respondents felt that "teacher resistance to change and a lack of orientation to the middle level philosophy were serious problems" (p. 80). In another survey completed by DeMedio and MazurStewart (1990), a questionnaire was sent to 2,876 randomly selected schools which contained grades six, seven and eight in 30 randomly selected states. They received 1,513 usable questionnaires, producing a response rate of 53\%. Demedio and Mazur-Stewart concluded:

the results of this study provide evidence that teachers and principals working in schools containing grades six, seven and eight (one or any 
combination) do support the belief that those preparing to teach middle grade students need special middle grade preparation and appropriate middle grade certification. (p. 70)

A comprehensive survey was conducted of 2,400 middle grades principals by the Center for Research on Elementary and Middle Schools at the John Hopkins University (Epstein \& MacIver, 1990). This study investigated the degree of implementation of recommended middle grades practices. This study found that "teachers in the middle grades vary in their education and certification more than teachers at any other level of schooling" (p. 59). This variety of education and certification is not an obstacle that elementary or secondary schools face. The study also showed

Increasingly, teachers are being given options to obtain separate certification for the middle grades (e.g., for grades 5-8 or 6-8) or "endorsements" that add special competencies to enable teachers to work with early adolescents in particular. A survey of state policies found that twenty-two states have special certification or endorsements for teachers in the middle grades (Children's Defense Fund, 1988). At least six other states are planning or considering these options. (p. 59)

The National Middle School Association has published a monograph entitled, Preparing to Teach at the Middle Level (Alexander \& MCEwin, 1988). It is a very comprehensive treatment of middle school teacher education and certification. This volume outlined the need for more and better teacher education for middle school practitioners and described six existing preparation programs at the University of Georgia, Gordon College, Illinois State University. University of Northern Colorado, Kent State University, and 
the University of North Carolina at Charlotte. Essential elements of middle level teacher education are also listed as follows :

(1) Thorough study of the nature and needs of early adolescents;

(2) Middle level curriculum and instruction;

(3) Broad academic background, including concentrations in at least two academic areas at the undergraduate level;

(4) Specialized methods and reading courses;

(5) Early and continuing field experiences in good middle schools. (p. 48)

Two additional sources on middle school teacher preparation were published in 1992 and 1994. In 1992, Scales' Windows of Opportunity: Improving Middle Grades Teacher Preparation, was commissioned by the Dewitt WallaceReader's Digest Fund and was conducted by the Center for Early Adolescence, The University of North Carolina at Chapel Hill. Over a three-year period this study was to:

(1) Develop new educational models and resources for use in middle grades teacher preparation. (2) Offer intensive technical assistance for a number of middle grades teacher education programs linked with local public schools. (3) Encourage and monitor debate among today's educational leaders working to revitalize middlegrades teacher preparation. (p. 2)

The study surveyed three groups of respondents: middle school teachers, deans of teacher education programs, and chief state school officers. The purpose of the study conducted by scales (1992) was to "review the status of teacher preparation for the middle grades and to provide 
recommendations for improvement" (p. 7). This investigation found that 26 different available forms of certification existed for teachers working at the middle grades level. In addition, no changes had occurred since a study conducted by Curtis (cited in Scales, 1992) found that 35 of the 50 states had some form of middle grades certification. However, 32 of the 35 states had elementary and/or secondary certificates that overlapped this middle grade certification plan. The option for overlapping certification is a means of giving teachers the greatest amount of options professionally, economically, and geographically, as contrasted with the distinctive middle school certificate. The overlapping certification is an advantage to the teacher; however, there is no research concerning the quality of teaching produced from either option. As scales further researched this issue he concluded:

The state-to-state variation in certification requirements indicates that there is an emerging consensus at the state level that some special preparation is necessary, but there is not necessarily agreement over what that preparation should comprise. (p. 19)

After an extensive literature review and a thorough analysis of the data gathered, the study delineated 10 conclusions and produced seven recommendations. Scales (1992) concluded that even though improvements have been made in the last decade as far as preparing educators to work specially at the middle level, the numbers show that fewer than one in five middle grades teachers received special preparation. The study also showed that there appeared to be 
agreement among middle level educators about what they should know and be able to do as well as about the idea that there are differences between the knowledge needed and the manner of preparation required for middle level teachers. In response to this need for special preparation the study found little evidence to indicate that teacher training institutions were changing their programs to facilitate this effort. In fact, "on 11 topics that the literature suggests should be covered in middle-grades teacher education, $26 \%$ to 658 of the 439 teachers rated their preparation as inadequate or poor" (p. 102). The teachers who participated in this study enumerated several areas in which they felt the least adequately prepared. These areas included cultural and language diversity and "how to help young adolescents manage their social and emotional development and reflect these characteristics in teaching and assessment techniques" (p. 102). Despite the feeling that they are inadequately prepared, more than $80 \%$ of the teachers surveyed were satisfied with their careers as middle grades teachers, while only $7 \%$ preferred not working with these grade levels.

Scales' (1992) study produced ideas about how to improve preparation such as earlier, longer, and more varied field experience opportunities. Additionally, the concept of providing student teaching experiences with expert mentor teachers is highly endorsed. On the optimistic side, the study reported that:

The emergence of National Council for the Accreditation of Teacher Education (NCATE) approved curriculum guidelines for the middle grades developed by the National Middle School 
Association (NMSA) and of new, outcome-based standards for middle-grades programs developed by the National Association of state Directors of Teacher Education and Certification (NASDTEC) can have a positive impact on changing teacher preparation programs and on defining what a good middle-grades preparation program looks like. (p. 103)

The conclusions of Scales' (1992) study led to seven recommendations and 30 specific actions related to how to implement these concepts. The first recommendation suggested that the educational community should come to common understandings about what the terms middle-school, middlegrades, middle-level really mean. Experts and leaders in the middle school movement should:

conduct a communications campaign among the wider education community to stimulate more consistent use of the term "middle-grades" in all communications that currently use only "elementary" or "secondary." (p. 105)

Besides creating common terminology, the need to reduce the number of different middle grades certifications was advised. Currently 26 different certificates are available with no single prevalent pattern. One means of supporting this recommendation came in the form of the endorsement of NASDTEC's initiative to strengthen the middle grades' standards.

The second recommendation addressed the need to foster leadership among middle grades professionals, to raise awareness of state and national associations. In the sample of educators who participated in the study, approximately only $2 \%$ were members of NMSA because most of them had never 
heard of the organization. To further the effort of increasing participation in this organization

mechanisms should be established for middle-grades educators to access rapidly information about early adolescence and model school programs and to network nationally with each other. (Scales, 1992, p. 114)

The leadership in these efforts was encouraged to work on the implementation of the other recommendations brought forth in the study as well as become active in the National Network on Educational Renewal and the Holmes Center for Faculty Leadership and Renewal at Ohio State University. In the third recommendation the focus was the improvement of the teacher education curriculum and field experience opportunities. The study findings showed that

only about $18 \%$ of teacher education institutions have a substantial middle-grades program. In the present study, just $17 \%$ of the teachers had any kind of special middle-grades program, and the national data suggest that at least $40 \%$ of these were probably add-ons of extra courses rather than major specializations. (Scales, 1992, p. 118)

The information worsened because at the undergraduate and the graduate level about 408 of the middle grades preparation programs failed to address even fundamental issues like the middle grades learner and the middle school concept. The middle grades experts across the country were encouraged to provide technical assistance to teacher training institutions to improve their programs by responding to the following suggestions that came from the teachers who participated in the study:

(1) improvement in field experiences and student teaching; 
(2) greater variety of developmentally responsive teaching and assessment techniques, especially cooperative learning, interdisciplinary or integrative curriculum and team teaching, student exhibitions and portfolios;

(3) deeper coverage of classroom management strategies;

(4) more comprehensive coverage of academic content areas;

(5) greater understanding of early adolescent development with special attention to young adolescents' social relationships and selfawareness issues, cultural and language diversity, teacher-based guidance, and involvement of parents/family and community resources in young adolescents' schooling. (p. 122)

Recommendation number four emphasized the importance of using middle level teachers as messengers to potential teachers about young adolescents and middle schools and the positive advantages of working at this level. One way to achieve this would be to work actively in an emerging network of high schools and middle schools that are being organized as "teaching career" schools (Scales, 1992).

An additional recommendation encompasses the need to educate the whole young adolescent through opportunities such as health and life skills education, intramural athletic programs, music, art, and teacher-based guidance.

Middle-grades teacher preparation programs should incorporate more opportunities for preservice teachers to learn how to utilize family and community resources and to observe communities which systematically meet the varied needs of young adolescents. (Scales, 1992, p. 134)

The sixth recommendation encouraged teacher preparation institutions to increase preservice teachers' understanding 
in relation to the teacher's role in site-based management. The nature of an effective middle school using teaming, an interdisciplinary approach, and the specialized organization to reflect young adolescents' unique developmental characteristics could provide an optimal situation for site-based decision making.

The final recommendation encouraged additional research that would assist in the continued improvement in middle grades teacher preparation programs. The focal point for the research would be to identify the characteristics of high quality preparation programs. This effort could identify what criteria would reliably and validly determine high quality programs from minimum standards middle level teacher preparation programs. In addition, this research could distinguish

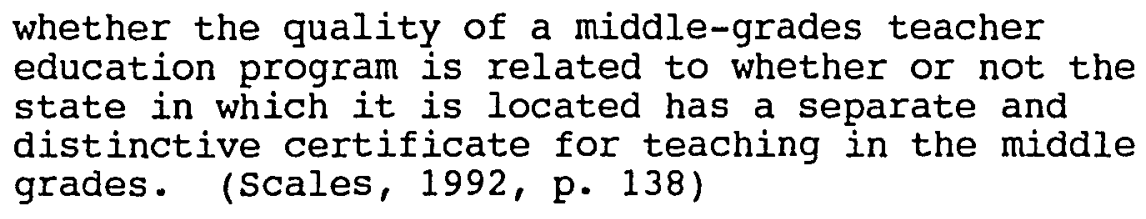
education program is related to whether or not the state in which it is located has a separate and distinctive certificate for teaching in the middle grades. (Scales, 1992, p. 138)

The most recent research on middle level teacher preparation was published by NMSA in 1994. In this study entitled Growing Pains: The Making of America's Middle School Teachers, Scales and McEwin (1994) surveyed teachers of grades six through eight in 1,100 schools in five states. The five states (Georgia, Kentucky, Missouri, North Carolina, and Virginia) were purposely selected because they issued "'authentic' middle level teaching certificates, i.e., certificates that were separate and distinct from elementary or secondary ones" (p. 11). In addition to this fact, these 
states also contained $57 \%$ of all of the undergraduate middle level teacher programs in the country.

The Scales and McEwin (1994) study showed a small increase in the percentage of educators who had received undergraduate preparation in special middle level programs, from 178 in 1991 to $22 \%$ in 1993. However, another finding of the study indicated that practicing middle school teachers who went on to graduate programs were more likely to choose special middle grades preparation programs. Scales and McEwin reviewed the results of their recent study, as well as those of a modified Delphi process that the Center for Early Adolescence in North Carolina conducted in 1992. Scales and McEwin also reviewed two other Center for Early Adolescence studies of middle grade teacher educators and middle grade teachers conducted by Scales (cited in Scales \& McEwin, 1992a), and concluded that there were 10 elements of an excellent middle grades teacher education program.

An exemplary preparation program should be conducted at a middle school site as much as possible. This would allow collaboration between middle schools and teacher preparation institutions. In this way, middle school teachers could provide the opportunity for continuing education for university faculty. Courses could be co-developed and coinstructed. The program would maintain a core library of resources recommended by teacher educators as essential for preparation. The faculty staffing these programs should model the techniques that they expect preservice teachers to learn. Primary among these techniques would be 
interdisciplinary/integrative curriculum, cooperative learning, teacher-based guidance (advisor/advisee), and portfolio/exhibition assessment approaches. In addition, the university faculty would be provided resources for ongoing professional development such as maintaining regular contact with young adolescents, including being involved in their instruction (Scales \& McEwin, 1994).

A great emphasis was placed on fieldwork for preservice teachers. It was suggested that they engage in fieldwork early in their programs, including the first and second years in their undergraduate work. These fieldwork experiences should not be limited to the classroom alone. They should include a variety of community settings that young adolescents frequent as well. In this way, they would be exposed to the systems in early adolescents' lives that respond to their unique characteristics. Preservice teachers would also be expected to be involved in activities which worked to link families and community resources with middle schools (Scales \& McEwin, 1994).

Lastly these programs should:

include extensive opportunities to learn about being an advisor in a teacher-based guidance program; interdisciplinary teaming; responding to students' cultural and language diversity; and, ensure that students acquire a comprehensive understanding of young adolescent social relationships and self-awareness concerns, especially health and sexuality. (Scales \& McEwin, 1994 , p. 61)

Two other important points became evident as a result of the Scales and McEwin (1994) study. First, the teachers responding to the study clearly stated that the special 
preparation of aspiring middle school teachers needed to be a comprehensive, carefully planned program that focused solely on teaching young adolescents, not a few classes that would be added to an existing elementary and/or secondary program or an endorsement-only program. Second, these researchers believed that the cumulative wisdom of decades of experience that is reflected in the data gleaned from their study indicated that all states should require a separate and unique certification for teachers working at the middle school level.

Although the 1992 Scales study and the study done by Scales and McEwin (1994) indicated that wide support from teachers, deans of teacher education programs, and chief state school officers existed, there are still a number of issues that continue to be unresolved in the debate about special preparation for middle school educators. One issue rests in the content and the effectiveness of such programs. In the Scales and McEwin (1994) study, the respondents who had participated in special middle level preparation were only somewhat more likely to rate their preparation programs higher than those who did not receive such training. From this same group, with special training, more than 408 did not have course work on teaching young adolescents, more than $50 \%$ did not have course work on curriculum and organization at the middle school, while almost $60 \%$ did not have pre-student teaching nor student teaching at the middle level. The data do not support programs of quality or effectiveness. 
In a 1990 study of teacher behaviors and their implications for middle level teacher education, Manning (cited in Scales, 1992) proposed that careful research should be conducted on the effects of planned variations in teacher preparation programs concluding that "a knowledge base specific to middle level teacher education has not developed to a degree where definite conclusions can be reached" (p. 26). In effect what Manning was proposing was that until enough effective programs are thoroughly researched, it would be unlikely that agreement on common elements and procedures would be forthcoming or of any significant value.

Additional controversy existed because the current recommendations from NCATE and NMSA emphasize undergraduate professional education courses and an increase in field experience. These requirements were viewed in a negative light by those who evaluated the process of teacher preparation in general. These generalists questioned the concepts of undergraduate majors as well as field experience because they were doubtful about the quality of either.

Other researchers (Sikula \& Roth, cited in Scales, 1992) purported that teacher preparation was an integral part of a complex interrelationship that existed between national accreditation, state program approval, and state certification. After reviewing middle grades teacher education efforts, Little and Shulman (cited in Scales, 1992) concluded that:

the ability of a teacher education institution to begin or sustain a middle-grades program depends on whether or not: states require separate and unique middle-grades certification; schools and districts 


\begin{abstract}
see a need for more middle-grades teachers; the current priorities of the higher education institution are focused on the middle grades; there are adequate numbers of students who enroll in the middle-grades program; and middle-grades issues are congruent with the "research and teaching interests of individual faculty members." (Scales, 1992, p. 46 )
\end{abstract}

Both the Sikula and Roth (cited in Scales, 1992) and the Shulman (cited in Scales, 1992) research indicated that at best this issue of special preparation and/or training was a very complicated one. Scales' study of 1992 reinforced this concept because he found that the specially prepared group and the group without special training were just as likely to agree or to disagree about whether middle level teachers ought to be prepared differently than other teachers.

Nearly $40 \%$ of the teachers surveyed by Scales (1992) felt that middle school teachers did not need to be prepared differently than other teachers. This finding was surprising to the researcher who understood that the belief in special preparation was one of the unquestioned presuppositions of the middle school movement. This belief in special preparation made intuitive sense but was not born out by the empirical data of the study. In addition, Scales was unable to locate examples of any rigorous studies which compared the teaching behaviors/efficacy of teachers who had received training in high quality middle level programs with teachers who were trained in high quality elementary or secondary programs. Further research in the area of teacher training appears to be necessary before any definite answers can be delineated. 
As stated earlier, for the purposes of this study, a detailed examination of the University of Georgia program and the University of Northern Colorado follows. These programs have existed for a long period of time and are recommended as quality training experiences for future middle level teachers.

\section{The University of Georgia}

\section{program}

The South was one of the first areas in the country to experience the middle school movement, with Georgia being in the forefront. Middle schools became a reality in the state of Georgia by 1969. At that time, there were 24 middle schools in the state and by 1976 the number had increased to 115 (Alexander \& McEwin, 1988). The proactive faculty at the University of Georgia did not want to wait for the state to establish criteria for a program in preparation of middle grade teachers that they would be responsible for delivering. Their Department of Elementary Education was being inundated with requests from school districts for staff development programs for middle school teachers. The impetus of these two concerns, spurred them to the decision to create a preservice baccalaureate program for middle school teachers. As the faculty began their planning process, they were unable to find existing programs to examine at that time. Other states had institutions that were also in the formative stages of planning a program, and no guidelines for establishing programs were to be found. This was not viewed as an obstacle by the faculty at the University of Georgia, 
who rather viewed the absence of models as an opportunity to design a creative program that would meet the special needs of teachers preparing to work in middle schools (Compton, $1988)$.

Before designing the program, the faculty discovered that they were facing three restrictions: (a) all degree programs at any of the institutions of the University of Georgia system had to fulfill general education requirements as laid out in the Regents' Core Curriculum; (b) all graduation requirements had to be met, including a written test on the Georgia and U.S. Constitutions; and (c) all degree programs had to be approved by the curriculum committee of the University of Georgia and the Board of Regents (Alexander \& McEwin, 1988). In addition to these three requirements that had to be met, the faculty decided upon two other guidelines for themselves: all teacher education programs belonged to the entire college, and shared decision making was viewed as necessary for a program to be effective; and the concept of the middle school as an organization for early adolescents had to be the foundation of the program. This was to be a unique program. Courses that were to be a part of the program were not to be courses from the elementary or secondary programs with new titles. They were to be designed specifically for the middle school preparation program.

It took two years for the program to be fully developed and be presented to the Board of Regents and the State Board of Education. When approval was granted in 1971, the program 
began. Five years later, in 1976, the state of Georgia approved special certification for teachers of middle grades. At that time, the criteria for state certification programs were drawn from the program at the college of Education at the University of Georgia. In Georgia, teaching certificates are available elementary $\mathrm{K}-4$, middle school 4-8, and secondary 7-12 levels (Compton, 1988).

Choosing to specialize and work at a specific level, be it elementary, middle, or secondary, is a decision made by students at the University of Georgia at the end of their sophomore year. Any public institution of higher education in the state of Georgia requires its students to dedicate their freshman and sophomore years to a general education. At the University of Georgia these 90 quarter hours, known as the Regents' Core, include: the humanities (literature, drama, language, fine arts), social science (geography, economics, history, sociology, philosophy), the biological and physical sciences, mathematics and physical education (Alexander \& MCEwin, 1988).

After deciding to undertake education as a major at the beginning of their junior year, students are provided an early field experience opportunity in their introductory course in education. This early exposure to life in a real school situation allows the student to experience what it is like to be a teacher at that specific organizational level, generally it is after this initial experience that students decide to remain at that level, to explore working with 
another age level, or to find another professional field to explore (Compton, 1988).

If the students decide to pursue teaching at the middle school level, they are required to choose two fields of specialization. The requirement for two fields of specialization allows them a broader perspective and enables them to demonstrate an interrelatedness between the two disciplines. One of the two fields must be language, mathematics, science or social science. The second field may be one of those previously listed or may be physical education, art, music, or industrial arts (Alexander \& MCEwin, 1988).

A unique characteristic of the University of Georgia program is the three member advisory team that works with each student. The student has an advisor from each area of specialization and one from middle school education. This team assists the student in selecting the specific courses, both content and methodology, which will be the most effective course of study in the two subject areas of specialization (Compton, 1988).

The middle school teacher certification program at the University of Georgia is divided into four professional phases. All phases of the professional preparation program are field based. The first phase begins during the junior year of study. In phase one, the students' focus is the nature of the middle school student, the concept of the middle school as a separate educational organizational level, and the role of the teacher in the middle school. 
Academic course work includes an introducation to the middle school, adolescent psychology (with an emphasis on early adolescence) and the teaching of reading. (Alexander \& MCEwin, 1988, p. 14)

For the field experience aspect of this phase, the student is assigned to a veteran middle school teacher who is a specialist in one of the two chosen fields of specialization. During this experience, the student is observed and instructs middle school students on an individual or small group basis.

During the second phase, the students are assigned to work with a classroom teacher who is a specialist in the students' other chosen field. In this field experience students work with individual students and both small and medium-sized groups. The focus for students in this second phase is the inter-relatedness of the chosen content fields, the process of planning instruction, and the responsibility of all teachers to be involved in reading instruction.

Course work includes "Teaching in the Middle School," "Teaching of Reading in the Content Fields," and special methods courses in one of the fields of specialization. (Alexander \& McEwin, 1988 , p. 14)

The third phase combines the students' two curricular areas of specialization. In this phase, the emphasis is on the integration of the subject specializations and ways of addressing students with special needs. During the field experience, the students are given the opportunity for small group and full class instruction.

Course work includes "The Middle School Curriculum," "Introduction to the Education of Exceptional children," and methods courses in both 
fields of specialization. (Alexander \& MCEwin, 1988, p. 14)

The final phase of the professional preparation program is student teaching. During this experience, the students divide their classroom time between the two areas of content specialization. If the students are assigned to a middle school where interdisciplinary teams are used, then the time spent there is divided between two teachers who work in the two content fields of specialization who are on the same team (Compton, 1988).

The middle school teacher education program at the University of Georgia is not a fixed program, it is a continually evolving program. The program is evaluated annually by its participants on a formal basis. In this evaluation, the students are asked to assess the quality and relevance of the courses, the value of the field experiences, and the effectiveness of the advisement process. Prior to licensing in the state of Georgia, prospective middle school teachers are required to take a teacher competency test, which includes content items in math, language, science, and social studies. Graduates of the University of Georgia program have consistently scored about $90 \%$ on these tests. The program also receives informal evaluation by its graduates. Many of them return for more advanced course work. The graduate advisors have an opportunity to discuss the level of satisfaction these practicing teachers are experiencing with their preparation. All of this data is used to make revisions in the program when the faculty deems 
them necessary. One such revision, was to include a new course on writing across the curriculum in the program. In general, the university has found that the school systems that have hired their graduates express a high degree of satisfaction with their employees who were trained at the University of Georgia (Compton, 1988).

The University of Northern

Colorado Program

The University of Northern Colorado was founded as a teacher education college (Colorado Normal) over 100 years ago in 1890. During those 100 years, it has developed a reputation as one of the leading teacher preparation institutions in the country. It has been declared the primary teacher education institution in colorado by the state legislature. The University of Northern Colorado:

is the only higher education institution in Colorado, (and one of a small number in the western United States), which provides a comprehensive teacher education program in middle school education. (Alexander \& MCEwin, 1988, p. 28)

The program was developed at the same time that middle school certification standards were being developed in colorado. These standards were developed in Colorado after the Colorado Junior High/Middle School Executives' Association drafted a position paper addressing the need for middle level teacher education and certification in the state. This action prompted the creation of a task force, consisting of representatives from higher education and public schools, charged with the revision of middle level teacher education standards. These revised standards were adopted by the state 
Board of Education in 1977. Middle school certification is not mandatory in the state of Colorado. In Colorado, teachers are certified elementary $\mathrm{K}-6$ and secondary 7-12. The middle school certification, 5-9, is optional (Alexander \& MCEwin, 1988).

Since its inception, as a small interdisciplinary program with a handful of students, the teacher education program has grown into a comprehensive one with approximately 200 majors. The program has expanded to include an on-campus masters, an external masters, a post-baccalaureate certification program, and a summer institute on middle school education. The University of Northern Colorado is committed to providing leadership in the field of teacher education and to this end "the goal of the middle school program is to have an impact on middle school education by developing better prepared teachers for this level" (Alexander \& McEwin, 1988, p. 29).

Like the University of Georgia, the University of Northern Colorado requires its students to complete the general education requirements before entering the Professional Teacher Education Program. Students are required to take courses in eight areas: arts and letters, English, writing and composition, social sciences, mathematics, sciences, physical education, and interdisciplinary/cultural studies (Alexander \& MCEwin, 1988).

In addition to the general education requirements, students must emphasize two liberal arts content fields. 
This can be accomplished in one of four possible ways:

(1) A secondary major in an academic area (60-70 quarter hours) with a minor (30 quarter hours).

(2) A broad major (50-60 hours specifically designed for middle school) such as social studies (incorporating all areas of social studies), science (incorporating life, physical and earth science), language arts (incorporating grammar, literature, and communication), or mathematics (incorporating mathematics and computer science). A support field equivalent to a minor (25-30 hours) is also required.

(3) Two broad fields containing equal hours in each field (36-40 hours each).

(4) Interdisciplinary preparation consisting of 9-12 hours in each of the following fields: language arts, social studies, mathematics, and science plus an additional 18-24 hours in each of two of these four fields. (Alexander \& McEwin, p. 31)

The remainder of the course work is divided between professional education and middle school education courses. All prospective teachers, regardless of their level of preparation, must complete the professional teacher education courses. These required courses are: Educational Psychology; Law in the Classroom; Educational Technology; Multiculturalism; Foundations of Education; Human Interactions; the Exceptional Child; and Field Experiences (Alexander \& McEwin, 1988).

Field experiences are an integral part of the University of Northern Colorado program also. Like the University of Georgia, the field experiences at the University of Northern Colorado begin with the orientation courses. The one unique feature of the University of Northern Colorado's program is 
the built-in opportunity for field experience at the Laboratory School on campus. This Lab School provides a site for research and curriculum development, as well as a place to emulate current educational practices that are appropriate for the middle school level. Field experience is not limited to the campus Lab School (Alexander \& MCEwin, 1988). The last set of required courses is in the area of middle school teacher education. These courses include: -Orientation to Education--students are introduced to current educational issues and are given the opportunity to observe an elementary, middle, and high school class in the Laboratory School.

-Orientation to Middle School--the needs and characteristics of the transescent plus an introduction to the essential curriculum components and instructional strategies appropriate for this level. The students also have an opportunity to visit several different middle schools.

-Two reading classes, one in developmental reading and one in teaching reading in the content fields.

-A psychology class in adolescent development.

-Two methods classes in the content fields which the respective students have chosen to emphasize. (Alexander \& MCEwin, 1988, p. 31)

The courses in the orientation to middle school strand cover the history, philosophy, and principles of middle school, classroom management, and an understanding of the developmental needs of the transescent in addition to those listed above. There are plans to expand the middle school orientation class to include an interdisciplinary methods block. This addition would be a supplement to the specific content methods courses that are already required (Alexander \& McEwin, 1988). 
Another special aspect of the University of Northern Colorado program is an option for students to major in both elementary and middle school teacher education. This double major allows students to receive both $\mathrm{K}-6$ and 5-9 certification. The additional requirements for the double major are an extended student teaching experience which includes both elementary and middle school experience, and both the elementary methods block and the middle school methods block must be taken (Alexander \& MCEwin, 1988). The need for preservice preparation programs for middle school educators is not being met by the majority of the teacher preparation institutions in this country. Successful programs do exist. They exist in states where middle school certification is mandatory--such as Georgia, and they exist in states where special middle school certification is an option--such as Colorado. The basic components of any such program should include: thorough study of the developmental needs of the early adolescent, early and continuing field experience in effective middle schools, study of effective middle school instructional strategies and curriculum, and the development of two fields of academic study at the undergraduate level.

NCATE Guidelines for Middle Level Undergraduate Teacher Education

The NMSA has been concerned with special preparation and accompanying certification of middle level teachers since its inception. Early in its history as an association it formed 
a committee--the Professional preparation and Certification Committee. This committee was charged with the following activities and responsibilities: representation on the NMSA Board, dissemination of information about teacher certification and preparation and coordination of NMSA's involvement as a constituent member of the National Council for Accreditation of Teacher Education (NMSA, 1990). NCATE is the primary accreditation agency for teacher education institutions in the United States (Alexander \& MCEwin, 1988). This committee was responsible for three major publications on the topic of middle school teacher preparation (Alexander \& MCEwin, 1988). The first, a paper entitled "Preparing Teachers for the Middle Grades: A Position Paper," was published in the November 1981 issue of the Middle School Journal. The second, was a position statement adopted by the NMSA Board of Directors in 1985. This document, entitled professional Certification and Preparation for the Middle Level: A Position Paper of the National Middle School Association, was disseminated nationwide to deans of colleges of education, state departments of education and other key personnel. The third, a major monograph entitled preparing to Teach at the Middle Level (1988) was published by NMSA. The research that went into these publications is the foundation for the guidelines adopted by NCATE for Middle Level Teacher Education. An important section from the preface to these guidelines stated:

Underlying these guidelines is the recognition that the roles and responsibilities of middle level 
educators are unique, and that they demand and deserve specifically designed preparation programs. These programs should provide educators with the specialized knowledge, skills, concepts and attitudes that will help them achieve high levels of success in working with early adolescents. The ultimate outcome will be educators who are dedicated and committed to early adolescents and their instruction. Institutions are encouraged to expand these basic components as they develop new programs and refine existing ones. (NMSA, 1989, p. 4)

The NCATE guidelines are divided into five categories:

1) Basic Program--Colleges and universities must demonstrate they have an identifiable middle school teacher education program.

2) Nature and Needs of Early Adolescents-Professional preparation programs must demonstrate the ability to prepare teachers who have an understanding of the physical, social, emotional, intellectual and moral development of young adolescents.

3) Middle Level Philosophy, Curriculum and Instruction--The program must help the prospective teacher understand and implement a variety of instructional strategies which facilitate curriculum integration, continuous self development, explanation and enrichment, teacher based guidance and evaluation procedures appropriate for early adolescents.

4) Teaching Fields and Methodology--Preparation for teaching fields should be in at least two unrelated fields and one methods course for teaching at the middle level should be provided.

5) Field Experience--Experience of observing, participating and teaching experience ranging from individual to group settings and a ten week student teaching experience should be provided. (NMSA, 1989 , p. 4)

Teacher education institutions that receive their accreditation through NCATE were asked to submit folios that outlined the programs that they had in middle level teacher 
education to NMSA. The folio review process was implemented in the fall of 1990 for those schools scheduled for NCATE visits in the spring of 1992. Those schools seeking accreditation through NCATE had to demonstrate implementation of these guidelines by the time of their visitations in 1992 . The November/December 1994 volume of High Strides, a bimonthly report on urban middle grades, published by NMSA, had a leading article entitled, "Teacher Education Misses the Middle: Few Colleges Prepare Teachers to Lead Middle School Classrooms" (Walzer, 1994). The article stated that: - . only 22 universities in the country that have fulfilled the guidelines for middle school education recommended by the National Council for Accreditation of Teacher Education (NCATE) . . Only one third of all colleges of education have any courses geared to middle school teaching and few have added them in the past few years . . But researchers mostly blame state governments for the lack of progress in middle school teacher preparation. Few states require middle school certificates to teach in middle school. In his study, Scales said that 35 states offer middlegrades certification, but 32 of them overlap with elementary or secondary certificates. (p. 4)

The NCATE guidelines are having an impact on the teacher training institutions; however, the impact appears to be a minor one at this point in time.

\section{Summary}

This chapter provided an overview of the literature that is relevant to this study. The review of literature is organized according to the following subcategories: current findings on adolescent development, effective middle level schools, effective middle level teachers, preparation 
programs for middle level teachers, preparation programs located at the University of Georgia and University of Northern Colorado, and NCATE guidelines for middle level undergraduate teacher education.

The early adolescents of the 1990s are facing challenges that are far different from those of their parents. Today students from the ages of 10 to 15 are confronted with violence, fragmented family structures, exposure to drugs and alcohol, poverty, and exposure to sexually suggestive advertisements, television and movies. This is a truly critical time in their lives and a time where many must turn to their schools and their teachers for the appropriate guidance for their lives. Adults in the school setting must be ready and able to assist these children in making the right choices and in understanding how they best learn.

Effective middle level schools are organized to meet the unique developmental needs of early adolescents. They provide positive learning environments where curiosity, creativity, and independence are encouraged. These institutions are flexible enough to adapt to their students' individual differences in intellectual, social, and biological maturation. Typically, they are organized in a manner that allows adults and students to develop close relationships (schools-within-schools, houses, teams) which better enable students to understand this transition time in their lives. In addition, these effective middle level schools promote a specialized curricular approach to meet the needs of their unique students. 
Effective middle level teachers are the key factor in the creation and maintenance of effective middle level schools. These teachers have a sound understanding of the developmental needs of the students with whom they work. They realize how important it is to utilize the natural activity levels and curiosity of their students. They therefore employ hands-on activities and group instruction as they work with their students as well as a variety of other effective instructional strategies that enable the children they teach to be actively involved in their educational program. These teachers are cognizant of the need to be flexible as they work with their early adolescent learners, and they are competent in their diagnosis of individual learning needs. Effective middle level teachers model important, appropriate behaviors to their students. They have abandoned the traditional role as the dispenser of knowledge and have assumed the position of being a coordinator of many sources of knowledge.

Preparation programs for middle level teachers provide the appropriate training opportunities for educators who wish to work with early adolescents. Unfortunately, these programs have only recently been available to aspiring middle level educators. Research has shown that teachers currently working at the middle school level have a wider variety of preparation and certification than do their counterparts at either the elementary or secondary level. Research also shows that current middle level practitioners, both administrators and teachers, acknowledge the need for more 
specialized preparation for professionals who choose to work with young adolescents. Studies have shown that the focus of these programs should be the nature of the early adolescent learner, effective instructional strategies for working with middle schoolers, appropriate curriculum, combined with training in a broad academic background balanced with concentrations in two academic areas at the undergraduate level.

Two exemplary middle school preparation programs have been in existence at the University of Georgia and the University of Northern Colorado. These programs are rated as two of the most successful by the NMSA. Though both are unique in nature, the two programs encompass the four areas of focus listed above as well as requiring early and continuing field experience in effective middle schools.

The NMSA has championed the cause of special preparation and/or certification of middle school teachers. Through its committee on Professional Preparation and Certification it has gained involvement as a constituent member of NCATE. NCATE has now adopted guidelines on middle level teacher education which it uses as it reviews accreditation of the teacher education institutions in the United States. It is anticipated that the NCATE guidelines for Middle Level Undergraduate Teacher Education could be the initiating force that stimulates teacher training institutions to provide specialized preservice preparation and certification programs for aspiring middle school personnel. 
As the number of middle schools continues to grow in our nation, how do we insure that these schools are quality educational facilities? These educational facilities are as effective as the people who work in them. Middle school personnel should understand its unique organizational, curricular, and instructional patterns. To provide quality educational experiences for young adolescents middle school teachers would benefit from a thorough understanding of their intellectual, social, emotional and psychological needs. In addition, these educators should also have a sound academic background in the subjects they will teach. 
CHAPTER III

METHODOLOGY AND PROCEDURE

Introduction

This chapter describes the research design and instrumentation used in the study. Case study methodology was employed in this research project to gather qualitative and quantitative data. The study investigated the following research questions:

1. Do the teachers and administrators of the River's Edge School District believe that there should be special preparation/certification for middle level educators incorporated into the teacher education program in the state of Oregon? For what reasons?

2. How did the River's Edge School District, with three schools containing students ages 10 to 14 , implement a middle school program? How did the district involve staff and parents in this process? How could the district assess the effectiveness of its progress toward this endeavor?

3. What are the unique preparation needs of aspiring middle level teachers as perceived by teachers and administrators of the River's Edge School District?

4. How should these needs be addressed by teacher preparation institutions? How can the River's Edge School 
District address the needs for inservice and staff development initiatives?

5. What do the teachers and administrators of the River's Edge School District recognize as the characteristics components of a model teacher preparation program for middle school teachers?

Data were gathered by the following means: (a) questionnaires were distributed to all teachers in two middle schools in the River's Edge School District in Oregon, (b) questionnaires were mailed to a sample of selected middle school administrators from the same district, (c) follow-up interviews were conducted with a sample of middle level teachers and three middle level administrators in the district, (d) district archives and school board minutes were examined and (e) the historical perspective was obtained through participant observation by the researcher who had worked in the district for over 20 years.

\section{Design of the Study}

This study was designed as a case study which investigated the values and perceptions of middle school teachers and administrators concerning preparation and certification knowledge and skills required for middle level educators. Yin (1989) proposed the use of case study methodology "when the investigator has little control over events, and when the focus is on a contemporary phenomenon within some real-life context" (p. 13). The researcher was not in a position to control the training of middle level 
educators (the contemporary phenomenon) within the River's Edge School District (the real life context). An additional component of case study methodology is the use of multiple sources of evidence. For the purposes of this study those sources included responses to the questionnaires, including demographic information and open-ended response questions, follow-up interviews, and district documents (school board minutes of meetings where district middle school studies were reported) and archival records (a notebook containing the original study report and a copy of all of the data concerning the last middle school study).

The primary units of analysis were the teachers employed in two middle schools within the River's Edge School district, administrators of the same district, and district records. The two schools in which the teacher respondents were employed were approximately the same size (500 students), contained grades six through eight, and had similar organizational plans and curricular programs. Their student populations were predominantly white, and their socioeconomic levels ranged from lower middle to upper class. The teacher population in one school was 23 and in the other was 26 .

The sample of administrators was also drawn from the River's Edge School District. The sizes of the schools these administrators served or had served ranged from 280 to 490 pupils. The size of the teaching staff in the schools ranged from 18 to 35 . 
The historical data included detailed, comprehensive notes belonging to the original middle school study committee which contained a copy of the report, notes from meetings of the committee, and information gathered from visitations to other middle schools and workshops. Additional items reviewed for the historical perspective were school board minutes, updates on the original study, and reports for the second middle school study which was conducted in 1990-1991.

This case study design, like other research designs, has its strengths and weaknesses. Among its strengths are: a historical and contextual understanding of data; a cultural interpretation of data; a more thorough and detailed description of events, people, and phenomena. Among a case study design's weaknesses are: lack of rigor, little basis for scientific generalization, length of time involved in completion, massive, and unreadable documents as products of the study (Yin, 1989). Concern is additionally raised about the validity and reliability of case study research. Yin suggested that four tests are relevant when focusing on the quality of a case study:

Construct validity: establishing correct operational measures for the concepts being studied; Internal validity (for explanatory or causal studies only, and not for descriptive or exploratory studies): establishing a causal relationship, whereby certain conditions are shown to lead to other conditions, as distinguished from spurious relationships; External validity: establishing the domain to which a study's findings can be generalized; and Reliability: demonstrating that the operations of a study--such as the data collection procedures--can be repeated, with the same results. (pp. 40-41) 
This case study meets the test of construct validity. Construct validity was established because the researcher employed multiple sources of evidence (participant observation, documentation: archival records, interviews, survey results); created an organized case study data base (notes, documents, tabular materials, narratives); maintained a chain of evidence (case study protocol, data collection records, analysis from initial research questions to the case study conclusions); and had participants of the study review it for accuracy and validity (Yin, 1989). Yin stated: case studies, like experiments, are generalizable
to theoretical propositions and not to populations
or universes. In this sense, the case study, like
the experiment, does not represent a "sample," and
the investigator's goal is to expand and generalize
theories (analytic generalization) and not to
enumerate frequencies (statistical generalization).
(p. 21) The results of this study are compared with the results of numerous studies that were previously conducted on specialized preparation for middle level educators. The reliability of this study, in an effort to minimize errors and biases, was based upon diligent documentation, procedural safeguards, such as the establishment of a protocol and data base, and the use of the multiple sources of evidence; however, since the reliability of the instruments and procedures was not tested, the reliability of the study is limited (Yin, 1989). 
Population and Sample

This study involved two distinct populations of middle school educators. The first group consisted of middle school teachers in two of the three middle schools in a suburban school district in oregon. The second group consisted of middle school administrators, the majority of whom worked, or at one time had worked, 'in middle schools also in the same district. This school district was known for its innovative and vigorous efforts to address the special preparation needs of middle level teachers. It had worked with staff on advisor/advisee development, interdisciplinary teaching, student management, and cooperative learning. A survey, developed by the researcher, was Imailed to both groups. The survey probed their beliefs about preparation and certification of middle level educators. The questionnaires varied only in the demographic information requested from each of the two groups. A follow-up interview, involving a representative sample of teachers and three current middle school administrators, was conducted to supplement and obtain a more in-depth understanding of the questions being investigated and the data previously gathered both from the survey and from the district records.

Because specific expert information was needed, the subjects chosen for the study were purposely selected teachers and administrators from the River's Edge School District. Schools were identified where teachers were thought to have extensivie experience with middle level 
education and who had valuable knowledge about middle school teaching and learning. The schools were selected because the River's Edge District underwent a major middle school study in 1980-1981, and had embarked upon a second study during the 1990-1991 school year. The teachers in the two middle schools were actively involved in researching the middle level movement during the 1989-1990 school year, in preparation for the 1990-1991 study. Besides being actively involved in the education of early adolescents on a daily basis, their investigation of the most up-to-date research on the middle school educational process provided them with an expert background which was important for this study. Additionally, the two schools were selected, rather than all three middle schools, because of the size of their student and staff populations as well as the fact that they added a historical perspective to the study.

The researcher selected a representative sample of teachers and administrators to interview who had participated in the original survey process. Subjects who participated in the interviews were still working in the River's Edge School District, because they were relatively easy to access and were still actively involved in the middle school process.

The middle school administrators who were selected as a sample were chosen because they were active participants in state and/or national middle school organizations. They were in regular attendance at state and/or national middle school conferences. Several of them had been members of a state task force that had been petitioning the state 
administrators' association for permission to establish a state affiliate organization with NMSA. Two of the participants spent the majority of their adminj.strative careers as middle school principals, before they proceeded to become superintendents or assistant superintendents. Even though they were central office administrators, they continued to be members of NMSA and to attend NMSA national conferences. This administrative sample was one of the most knowledgeable groups in the state concerning current and appropriate middle school practices.

The three administrators who were involved in the follow-up interview process were two assistant principals and one principal who were employed by the district during the 1993-1994 school year. The principal received his professional training in the Midwest and had taken graduate course work in special middle school preparation. The two assistant principals were trained in the state of Oregon and their expertise is attributable to independent study and on the job practice.

The Questionnaire

The questionnaire (Appendix A) used in this study was developed by the researcher. After extensive research on middle school education, and enumeration of the essential elements of a middle school--including organizational strategies--the components of the instrument were synthesized.

The initial draft of the instrument was submitted to an expert review by two university researchers. These experts 
analyzed the instrument in terms of deciding if the items included in it did sample a significant aspect of the purpose of the investigation. It also examined the meaning of specific terms to see that they would have the same meaning to all respondents. After this expert review, the instrument was field tested on 10 middle school teachers and two middle school administrators. The teachers who participated in the field testing were all members of the faculty of a third middle school in the same suburban district as the population used for the study. One of the administrators who took part in the field testing was from the same district, while the other was from another suburban district.

Two participants in the teachers' field testing sample felt that question numbers 4 and 8 under the SPECIAL PREPARATION section of the questionnaire asked for essentially the same information. This was not a concern of the administrative participants. After examination of all the answers to the questionnaires, the researcher decided to make no further changes in the instrument. Question number four asks for types of courses or special preparation for teaching middle school and question number eight refers to the kind of training (i.e., inservice, college courses, seminars, etc.) that would be the most appropriate. It was decided at that point that there were no ambiguities in content in the questionnaire. Additionally, a comparison of the second administration of the questionnaire with the field testing showed a similarity in responses. Both the expert 
review and the field testing helped to establish the validity of the questionnaire.

The data gathered from the questionnaire were analyzed to determine the degree to which special preparation and/or certification would be endorsed by the middle level educators in the sample. In addition, the responses to the open-ended questions were reviewed for ideas from the respondents about what components they considered would be important in a model preparation program.

\section{Interviews}

Follow-up interviews were conducted at the end of the 1993-1994 school year. Ten of the original 30 teachers were selected to be interviewed. These 10 were a representative sample of the survey group: in gender, six were female and four were male; in age, one was in the 20-29 age category, two were in the 30-39 age category, four were in the 40-49 age category, three were over 50 years of age; in experience, one had worked between 1-5 years, one had worked between 6-10 years, three had worked between 11-15 years, two between 16-20 years, and three had more than 20 years of experience; in certification, three held elementary certificates, four held secondary certificates, and three held specialist certificates. The profile of the three administrators was as follows: two female and one male; three with master's degrees; three from 40-49 years of age; three with 16-20 years of experience; and three with $\mathrm{k}-12$ administrative certification. The 13 interviews were all personally conducted, recorded, and transcribed by the researcher. 
These interviews were audiotaped and completed on an individual basis. The amount of time it took to conduct each interview ranged from 30 minutes to 90 minutes, averaging about 45 minutes. Staff met with the researcher before or after school or during a preparation period. Each interview was transcribed verbatim by the researcher. Each interviewee was asked to respond to the following set of questions:

What is your ideal of a successful program for students in the middle grades? How well do your school's present practices match your ideal? Are students' developmental needs being addressed/met? In what ways?

What opportunities for inservice on middle school concepts have been offered by your district or school since 1990? In what ways were these inservice programs useful to you? Were you able to implement the concepts presented in these inservice programs? What were the difficulties you faced in these implementations? Have these inservice opportunities actually influenced your day-to-day interaction with students? Or your instruction?

Do you feel a need still remains for inservice activities that address middle school philosophies/programs? In what areas does that need exist? How do you feel that need could best be addressed?

What do you hope to see as outcomes of the 21 st Century Grant that the district middle schools have been awarded? How do you see yourself affected by this grant? How will your needs be met through this process? 
In the next five years, what do you view as the needs for middle school personnel in this school district? How do you see those needs best being met?

After transcribing all of the interviews, the researcher analyzed the data for similar themes/ideas as well as compared the responses from the open-ended questions in the original survey to the responses of the interview questions. Common themes did appear in the two sources of information and are outlined in chapter IV.

\section{Historical Data}

The researcher met with the superintendent's secretary to discover how copies of historical documents concerning the 1980-1981 middle school study, the 1990-1991 middle school study, and the 21 st century Grant could be located. All of the minutes of school board meetings for the last 20 years were located in a safe in the basement of the district administration building. Information concerning the last five years was maintained in the district files in the superintendent's office. The researcher located minutes from the school board meetings held in 1981, 1982, and 1983 which contained information regarding the middle school program/study of the district in the vault and those pertaining to the 1990-1991 middle school study and the 21st Century Grant in the recent files in the district office. The researcher contacted two of the original members of the 1980-1981 middle school study to see if either might have the documentation regarding the process and the actual 
report. These two employees were the only two remaining with the district since that study. A notebook containing all of the information was located in the files of one of the members. The researcher was a participant in the 1990-1991 middle school study and had maintained a complete file documenting the process and containing the report. All of these historical documents were carefully examined by the researcher and pertinent information was utilized in the analysis of all the data related to the study.

\section{Data Gathering Procedures}

District office permission to conduct the research in both schools was obtained prior to the initiation of the study. The teacher questionnaires were distributed to the teachers personally by the researcher during the initial stage of the research in 1990. At both schools, the questionnaires were handed out at a regularly scheduled staff meeting thus not requiring the participants to attend a special meeting. During the meeting, the researcher read a letter that accompanied the questionnaire, explained the purpose of the study, answered staff's questions, informed the prospective participants about how they could receive copies of a summary of the findings, and assured them that confidentiality would be maintained.

Teacher questionnaires were returned to the principal in one building and the assistant principal in the other and personally gathered by the researcher at each school after reminders were sent through administrators. Extra 
questionnaires were also available at both schools for staff members who might have misplaced theirs. In one school, nine questionnaires of the total 23 distributed were returned, creating a return rate of 39\%. In the second school, 21 questionnaires of the total 26 were returned for a return rate of $81 \%$. The return rate in the second school may have been higher because the researcher was working in that school at the time of the study. The overall return rate for the teacher questionnaires was $61 \%$.

The administrative questionnaires were mailed to the 10 participants accompanied by a letter that explained the purpose of the study. All 10 administrators returned the questionnaires by mail, hence the return rate was 1008 for the administrators.

As previously described, all of the follow-up interviews were conducted, recorded, and transcribed by the researcher. The historical data was personally gathered by the researcher. The cooperation of the district employees who were interviewed and those who participated in the middle school studies facilitated the data collection.

\section{Data Analysis}

The data obtained from the returned questionnaires, from the district historical documents, and from the transcribed interviews are summarized and displayed by use of tables and narrative description in Chapter IV of the study. Inferential statistics, employing chi-square and cross tabs, 
were attempted but could not be used for the purposes of analysis because of insufficient numbers.

Summary

This chapter described the research design and the methodology for the case study. The sample of teachers and administrators was drawn from the River's Edge School District, a suburban school district in oregon. The research samples of teachers and administrators were both asked to respond to a researcher-developed questionnaire which collected demographic data and information about middle school preparation and certification needs. The instruments varied only in the demographic information requested from the two groups of respondents. The researcher administered the questionnaire to teachers in two schools, and mailed the questionnaires to the sample of educational administrators. Follow-up interviews were conducted by the researcher with a representative sample of 10 teachers and three administrators from the same district. Relevant information was also obtained from district records that had been maintained by the district and its employees and were examined by the researcher. Data analysis is presented in Chapter IV. 
CHAPTER IV

DATA ANALYSIS

This chapter presents the analysis of the data derived from responses to the researcher-prepared questionnaire, the follow-up interview process, and the district documents and archival records. The questionnaire (Appendix A) was completed by middle school teachers and administrators in the River's Edge School District, a suburban school district in oregon. The interviews were conducted with a representative sample of 10 teachers from the original sample and three administrators. One of the administrators participated in the survey process, while the other two were new to the district after the survey was conducted. The interview questions are listed in the previous chapter. The district documents included the 1980-1981 middle school study report; the 1990-1991 middle school study report; minutes of school board meetings; a notebook belonging to a member of the 1980-1981 study which contained agendas of committee meetings, minutes from committee meetings, recommendations for changes, communication from the committee to the superintendent; copies of the research articles used for the 1990-1991 study; and a copy of the 21st Century Grant application. 
The River's Edge School District

The River's Edge School District is a suburban district in Oregon. The district's population is predominantly white, lower middle to upper class. The school district reflects the population and the growth rate of the community. Presently, the district consists of one high school (with a second high school scheduled to open in 1995-1996), three middle schools, and six elementary schools. The student population totals approximately 6,800. The population of the three middle schools ranges from 400 to 780 . During the early 1980s, when the district began to initiate the middle school concept, the district had a population of approximately 3,700. At that time, the district had one high school, three middle schools (one just newly built), and four elementary schools.

\section{Development of Middle Schools in the River's Edge School District}

The concept of middle school education came to the forefront in the River's Edge School District in the early 1980 s when three new administrators were hired to begin the development of quality middle level educational facilities. A nationwide search was conducted for these three principals. With the opening of a new middle school, the district felt it was an opportune time to implement programs that addressed the needs of the early adolescent. Prior to this time, the schools in the district were organized in a 1-4 (kindergarten 
became a part of the school district program during the 1981-1982 school year), 5-8, 9-12 configuration. The 5-8 schools ran self-contained programs for the fifth and sixth grade students and junior high programs for the seventh and eighth graders. With the opening of the new middle school, the district decided to embark upon a formal study of middle level education.

\section{The 1980-1981 Middle School Study}

A committee of community members, teachers, students, and administrators was organized in 1980-1981. In June of 1981, the Middle School study Committee submitted a report to the school board outlining goals and recommendations in relation to their efforts to form exemplary middle school programs. The committee drafted several general recommendations and a number of specific recommendations in the following areas of the middle school program: (a) organization, (b) curriculum, (c) guidance/counseling, and (d) co-curricular activities. The middle school committee went through a systematic process to formulate its initial report involving an extensive review of the available middle school research, visitations to other middle school programs, and participation in workshops and seminars. With this information the committee concluded that because of the characteristics of a middle school program the following organizational considerations should be addressed: (a) flexible structure (space, time, curriculum, and grouping), (b) activities to release energies, (c) shift in 
routine to avoid monotony, (d) allowance for wide variation in student abilities and learning styles, (e) opportunities for student choice of subjects, (f) student participation in establishing classroom regulations, (g) consistent student behavior expectations, (h) student government, (i) help in decision-making skills, (j) support of staff in coping with student behavior and academic needs, and ( $k$ ) promotion of parent understanding of students' developmental needs and characteristics. The committee considered the middle school years as transitional years where students move from the more dependent relationships of the elementary school to the increasingly independent responsibilities of the high school.

In addition, the committee created a philosophy statement designed to provide rigorous educational experiences for students that promote the development of the total person and that met the following program objectives: (a) provide an atmosphere for flexible learning styles, (b) respond to individual needs, (c) develop positive self concepts, (d) develop standards of mastery of basic skills, (e) encourage an attitude that reinforces the joy of learning, (f) meet the physical and developmental needs of the preadolescent, (g) teach responsibility for one's own actions, (h) provide equal educational experiences and opportunities, and (i) provide an ongoing program of evaluation.

The committee also made the following suggestions to the district: (a) fiscal resources necessary to implement the program recommendations should be provided, (b) equal 
educational opportunities should be provided through comparable programs at all of the district's middle schools, (c) program goals need to be supported at the district and individual school levels through inservice training and parent education, (d) further committee work involving parents and staff should facilitate the implementation of the program, (e) an ongoing program of evaluation should be developed to review and modify the programs, and (f) principals and staff should begin work as soon as possible to draft budgetary and non-budgetary time lines for implementation of the program recommendations.

The organizational structure of the middle school program for the district prompted three program goals: (a) middle schools should be large enough to facilitate curriculum and staff diversity, meet individual student needs, and maximize opportunities for learning (400-600 students), (b) schools should provide an instructional program that maximizes ease of transition from primary school to high school, while offering a unified program (grades $6-8)$, (c) the best staffing pattern to support the recommended curriculum should be provided. In addition, they recominended further study of the following issues: (a) the merits of interdisciplinary team teaching, (b) the administrative structure of the schools with regard to providing adequate support for teachers and programs, and (c) the best combination of elementary and secondary prepared teachers to carry out an exemplary middle school program. 
The second set of program goals addressed the curricular area of middle level schooling: develop problem solving applications, including analytic thinking skills in language arts (writing), vocational and career education, math, science, social studies (including use of simulations), health (including areas of problems of adolescents), and an advisor/advisee program; create a strong curriculum component that would meet guidance and counseling needs of students (advisor/advisee program); provide hands-on or manipulative experiences for students, including additional vocational/lifelong learning experiences including home economics, industrial arts, and computer literacy. The study columittee believed it would be important to include a program goal concerning the development of a program to teach organizational and study skills. To bring this goal to fruition a staff committee would need to develop a study skills/organizational strand for all appropriate areas of the curriculum and support this concept through inservice training for staff.

Another curriculum based program goal focused on including appropriate skill based/continuous progress components in the middle school curriculum. The program was to be developed in a manner to facilitate a transition for students from the primary school through the high school curriculum. Management and evaluation systems needed to be created to support continuous progress programs.

The last curriculum goals sought to provide appropriate enrichment and exploratory experiences for all middle school 
students. The study committee realized that a quality guidance and counseling program needed to be an integral part of the middle school educational setting. They promoted the development of an advisor/advisee program that would include: advisors who would function in some counseling type role in cooperation with the school counselor; and advisee group of more than one grade level, described as a "family" of no more than 20 students, some of whom would change yearly; a group-process mental health, self-development curriculum; opportunities for teaching organizational and time-use skills; advisor roles which involve becoming the "expert" on each advisee and representing advisees in communicating with other staff and with parents; advisor tracking of the academic and developmental growth of each advisee, coordinating the reporting of progress to the students, parents, other teachers and the high school; and, the school counselor roles would essentially remain as they were currently with the addition of the tasks of assisting advisors with materials and techniques for use in their advisee groups. It was recommended that this goal should be supported through appropriate staff development as well as through adequate curriculum materials.

Three other goals addressed the importance of developing a parent education program, including appointing a districtwide staff/parent committee to develop overall goals for a parent education program; training staff members in a variety of strategies for dealing with behavior and discipline issues, after an evaluation of current practices; targeting 
the development of a grading/report system that would support the recommended curriculum while continuing the use of parent conferences, however, expanding the concept to include student participation in such conferences.

The study committee investigated a co-curricular program as a means for involving students in the development of citizenship, social skills, athletic skills, leadership skills, community service, and common interest programs. In late August of 1982, the middle school principals provided a progress report to the superintendent in each area of the original study along with a list of planned tasks for completion for the 1982-1983 school year: expanding opportunities for exploration and enrichment; continuing development of computer science programs and the use of computers in instruction; refining the advisor/advisee program, including staff development for teachers; establishing building-wide student management systems; evaluating current grading and reporting systems; improving open house and conferencing formats to more effectively communicate with parents; reviewing the co-curricular programs in relation to age appropriateness and to other school goals. Modifications in a variety of areas occurred as a result of this study.

\section{The 1990-1991 Middle School Study}

The River's Edge School District did not formally revisit the study of middle school program goals again until the 1990-1991 school year. During the years between the two 
efforts, each middle school developed its own unique program. The targeted goals of the 1980-1981 study seemed to be forgotten; indeed the researcher, who was employed by the district during the original study, was not aware that such a comprehensive effort had taken place. The need for re-evaluation again arose with the opening of another new middle school in the district. The 1990-1991 study committee was composed of middle school principals, teachers, counselors, parents, and district office administrators. Subcommittees were organized to study curriculum and instruction, athletics and activities, and counseling and advisory. This effort, as the one in 1980-1981, began with an extensive study of the current middle school literature. Team members also participated in school-site visits, state sponsored middle school workshops and conferences, and three staff from each middle school attended the National Middle School Conference put on by NMSA.

In April of 1991, the committee presented a preliminary report to the school board. The report provided a middle school mission statement and recommendations from the curriculum and instruction subcommittee. The mission statement stipulated that the River's Edge School District recognized the unique intellectual, social/emotional, and physical needs of middle school students. The district would provide a challenging and developmentally appropriate educational program at the middle school level. In addition, the program would prepare students to be contributing members of local and global communities. The mission statement was 
based on the belief that all students can bel successful learners. The statement was followed by a number of belief statements :

1. Schools should foster a lifelong love and joy for learning;

2. All students need to become valuable members of small learning communities;

3. Instruction should reflect diverse teaching strategies that support students' varied learning styles;

4. Instruction should foster critical thinking, problem-solving, and creativity;

5. All students should be provided a challenging core curriculum and exploratory learning experiences which are purposeful and relevant to all students;

6. The curriculum should reflect the integration of subject areas;

7. The curriculum should teach students a sense of social and political responsibility and foster effective interpersonal skills;

8. The curriculum should provide students with technological and reference skills to support success in a rapidly expanding world of knowledge;

9. Classrooms should provide a physicall learning environment that would support students' security, communication, and exploration;

10. Student performance should be monitored and evaluated in a timely and appropriate manner; 
11. Student learning should be viewed as being primarily dependent upon the educational relationships between students and teachers. The statement concluded by expressing that the goals of the district middle school program could be significantly enhanced by strong school, home, and community partnerships.

The curriculum and instruction subcommittee investigated the following areas: teaming, block scheduling, interdisciplinary teaching, cooperative learning, tracking, exploratory/elective programs, and a variety of instructional strategies. Recommendations were made in each area. The subcommittee proposed that teaming should be an initial step in the transition to a middle school program. Inservice training for teachers in the teaming process was viewed as essential to the ultimate success of this strategy. It was recommended that block schedules be the form of scheduling to be used at the middle school level. Formal training in the process of schedule building of this manner should be provided for all assistant principals. Also the subcommittee felt that interdisciplinary teaching should be implemented slowly, perhaps one unit a year. The district should provide training in thematic instruction and teaming and provide common planning time for teachers. Another recommendation was that cooperative learning should be employed as one of the variety of instructional strategies at the middle school level. In addition, opportunities for formal training in cooperative learning should be offered by the district on a regular basis. 
The subcommittee advocated that tracking, as an instructional practice, should be eliminated at the middle school level. The last curricular area to be "de-tracked" should be math. Support should be given to teachers in need of assistance in working with heterogeneous groupings of students. They decided that an elective or exploratory program should be an integral part of a middle level school. The opportunity for all students to experience quality elective classes in all three schools was an important part of an effective middle school program.

Finally, the curriculum and instruction committee presented recommendations on 12 learning strategies:

1. Academic goal setting--Teachers need to help students develop their own goals that are both realistic and directed at improving skill deficits. This allows students to experience a sense of understanding and control of their learning;

2. Active instruction--Teachers should include students in a variety of instructional methods that tend to actively involve them in the learning process such as, discussions, games, answering questions, responding to classmates comments, discovery learning;

3. Assessment--Students should evaluate their own progress as a part of the assessment process;

4. Critical thinking--Middle school teachers can help students develop concepts in viewing learning as something that relates to their own lives, and that helps them to 
relate their learning to their own beliefs, feelings and behaviors;

5. Direct instructional approach--This is a valuable part of teaching strategies when additional strategies are used in combination with it;

6. Inquiry method--This strategy should be put to use to enable students to learn through researching, questioning, and asking;

7. Learning how to learn--Students must be instructed in how they best learn;

8. Manipulatives--The "concrete to abstract" type of learning strategy should be used because developmentally middle school students are beginning to think about cause and effect relationships and the consequences of their decisions;

9. Real life application--This learning method is extremely relevant to the middle school student because it relates specifically to them and to their experiences;

10. Simulation--This is an appropriate strategy because it incorporates a variety of instructional techniques;

11. Thematic learning--The process of meaningfully integrating many subjects should be used to allow for both large and small concept learning;

12. Whole language combination--An effective strategy because it allows students to experience the fact that writing is used for everything and in every subject. The other two subcommittees, athletics and activities and counseling and advisory, did not present preliminary reports at that time. 
All efforts of the district the following school year focused on the opening of the new middle school and the transformation of the previous middle school into a remodeled primary school. Administrative changes at two of the middle schools and lack of district coordination resulted in very little follow through on any of the recommendations or the continuation of the middle school study committee.

The 21st Century School Improvement

Grant

During the 1993-1994 school year, the middle schools established a 21st Century Consortia. The purpose of this group was to pursue new areas of study at the middle level in order to prepare students for the Certificate of Initial Mastery (CIM) outcomes, a requirement of the Oregon Education Act for the 21st Century.- Their first goal was to review the literature and examine existing models which have restructured the use of time at the middle level. The primary activities related to this goal were researching alternative schedules and configurations of the school day. A number of site visits occurred and other middle schools were surveyed regarding possible scheduling and time configuration models. The outcome for this goal was to be a change in the current time configurations in the consortia schools.

The second goal was to examine ways to modify traditional methods of instruction. A research team was formed to study, explore, and evaluate the use of technology at the middle level. Study teams investigated the area of 
alternative assessment opportunities, methods for creating lifelong learners, and identification of benchmarks for student learning outcomes. Assistance in this goal came through networking with other schools and from educational institutions and organizations. The outcome for the second goal was the identification of specific student outcomes directed at meeting the CIM requirements.

The final goal was to enhance instructional opportunities for student learning which would result in increased parent and community involvement. A systematic avenue to keep the parent community informed was to be investigated, including the use of cable television and a variety of other media sources. Teachers and parents researched ways to teach critical, creative, and reflective thinking in decision-making and problem solving. The outcome of this goal was to be increased parent/community participation in the educational process at the middle school level.

\section{Description of Respondents}

The sample for the questionnaire is divided into two categories: middle school teachers and administrators. The teacher sample is described in terms of purpose for selection, location, size, age, gender, academic preparation, number of years taught and in present position, number of years experience at the middle/junior high school level, and number with elementary, secondary, or specialist certification. The administrator sample is described in terms of size, purpose for selection, location, age, gender, 
academic preparation, number of years in administration and in present position, and number of years experience at the middle/junior high school level.

Teachers who participated in the study were employees in two of the three middle schools in the River's Edge School District. The total number of teachers surveyed was 49 , in grades six, seven, and eight. of the 49 questionnaires distributed, 30 were returned, resulting in a return rate of 61\%. A representative sample of this group was selected to be participants in the follow-up interview process. Ten administrators were asked to participate in this study. All 10 returned their questionnaires resulting in a 1008 return rate. All 10 of the administrators were employed, or at one time had been employed, in the River's Edge School District. These administrators were actively involved in state and national middle school associations and had participated in the first district middle school study; hence they were chosen to participate. A representative sample of three middle school administrators, who were employed by the River's Edge School District during the 19931994 school year, participated in the interview process. The demographic profiles of the samples are presented in Appendix B. Age of the teacher respondents was recorded in the following categories: $20-29 ; 30-39 ; 40-49 ;$ and 50 and over. The majority of the teacher respondents (73\%) belonged to the 40 or above age group, while only $27 \%$ belonged in the age group 40 and under. The majority of the 10 interview participants also belonged to the 40 or above age group. 
The total administrative sample was 10 respondents. The majority of the administrators (90\%) belonged to the 40 and over age group, while only $10 \%$ belonged to the group below the age of 40 . All three of the administrators who were interviewed were in the 40-49 age category.

Twenty of the teacher respondents were female and 10 were male. Of those teachers interviewed, 4 teachers were male and 6 were female. In the administrator questionnaire sample, 8 respondents were male and 2 were female. Two of the 3 administrators interviewed were female and 1 was male.

Fourteen of the teacher respondents in the questionnaire sample held bachelor's degrees and 16 held master's degrees. Seven of the teachers interviewed held master's degrees and 3 held bachelor's degrees. In the administrator questionnaire sample, 7 respondents held master's degrees and 3 held doctorates. All 3 of the administrators interviewed held master's degrees.

The experience categories on the questionnaire were formed in the following manner: 1-5 years, 6-10 years, 11-15 years, 16-20 years, and over 20 years. The majority of the respondents $(83 \%)$ had over 10 years of teaching experience, while only $17 \%$ had less than 10 years of experience. In general, the teacher respondents could be considered a veteran group of educators. The same distribution holds true for the teachers who were interviewed, with the majority having over 10 years of experience.

The same experience categories were included in the administrative questionnaire. The majority of this group 
(60\%) had more than 10 years of experience as educational administrators; however, the three administrators who were interviewed were all relatively inexperienced, having five years of experience or less.

The respondents were asked to indicate their total number of years of experience in their present positions. Within the teacher group, these totals ranged from 33 years to 1 year. For teachers, the mean number of years of experience in their present position for was 10 years, while the median was 5 years. In the administrator group, the number of years in their present position ranged from a maximum of 11 years to a minimum of 1 year. The mean number of years of experience in their present position for the administrators was 3 , while the median was 4 .

The respondents were asked to indicate the total number of years of experience that they had at the middle/junior high school level. In the teacher group, the number of years at the middle/junior high school level ranged from a maximum of 33 years to a minimum of 2 years. The mean number of years of experience at the middle/junior high school level for the teacher respondents was 14 years; the median was 10 years. The years of middle school experience for the teachers who were interviewed ranged from 30 to 3 . The mean number of years of experience was 11, while the median was 10. In the administrator group, the number of years of administrative experience at the middle/junior high school level ranged from 21 years to 1 year. The mean number of years of experience for the administrator group was 9. The 
median was 4 years. The three administrators who were interviewed had 5,3 , and 1 year(s) of experience at the middle school level.

The teacher respondents were given 11 subject areas to indicate what they were currently teaching: language arts, reading, math, science, physical education, health, vocal music, instrumental music, social studies, art and other. Teachers could indicate more than one area. If for example, they taught both language arts and social studies, they would check off both. The responses showed 15 language arts, 9 reading, 7 math, 3 science, 3 physical education, 3 health, no vocal music, no instrumental music, 13 social studies, 1 art, and 2 other (special education and counseling). The survey was done in 1990 and the district has made changes in its curriculum since that time. Reading (now literature) and language arts are now being taught together in a block of time. The interviews were conducted after that change (1994) and of the teachers interviewed, two taught science, four taught language arts/literature, one taught math, one taught $\mathrm{PE} /$ Health, one special education and one was a counselor who was also a certified elementary teacher.

Teachers were asked to indicate one of three levels of certification: elementary, secondary, or specialist. Four respondents indicated more than one level. One respondent indicated all three levels, including educational media specialist. Three respondents who were elementary certified indicated holding specialist certificates (counseling) or endorsements (reading, math). The totals indicated in the 
survey were: elementary certification 17, secondary certification 8, specialist certification 10 . The other specialist certifications listed included three with $\mathrm{K}-12$ Physical and Health Education, two Handicapped Learner/Learning Disabled, and one K-12 Art. The adjusted totals (removing double certifications and using only the certification of their current position) left the data to show: 17 elementary certified (57\%); 7 secondary certified (23\%); and 6 specialist certified (20\%). The 10 teachers involved in the interview process held the following certifications (using only the certifications for which they were currently employed): 3 held elementary certificates, 4 held secondary certificates, and 3 held specialist certificates.

Presentation of Survey Data

The survey included several open-ended questions that provided participants with an opportunity to express their ideas about special training/preparation and certification for middle school teachers. Respondents also identified the type of training in middle school concept areas they had experienced and ranked the importance of seven developmental needs of early adolescents.

\section{Special Preparation of Teachers}

The survey requested that teachers indicate if they had any training which directly prepared them for teaching at the middle/junior high school level before they actually began teaching at that level. Twenty-four respondents indicated 
that they had not received any training before teaching at the middle/junior high school level, while 6 respondents indicated that they had received some training. These results indicated that $80 \%$ of the respondents had no training which directly prepared them for teaching at the middle and/or junior high school level and $20 \%$ indicated that they did have prior training. Those that responded that they did have training were asked to indicate if the training they received was at the undergraduate or graduate level. Four respondents $(67 \%)$ received training at the undergraduate level and 2 respondents (33\%) received that training at the graduate level. The respondents were asked to list the kind of training they had received. The following are the responses recorded: a class in middle school at the undergraduate level; Professional Teaching Semester--lst Quarter at a university, K-12 school preparation for math lessons and teaching math classes from sixth to 12 th grade; 2nd quarter student Teaching all day every period at a junior high school; cadet teaching; psychology classes dealing with development, also education classes dealing with growth/behavior changes; (graduate) student teaching at a middle school; and some course work.

\section{Special Preparation of Administrators}

Administrators who participated in the survey were also asked to respond to the same question about receiving any training that directly prepared them for working at the middle/junior high school level before working at that level. 
The results from the administrators were more closely divided. Of the total sample of 10 administrators, 5 (50\%) indicated they had no prior training and 5 (50\%) indicated they did have prior training. Of those who indicated they had prior training, 4 respondents (80\%) received that training at the graduate level and 1 administrator (20\%) received the training at the undergraduate level. The administrators were also asked to list the kind of training they had received. These are their responses: graduate curriculum courses in junior high school; the junior high training program; child and adolescent psychology; guidance in junior high; junior high organization; a two-course graduate sequence on junior high schools (1972-1973, no longer offered); development stages of early adolescent; workshops on philosophy of middle schools; guidance with early adolescents; school organization $\mathrm{k}-12$; undergraduate courses on the middle school/junior high.

\section{Training in Middle School Concept}

\section{Areas}

In another section of the questionnaire, respondents (both teacher and administrator) were asked to indicate the level of training they had received in eight different middle school concept areas. These areas included: advisor/advisee; interdisciplinary team teaching; intramural program; core program; activities program; block scheduling; variety of teaching strategies; and exploratory/elective program. Respondents were asked to indicate at what level they received this training: undergraduate, graduate, formal 
inservice, or learned on the job. They were also asked to indicate the degree of adequacy of such preparation: no preparation; minimum preparation; or adequate preparation. Tables 1 through 16 provide the data for both the teachers and the administrators in each of these concept areas. In the narrative analysis of this information on training in middle school concept areas, the researcher combined the participant pool (using the total number of respondents) and collapsed the results of the two training categories (minimum and adequate) in an effort to better interpret the data.

The Advisor/Advisee Concept

The advisor/advisee program is the process in which an advisor (teacher, administrator, specialist) meets on a regular basis with a group of students and serves as an advocate for each advisee in academic and personal issues. Responses from teachers to the Advisor/Advisee training concept area are recorded in Table 1 and those of administrators are found in Table 2 . 
Table 1

Advisor/Advisee Training for Teachers

\begin{tabular}{|c|c|c|c|c|c|c|}
\hline \multirow{3}{*}{ Level of Training } & \multicolumn{6}{|c|}{ Amount of Training } \\
\hline & \multicolumn{2}{|c|}{ None } & \multicolumn{2}{|c|}{ Minimum } & \multicolumn{2}{|c|}{ Adequate } \\
\hline & $\underline{\mathbf{f}}$ & $q$ & $\underline{\mathbf{f}}$ & $q$ & $\underline{\mathbf{f}}$ & 8 \\
\hline \multirow{4}{*}{$\begin{array}{l}\text { Undergraduate } \\
\text { Graduate } \\
\text { Formal Inservice } \\
\text { On the job }\end{array}$} & 29 & 97 & 0 & 0 & 3 & 10 \\
\hline & 26 & 87 & 3 & 10 & 1 & 1 \\
\hline & 20 & 67 & 7 & 23 & 1 & 3 \\
\hline & 6 & 20 & 11 & 37 & 13 & 43 \\
\hline \multicolumn{7}{|c|}{ Table 2} \\
\hline \multicolumn{7}{|c|}{ Advisor/Advisee Training of Administrators } \\
\hline \multirow{3}{*}{ Level of Training } & \multicolumn{6}{|c|}{ Amount of Training } \\
\hline & \multicolumn{2}{|c|}{ None } & \multicolumn{2}{|c|}{ Minimum } & \multicolumn{2}{|c|}{ Adequate } \\
\hline & $\underline{\mathbf{f}}$ & $q$ & $\underline{\underline{f}}$ & $q$ & $\underline{\underline{f}}$ & $q$ \\
\hline Undergraduate & 10 & 100 & 0 & 0 & 0 & 0 \\
\hline Graduate & 7 & 70 & 1 & 10 & 2 & 20 \\
\hline Formal Inservice & 4 & 40 & 3 & 30 & 3 & 30 \\
\hline on the job & 0 & 0 & 6 & 60 & 4 & 40 \\
\hline
\end{tabular}


The Interdisciplinary Teaching

Concept

Interdisciplinary teaching is the process by which teams of teachers work together to teach basic subjects to a common group of students. In this process, subjects are not taught in isolation but integrated together. The same process can be achieved by individual teachers who teach more than one subject (i.e., literature and social studies, science and math) as integrated units. Responses from the teachers to the interdisciplinary teaching training concept area are recorded in Table 3; the administrator responses can be found in Table 4.

Table 3

Interdisciplinary Teaching Training of Teachers

\begin{tabular}{|c|c|c|c|c|c|c|}
\hline \multirow{3}{*}{ Level of Training } & \multicolumn{6}{|c|}{ Amount of Training } \\
\hline & \multicolumn{2}{|c|}{ None } & \multicolumn{2}{|c|}{ Minimum } & \multicolumn{2}{|c|}{ Adequate } \\
\hline & $\underline{\underline{f}}$ & 8 & $\underline{\mathbf{f}}$ & 8 & $\underline{\mathbf{f}}$ & $q$ \\
\hline Undergraduate & 27 & 90 & 3 & 10 & 0 & 0 \\
\hline Graduate & 21 & 70 & 8 & 27 & 1 & 3 \\
\hline Formal Inservice & 23 & 77 & 5 & 17 & 2 & 7 \\
\hline on the job & 9 & 30 & 9 & 30 & 12 & 40 \\
\hline
\end{tabular}


Table 4

Interdisciplinary Teaching Training of Administrators

\begin{tabular}{|c|c|c|c|c|c|c|}
\hline \multirow{3}{*}{ Level of Training } & \multicolumn{6}{|c|}{ Amount of Training } \\
\hline & \multicolumn{2}{|c|}{ None } & \multicolumn{2}{|c|}{ Minimum } & \multicolumn{2}{|c|}{ Adequate } \\
\hline & $\underline{\mathbf{f}}$ & 8 & $\underline{\mathbf{f}}$ & 8 & $\underline{\underline{f}}$ & $q$ \\
\hline Undergraduate & 10 & 100 & 0 & 0 & 0 & 0 \\
\hline Graduate & 7 & 70 & 2 & 20 & 1 & 10 \\
\hline Formal Inservice & 3 & 30 & 5 & 50 & 2 & 20 \\
\hline on the job & 1 & 10 & 4 & 40 & 5 & 50 \\
\hline
\end{tabular}

\section{The Intramural Program Concept}

An intramural program at the middle school level is usually an opportunity for an organized activity, usually of an athletic nature, where two groups of students play against each other (i.e., volleyball, soccer, basketball). These groups of students are not established by ability or gender, and the purpose of the activity is neither competitive nor interscholastic in nature. It is an opportunity for some much needed physical activity. Responses from teacher participants to the intramural program training concept area are reported in Table 5; the administrator responses are recorded in Table 6 . 
Table 5

Intramural Program Training of Teachers

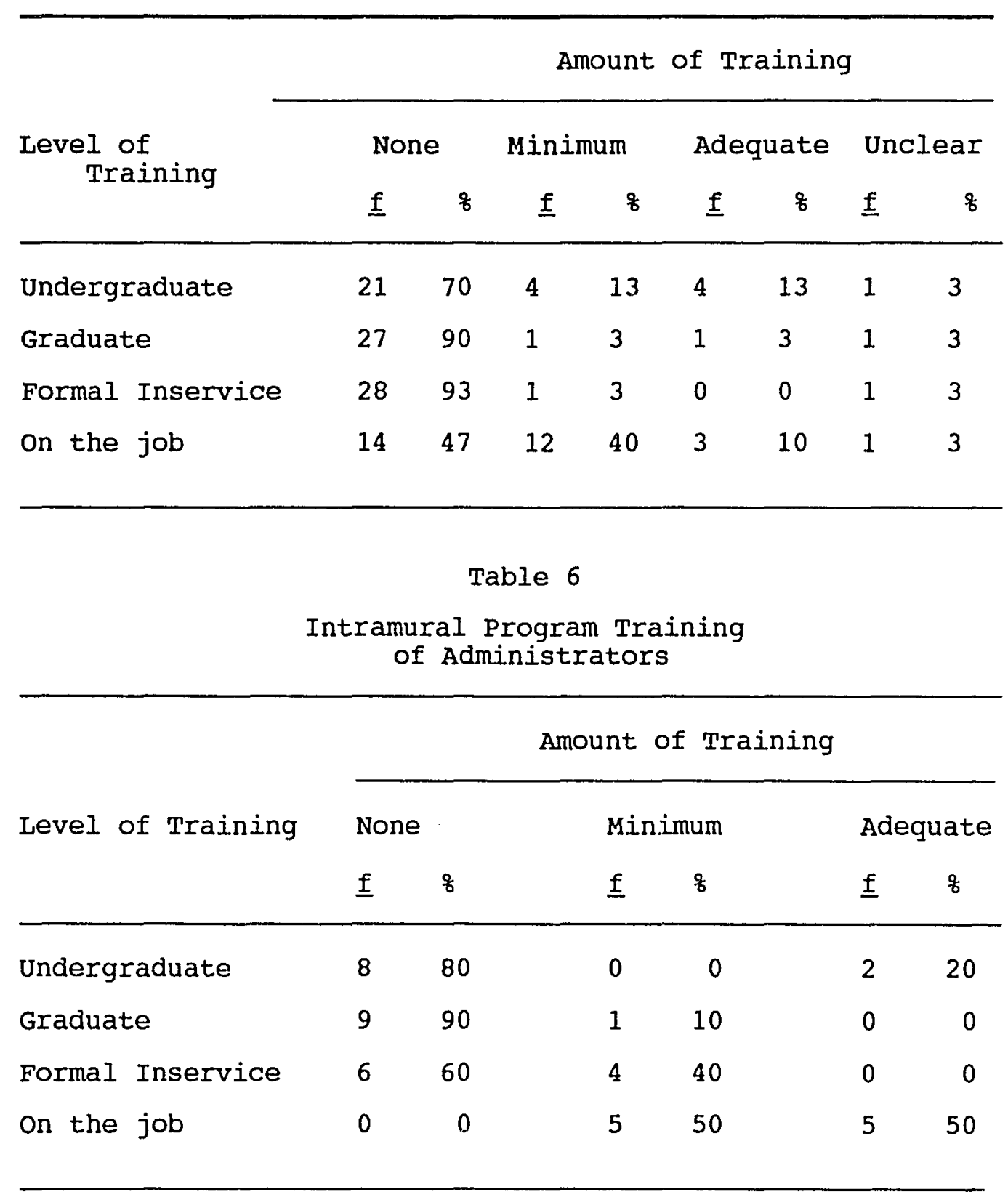


The CORE Program Concept

A CORE program is a way of scheduling in which a number of subjects, generally language arts, Iiterature, and social studies, are taught in a block of time by the same teacher to a common group of students. Responses from teachers to the CORE program training concept area are recorded on Table 7 and those of the administrators are in Table 8.

Table 7

CORE Program Training of Teachers

\begin{tabular}{|c|c|c|c|c|c|c|c|c|}
\hline \multirow{3}{*}{ Level of Training } & \multicolumn{6}{|c|}{ Amount of Training } & \multirow{2}{*}{\multicolumn{2}{|c|}{ Unclear }} \\
\hline & \multicolumn{2}{|c|}{ None } & \multicolumn{2}{|c|}{ Minimum } & \multicolumn{2}{|c|}{ Adequate } & & \\
\hline & $\underline{f}$ & $q$ & $\underline{\underline{f}}$ & $q$ & $\underline{\underline{f}}$ & $q$ & $\underline{\mathbf{f}}$ & $q$ \\
\hline Undergraduate & 25 & 83 & 1 & 3 & 1 & 3 & 3 & 10 \\
\hline Graduate & 25 & 83 & 1 & 3 & 1 & 3 & 3 & 10 \\
\hline Formal Inservice & 24 & 80 & 2 & 7 & 1 & 3 & 3 & 10 \\
\hline On the job & 9 & 30 & 7 & 23 & 11 & 37 & 3 & 10 \\
\hline
\end{tabular}


Table 8

CORE Program Training of Administrators

\begin{tabular}{|c|c|c|c|c|c|c|}
\hline \multirow{3}{*}{ Level of Training } & \multicolumn{6}{|c|}{ Amount of Training } \\
\hline & \multicolumn{2}{|c|}{ None } & \multicolumn{2}{|c|}{ Minimum } & \multicolumn{2}{|c|}{ Adequate } \\
\hline & $\underline{f}$ & 8 & $\underline{f}$ & 8 & $\underline{\mathbf{f}}$ & 8 \\
\hline Undergraduate & 8 & 80 & 1 & 10 & 1 & 10 \\
\hline Graduate & 6 & 60 & 3 & 30 & 1 & 10 \\
\hline Formal Inservice & 4 & 40 & 4 & 40 & 2 & 20 \\
\hline on the job & 0 & 0 & 5 & 50 & 5 & 50 \\
\hline
\end{tabular}

\section{The Activities Program Concept}

An activities program in a middle school provides opportunities for the students to be involved in leadership, community service, intramurals, athletics and other relevant activities during their formative years. Responses from teachers to the activities program training concept area are recorded in Table 9 and those of the administrators are in Table 10 . 
Table 9

Activities Program Training

of Teachers

\begin{tabular}{|c|c|c|c|c|c|c|c|c|}
\hline \multirow{3}{*}{ Level of Training } & \multicolumn{8}{|c|}{ Amount of Training } \\
\hline & \multicolumn{2}{|c|}{ None } & \multicolumn{2}{|c|}{ Minimum } & \multicolumn{2}{|c|}{ Adequate } & \multicolumn{2}{|c|}{ Unclear } \\
\hline & $\underline{f}$ & 8 & $\underline{\mathbf{f}}$ & 8 & $\underline{\underline{f}}$ & $q$ & $\underline{f}$ & 8 \\
\hline Undergraduate & 25 & 83 & 2 & 7 & 1 & 3 & 2 & 7 \\
\hline Graduate & 25 & 83 & 1 & 3 & 2 & 7 & 2 & 7 \\
\hline Formal Inservice & 25 & 83 & 1 & 3 & 2 & 7 & 2 & 7 \\
\hline on the job & 9 & 30 & 7 & 23 & 12 & 40 & 2 & 7 \\
\hline
\end{tabular}

Table 10

Activities Program Training

of Administrators

\begin{tabular}{|c|c|c|c|c|c|c|}
\hline \multirow{3}{*}{ Level of Training } & \multicolumn{6}{|c|}{ Amount of Training } \\
\hline & \multicolumn{2}{|c|}{ None } & \multicolumn{2}{|c|}{ Minimum } & \multicolumn{2}{|c|}{ Adequate } \\
\hline & $\underline{f}$ & 8 & $\underline{\mathbf{f}}$ & $q$ & $\underline{\underline{f}}$ & $q$ \\
\hline Undergraduate & 9 & 90 & 1 & 10 & 0 & 0 \\
\hline Graduate & 9 & 90 & 1 & 10 & 0 & 0 \\
\hline Formal Inservice & 6 & 60 & 2 & 20 & 2 & 20 \\
\hline on the job & 1 & 10 & 3 & 30 & 6 & 60 \\
\hline
\end{tabular}


The Block Scheduling Concept

Block scheduling is a type of organizational process often used at the middle school level. In a block schedule, a block of time is set aside for the instruction of basic subjects. During this time, an interdisciplinary team or an individual teacher, schedules their students for each subject: math, sceince, social studies, language arts, literature. It allows for flexibility in the amount of time that is spent on any one subject on any one day, e.g., one day math could be 40 minutes in length and another day it could be 90 minutes. This process also allows teachers to have control over their own students and their own schedules. Responses from teachers to the block scheduling concept area are recorded on Table 11 and those of the administrators are in Table 12 .

Table 11

Block Scheduling Training of Teachers

\begin{tabular}{lccccccccc}
\hline & \multicolumn{7}{c}{ Amount of Training } \\
\cline { 2 - 10 } Level of Training & None & \multicolumn{1}{c}{ Minimum } & Adequate & Unclear \\
& $\underline{f}$ & $q$ & $\underline{f}$ & $q$ & $\underline{f}$ & $q$ & $\underline{f}$ & $q$ \\
\hline Undergraduate & 26 & 87 & 1 & 3 & 0 & 0 & 3 & 10 \\
Graduate & 24 & 80 & 2 & 7 & 1 & 3 & 3 & 10 \\
Formal Inservice & 25 & 83 & 2 & 7 & 0 & 0 & 3 & 10 \\
On the job & 15 & 50 & 7 & 23 & 5 & 17 & 3 & 10 \\
\hline
\end{tabular}


Table 12

Block Scheduling Training of Administrators

\begin{tabular}{lrrrrrr} 
& \multicolumn{7}{c}{ Amount of Training } \\
\cline { 2 - 7 } Level of Training & \multicolumn{2}{c}{ None } & \multicolumn{2}{c}{ Minimum } & \multicolumn{2}{c}{ Adequate } \\
& $\underline{f}$ & $q$ & $\underline{\underline{f}}$ & $q$ & $\underline{f}$ & $q$ \\
& 10 & 100 & 0 & 0 & 0 & 0 \\
Undergraduate & 8 & 80 & 2 & 20 & 0 & 0 \\
Graduate & 5 & 50 & 2 & 20 & 3 & 30 \\
Formal Inservice & 0 & 0 & 4 & 40 & 6 & 60 \\
On the job & & & & & & \\
\hline
\end{tabular}

\section{Varieties of Teaching strategies}

The concept of using a variety of teaching strategies implies that the middle school teacher does not solely rely upon the direct teaching method, rather that the teacher employs a variety of styles such as discussion, cooperative learning, simulations, use of manipulatives, the inquiry methods, and others. Responses from teachers regarding the variety of teaching strategies concept area are found in Table 13 and responses of the administrators are found in Table 14 . 
Table 13

Varieties of Teaching Strategies

Training of Teachers

\begin{tabular}{lrrrrrrr} 
& \multicolumn{9}{c}{ Amount of Training } \\
\cline { 2 - 8 } Level of Training & \multicolumn{2}{c}{ None } & \multicolumn{2}{c}{ Minimum } & \multicolumn{2}{c}{ Adequate } \\
& $\underline{f}$ & 8 & & $\underline{f}$ & 8 & $\underline{f}$ & 8 \\
\hline Undergraduate & 10 & 33 & 11 & 37 & 9 & 30 \\
Graduate & 4 & 13 & 11 & 37 & 15 & 50 \\
Formal Inservice & 6 & 21 & 8 & 29 & 16 & 53 \\
On the job & 3 & 10 & 5 & 17 & 22 & 73 \\
\hline
\end{tabular}

Table 14

Varieties of Teaching Strategies Training of Administrators

\begin{tabular}{|c|c|c|c|c|c|c|}
\hline \multirow{3}{*}{ Level of Training } & \multicolumn{6}{|c|}{ Amount of Training } \\
\hline & \multicolumn{2}{|c|}{ None } & \multicolumn{2}{|c|}{ Minimum } & \multicolumn{2}{|c|}{ Adequate } \\
\hline & $\underline{\underline{f}}$ & $q$ & $\underline{\mathbf{f}}$ & 8 & $\underline{f}$ & $q$ \\
\hline Undergraduate & 6 & 60 & 0 & 0 & 4 & 40 \\
\hline Graduate & 5 & 50 & 2 & 20 & 3 & 30 \\
\hline Formal Inservice & 3 & 30 & 2 & 20 & 6 & 60 \\
\hline on the job & 0 & 0 & 1 & 10 & 9 & 90 \\
\hline
\end{tabular}


Exploratory/Elective Program Concept

An exploratory or elective program provides the opportunity to the middle school student to explore classes other than the basics. Some examples of such options would be: instrumental music, computers, vocal music, drama, journalism, art, foreign language. An exploratory course is usually limited in scope and typically lasts from six to 18 weeks. Responses from the teacher group to the exploratory/elective program concept area are recorded in Table 15; the administrator group responses are recorded in Table 16 .

Table 15

Exploratory/Elective Program

Training of Teachers

\begin{tabular}{lcccccccc}
\hline & \multicolumn{7}{c}{ Amount of Time } \\
\cline { 2 - 9 } Level of Training & \multicolumn{1}{c}{ None } & Minimum & Adequate & Unclear \\
& $\underline{f}$ & $q$ & $\underline{f}$ & $q$ & $\underline{f}$ & $q$ & $\underline{f}$ & $q$ \\
\hline Undergraduate & 27 & 90 & 2 & 7 & 0 & 0 & 1 & 3 \\
Graduate & 25 & 83 & 2 & 7 & 2 & 7 & 1 & 3 \\
Formal Inservice & 23 & 83 & 2 & 7 & 2 & 7 & 1 & 3 \\
On the job & 6 & 20 & 11 & 37 & 12 & 40 & 1 & 3 \\
& & & & & & & & \\
\hline
\end{tabular}


Table 16

Exploratory/Elective Program of Training Administrators

\begin{tabular}{|c|c|c|c|c|c|c|}
\hline \multirow{3}{*}{ Level of Training } & & \multicolumn{5}{|c|}{ Amount of Training } \\
\hline & \multicolumn{2}{|c|}{ None } & \multicolumn{2}{|c|}{ Minimum } & \multicolumn{2}{|c|}{ Adequate } \\
\hline & $\underline{f}$ & $q$ & $\underline{\mathbf{f}}$ & $q$ & $\underline{f}$ & $q$ \\
\hline Undergraduate & 8 & 80 & 2 & 20 & 0 & 0 \\
\hline Graduate & 6 & 60 & 4 & 40 & 0 & 0 \\
\hline Formal Inservice & 3 & 30 & 4 & 40 & 3 & 30 \\
\hline on the job & 0 & 0 & 2 & 20 & 8 & 80 \\
\hline
\end{tabular}

In all eight of the middle school concept areas (advisor/advisee, interdisciplinary teaching, intramural program, CORE, activities program, block schedule, variety of teaching strategies, exploratory/elective program, a minimum amount of training for both teachers and administrators was received through undergraduate course work. The only exception was training in a variety of instructional strategies where 20 people (66\%) received either minimum or adequate preparation as undergraduates. The second highest amount of training was in intramural activities where $25 \%$ of the people reported receiving either minimum or adequate training. In the remaining concept areas, $10 \%$ or less of the respondents received minimum or adequate training at the undergraduate level. 
At the graduate level, a similar phenomenon existed. The only middle school concept area where respondents indicated they received either minimum or adequate training was in a variety of teaching strategies. Seventy-eight percent of the respondents reported receiving graduate training in this concept area. Responses showed that more training in middle school concept areas was received by the participants at the graduate level than at the undergraduate level. Interdisciplinary teaching (30\%) and exploratory/elective programs $(20 \%)$ were the other two areas where a greater number of respondents had received training at the graduate level.

The amount of training in middle school concept areas through the formal inservice process showed a marked increase over training at the undergraduate or graduate level. Seventy-eight percent of the participants received minimum or adequate training in a variety of teaching strategies, while $40 \%$ received training in the advisor/advisee concept, $35 \%$ on interdisciplinary teaching, and $33 \%$ on the advisor/advisee program concept. The concept areas of intramurals, activities, and block scheduling were the areas where the least number of respondents reported receiving minimum or adequate training (20\% or less).

The amount of training received on the job by participants proved to be more than at the undergraduate and/or graduate level but less than through the formal inservice process. Eighty-five percent of the respondents received minimum or adequate training in the advisor/advisee 
concept, $78 \%$ reported the same level of training in a variety of teaching strategies, and $33 \%$ in the exploratory/elective program. In the remaining five concept areas (interdisciplinary teaching, block scheduling, CORE, intramurals, activities), $20 \%$ or less of the respondents indicated that they had received minimum or adequate preparation.

This data would indicate that the teachers of the River's Edge School District received the majority of their preparation in middle school concept areas through the formal inservice process. It would also suggest that the area in which the majority of the participants received training was in a variety of instructional strategies. This concept area could be a valid area of training at all levels of teacher preparation which would most likely account for the high incidence of training among the participants of this study.

\section{Perceived Needs of Young} Adolescents

In a different section of the questionnaire, on a likert scale, respondents were asked to rank the importance of seven developmental needs of young adolescents (diversity, selfexploration/self-definition, school/community participation, positive social interaction with peers/adults, physical activity, competence/achievement, structure and clear limits) as they perceived them. The likert scale rankings were: 1 = unimportant; 2 = somewhat important; 3 = neutral; 4 = important; and, 5 = extremely important. The results are presented in Table 17 . 
Table 17

Perceived Developmental Needs

of Early Adolescents

\begin{tabular}{|c|c|c|c|c|c|c|c|c|c|c|c|}
\hline \multirow{2}{*}{\multicolumn{3}{|c|}{ Need Group }} & \multicolumn{6}{|c|}{$\underline{\underline{f}}$} & \multicolumn{3}{|c|}{8} \\
\hline & & & & & & & & & & & \\
\hline \multirow[t]{2}{*}{$\mathrm{A}$} & Teach & 0 & 2 & 4 & 8 & 17 & 0 & 3 & 13 & 27 & 57 \\
\hline & Admin & 0 & 0 & 0 & 6 & 4 & 0 & 0 & 0 & 60 & 40 \\
\hline \multirow[t]{2}{*}{$\mathrm{B}$} & Teach & 0 & 1 & 1 & 8 & 20 & 0 & 3 & 3 & 27 & 67 \\
\hline & Admin & 0 & 0 & 0 & 2 & 8 & 0 & 0 & 0 & 20 & 80 \\
\hline \multirow[t]{2}{*}{$C$} & Teach & 0 & 0 & 1 & 11 & 18 & 0 & 0 & 3 & 37 & 60 \\
\hline & Admin & 0 & 0 & 0 & 5 & 5 & 0 & 0 & 0 & 50 & 50 \\
\hline \multirow[t]{2}{*}{$D$} & Teach & 0 & 0 & 0 & 6 & 24 & 0 & 0 & 0 & 20 & 80 \\
\hline & Admin & 0 & 0 & 0 & 0 & 10 & 0 & 0 & 0 & 0 & 100 \\
\hline \multirow[t]{2}{*}{$\mathrm{E}$} & Teach & 0 & 0 & 0 & 5 & 25 & 0 & 0 & 0 & 17 & 83 \\
\hline & Admin & 0 & 0 & 0 & 3 & 7 & 0 & 0 & 0 & 30 & 70 \\
\hline \multirow[t]{2}{*}{$F$} & Teach & 0 & 0 & 0 & 5 & 25 & 0 & 0 & 0 & 17 & 83 \\
\hline & Admin & 0 & 0 & 0 & 3 & 7 & 0 & 0 & 0 & 30 & 70 \\
\hline \multirow[t]{2}{*}{ G } & Teach & 0 & 0 & 0 & 5 & 25 & 0 & 0 & 0 & 17 & 83 \\
\hline & Admin & 0 & 0 & 0 & 1 & 9 & 0 & 0 & 0 & 10 & 90 \\
\hline
\end{tabular}

* $A=$ diversity; $B=$ self-exploration/self-definition;

$\mathrm{C}=$ school/community participation; $\mathrm{D}=$ positive social interaction with peers/adults; $\mathrm{E}=$ physical activity; $\mathrm{F}=$ competence/achievement; $\mathrm{G}=$ structure/clear limits

The majority of the teacher respondents ( $83 \%)$ indicated that the developmental need for diversity was an important 
one for young adolescents, ranking it either a 4 or 5 on the Likert scale. The entire administrator respondent group (100\%) ranked the need for diversity as important or extremely important. The majority of the teacher group (93\%) perceived the young adolescent developmental need for selfexploration/self-definition as important, ranking it either a 4 or 5 . One hundred percent of the administrators who completed the questionnaire perceived the need for selfexploration/self-definition as important or extremely important. The developmental need for participation in their school and/or community was viewed by the majority of the teachers responding to the questionnaire (97\%) as important, ranking it a 4 or 5 on the Likert scale. Among the administrator participants, 1008 perceived this need as either important or extremely important. One hundred percent of both the teacher and administrator respondents ranked the young adolescent developmental need for positive social interaction with peers/adults as a 4 (important) or 5 (extremely important) on the Likert scale in the questionnaire. The developmental need for physical activity was perceived as important or extremely important by all (1008) of the administrator and teacher participants in the study. The entire group of respondents, both teachers and administrators, reported that they perceived the developmental need for competence and/or achievement as important or extremely important. The last developmental need for structure and clear limits was perceived as important or extremely important by 1008 of the respondents. 
Presentation of Interview Data

After analyzing the responses to the survey a decision was made to conduct follow up interviews with a representative group of the original sample. Ten teachers and three administrators were interviewed personally by the researcher during the first two weeks of June 1994. Each interview was audio-taped. The researcher also personally transcribed each interview. The five sets of questions used in the interviews are listed in chapter III. The time lapse of four years between the survey and the interview process could have biased the results, but it also added an additional opportunity to trace more historical data.

\section{Successful Middle School programs}

Common themes emerged in the responses of the interviewees as they did in the responses to the surveys. Half of the teachers (five) and two of the administrators felt that successful middle school programs had teams of teachers working with a common group of students. Eight teachers and one administrator discussed the importance of choice, variety, and exploration for middle school students in their educational program. Ideal programs were described as containing interdisciplinary/integrated curriculum by four teachers and two administrators. Other elements mentioned by interviewees were: relevant/real-life experiences (three teachers); advisory programs (two teachers, one administrator); activity or hands-on learning opportunities 
(three teachers, one administrator); and, developmentally appropriate programs (two teachers, one administrator). The majority of the respondents (nine teachers, two administrators) felt that their schools' programs did not correspond to those they described as being ideal and successful. Responses ranged from: not yet, not at all, being ignored, to working toward it but not there yet. Interviewees reported that the developmental needs of students were being addressed to a certain degree. They had good ideas about things that could occur that would help with this process or things that needed more attention. Using their exact phrases, suggestions were as follows: try to develop excitement; explore the things that students love; kids need to feel a part of the (school) community; (schools) need positive leadership; students need more sense of belonging/having fun; school could do more as far as trying to get kids involved; still too much sitting; emotional development really does not get addressed until it is a problem; need to increase content of advisory; need to replace interschool sports with intramurals; need to add advisory; teachers need more staff development. A few responses focused on the positive elements of their schools such as: transition to sixth grade as being one of the best ways to think about their developmental needs; people are trying to do interdisciplinary things; after school activities; extracurricular activities; community service; student government; some people are trying to make connections with the students. 


\section{Inservice opportunities}

The second set of interview questions focused on the inservice opportunities that were available to the middle school teaching staff in the River's Edge School District. The majority of the respondents expressed frustration because very few opportunities for specialized middle school training had been offered. District-wide opportunities that were listed were applicable to middle school teachers, but were also beneficial to teachers from all levels. Two training programs were run in conjunction with two nearby higher education institutions, Lewis and Clark College and Washington State University. The program through Lewis and clark focused on cooperative learning and the program at Washington State provided training in action research. The other responses described building-specific opportunities.

The 10 teachers who were interviewed are now assigned to three middle school buildings. The training strand in one building centered on the teaming process. Several teachers from the building had accompanied their administrators to a seminar on interdisciplinary teaming sponsored by the oregon Middle Level Association (OMLA). After attending the conference and visiting several middle schools where successful teaming was occurring, they planned to provide inservice and form study groups to begin to facilitate the process of establishing teams within their own building. They dedicated one staff meeting late in the school year to a discussion on teaming and that proved to be the extent of what was accomplished. Their principal was transferred to 
another building and two of the strongest teacher advocates left the school at the end of the year, so the momentum dwindled.

A second training program was provided during the 19901991 school year in another middle school building in the district. This school contracted with a professor, from Lewis and Clark College, who is an expert on student behavior management, to provide a course on student management for their faculty. This staff was moving to a new facility in the fall and they wanted to work on creating a student management plan. In addition, they reviewed the developmental needs of the early adolescent and discussed successful instructional strategies.

The program at the third middle school in the district addressed the problems of drug and alcohol abuse among early adolescents. This staff had local police officers and a teacher-counselor from a neighboring school district provide inservice activities about what successful drug/alcohol prevention programs look like, as well as developing procedures for dealing with students who have been identified as having substance problems.

Several of the interviewees and a number of other teachers and administrators attended the 1993 National Middle School Conference in Oregon. This experience was described by one of the administrators:

one of the biggest benefits that I saw was that the National Middle School Conference . . (it) provided a wonderful opportunity to have nationally recognized middle school people have contact with all of our staffs. 
One of the teachers felt that attending this conference made a big difference in understanding middle school concepts:

I've also been fortunate because some of the things that I have learned along the way at these conferences, as a problem comes up in my building, I am able to suggest a solution, or at least a way to explore the problem from what I have learned. only a couple of teachers could relate practical

application of what they had learned in inservice

opportunities. Examples of some comments were: "in action

research inservices we looked at what kids view as important

things in learning"; "in behavior management inservices we

received an incredibly helpful, comprehensive overview on

student management and instructional strategies." One

teacher described an experience thus:

The one thing I liked about TESA (Teacher

Expectations and Student Achievement) was just that

its emphasis was on really making sure that all

kids were participating, so that it was harder for

Joe to sit in the back and disappear. And the

emphasis on participation was always positive, was

how to apply positive reinforcements.

There was resounding agreement that there were still

many needs for inservice activities on middle school

philosophy and programs. The following were comments from

the teacher interviewees about inservice opportunities in the River's Edge School District:

Absolutely, necessary, crucial, critical. I've felt this way for six years and still it is not happening . . Inservice needs to occur to help staff learn how to work together successfully, make decisions, solve problems, deal with conflict... And then $I$ believe a continued inservice needs to occur to help us develop integrated curriculum, effective integrated curriculum, and effective assessment of students within that curriculum . . . We need to find new ways to assess students, with portfolios in all areas, as well as teaching 
students some self-assessment techniques. And teaching practices that help teachers deal with middle level students . . more active learning, questioning strategies, teaching multi-graded classes.

Yes, I believe there is a definite need for organized inservice. I think it has been disconnected in the past. I don't believe that it has been structured so that you can have a sense of where you are going, and then you build on that through inservices that develop the concepts that have been taught before . . . I think we still need to hear more about middle school research even though we work with them all the time... I think we need to understand what interdisciplinary teaming can look like.

- . just talking about middle school. What it looks like, what the kids look like. I think more information and practical experience . . role play, behavior change, behavior intervention.

Teaching strategies, grading strategies, and then personal interactive strategies that are effective with this grade level.

Administrators were in agreement with the teaching staff about the importance of inservice activities. Their comments included:

- . first of all, we need to start talking about the developmental needs of the middle school child. What does the preadolescent need? How do we adapt our curriculum? How do we focus our school to meet those needs? . . I think classroom management classes are real important because of the age this group is and the fact that they're not always in control of their emotions. How not to back them into a corner and get in a power struggle. How to give them some dignity, but to refocus them in the right direction. . . I think that we need to be teaching teachers how to do some performance task work around reasoning skills so the kids are challenged to think at a higher level. 
The 21st Century School Improvement

Grant

The district's latest effort of school improvement at the middle school level through the 21 st century grant, was viewed in a variety of ways by teachers and administrators. The majority of staff interviewed were not actively involved in this process. Most of their responses indicated that because they were not on the consortia councils they knew very little about this school improvement/staff development grant. They knew that it had something to do with a restructured day, site councils, and meeting the requirements of the 21st Century School Improvement Bill adopted by the Oregon State Legislature. Those who were active participants provided the following commentary:

Initially, just getting site councils, effective site councils, of the community, parents, teachers, and administration, working together to make decisions. Be able to effectively change the way we schedule our day into teaming practices.

inservice the staff on how to work together in teams . . bring in someone to help us put a schedule together, a simple block schedule together

I guess $I$ am in a discouraged point of view with that one. We'd hoped to see something happen right away, and of course it didn't work out. In the most positive aspect, I would hope that we decide how we use our money and time and I would hope that we go fearlessly after some change immediately-change in schedules, change in planning.

I think we'll see some progress hopefully toward more block scheduling, more contact time with staff members determining the length of time that they would like to have contact with kids, based on the curriculum delivery that they to do that day, not based on the bell.

I think that we want to look not only at how we structure time differently for kids, but also 
choosing a variety of the best instructional

practices - . . One of our other goals was written

around creating benchmarks and aligning our

instructional goals to meet those.

The prevalent themes surrounding the question about the

21st Century Grant focus on effective teaching strategies, organizational issues, scheduling, effective school site

councils, and middle school concepts/philosophy. These

themes were common among both the teacher and the

administrator interviewees.

A few of the interviewees had ideas about how the grant would effect them personally. A physical education and health specialist felt that it could provide:

More curriculum money for teams. We have not done a lot. There's one time we had eight hours to work on curriculum with the eighth grade team. It would be nice to have some grant money to do that.

A handicapped learner specialist saw the opportunity this way:

Well, I think the higher the skill level of the faculty and the more confidence they feel in working with the CIMS and CAMS (Certificate of Advanced Mastery) will make my job easier, because I won't have to do those kinds of steps, and the teachers then will feel comfortable working too, will know how to work with some of the children who are handicapped who have to meet those requirements too.

Some teachers expressed concern about how effective this process might be:

If it helps me in the classroom, then I say it's helpful. So, my sense is that it's going to take some very strong, intensive sort of training to change how we do things. It has to be an ongoing thing. 
I sort of feel like we are back to the middle school study committee that we had several years ago. We talk a lot and nothing really changes.

Needs of the Middle School Personnel in the River's Edge School District

Responses to the last interview question, about what each person viewed as the needs for middle school personnel in the district in the next five years, also brought a variety of suggestions:

I think all middle school personnel should be specifically trained to teach middle level students. They should have course work . . or inservicing on middle level needs of students, and current effective practices for middle schools.

I see a real need for middle school teachers to be middle school teachers . . . if you are going to teach middle school, there's a responsibility to that age level. It needs to be seen as a job that has some extremely different characteristics to it, and the teacher doing it needs to be competent to deal with those specific differences . . . when you go through teacher training there's elementary and there's secondary and there is no particular area that addresses middle school. And it is a different beast. It's not high school and it's not elementary. It is so different that it needs to be treated that way.

First thing I'd say is that we're going to have to get a certification in oregon that supports middle level specifically. It is in other states. Where the training for middle level is different than elementary, different than high school . . the people come out with a sound basis in middle school philosophy, they have a good philosophy on block scheduling, they don't necessarily have the secondary model of 45 minute periods, they don't necessarily have the elementary model where they control the entire day. I think that is critical in the next five years if we're going to progress forward.

We need to do more teaming . . And I think everybody, every school, ought to have an advisory, 
Data Synthesis

The data derived from the questionnaires, the interviews in this study, and district documents were used to answer the following research questions:

1. Do the teachers and administrators of the River's Edge School District believe that there should be special preparation/certification for middle level educators incorporated into the teacher education program in the state of Oregon? For what reasons?

2. How did the River's Edge School District, with three schools containing students ages 10 to 14 , implement a middle school program? How did the district involve staff and parents in this process? How could the district assess the effectiveness of its progress toward this endeavor?

3. What are the unique preparation needs of aspiring middle level teachers as perceived by teachers and administrators of the River's Edge School District?

4. How should these needs be addressed by teacher preparation institutions? How can the River's Edge School District address the needs for inservice and staff development initiatives?

5. What do the teachers and administrators of the River's Edge School District recognize as the characteristics or components of a model teacher preparation program for middle school teachers? 
Special Preparation/Certification for Middle Level Educators

The questionnaire is divided into three sections: school demographics, teacher/administrator demographic information, and special preparation. One question in the section on special preparation addressed the need for special preparation/certification for middle level educators. A second question on special preparation asked the participants to respond to whether they felt special certification for middle school teachers should be required. The reasons why they felt this preparation was necessary centered around being better prepared to meet the developmental needs of their students, being able to provide appropriate learning environments for students, and being able to understand and reach their students' unique characteristics. The results of how these two questions were answered are presented in Table 18 .

Table 18

Special Preparation/Certification

for Middle Level Teachers

\begin{tabular}{lccccc}
\hline & & Preparation/Training & \multicolumn{2}{c}{$\begin{array}{c}\text { Certification } \\
\text { Required }\end{array}$} \\
\cline { 2 - 6 } Respondents & $\begin{array}{c}\text { Desirable/ } \\
\text { Crucial }\end{array}$ & Unnecessary & Yes & No & Maybe \\
\hline Teachers & 29 & 1 & 19 & 9 & 2 \\
Administrators & 10 & 10 & 10 & 0 & 0 \\
\hline
\end{tabular}


Another question in the section of the survey on special preparation, asked the respondents to indicate if they felt separate certification should be required for middle level teachers, administrators, and/or counselors. The responses from the teacher group were as follows: separate certification of teachers- -19 (63\%) yes, 9 (30\%) no, 2 (7q) maybe; separate certification of administrators--16 (53\%) yes, 12 ( $40 \%)$ no, 2 (7\%) maybe; separate certification of counselors--16 (53\%) yes, 12 (40\%) no, 2 (7\%) maybe. The administrator responses were: separate certification of teachers 10 (1.00z) yes; separate certification of administrators--nine (90z) yes, 1 (10z) recommended, not required; separate certification of counselors--9 (90\%) yes, 1 (10\%) recommended, not required.

\section{Unique Preparation Needs of Middle Level Educators}

The concept of unique preparation needs for middle level educators was addressed in two questions in the section on Special Preparation in the survey. The first question (III, 3) was a Likert scale on which the respondents were asked to rank the importance of seven developmental needs of the young adolescents with whom they work. The second question (III, 4) was an open-ended question that asked the respondents to list the types of courses or special training that they felt would have better prepared them for teaching/working at the middle school level. In the interview process, the 
interviewees were asked: Are students' developmental needs being addressed/met? In what ways?

In question III, 3, the ranking of importance of developmental needs of young adolescents, translates into appropriate training strategies for educators who wish to work with transescents. As reported, the majority of both teacher and administrator respondents felt that all seven developmental needs: the need for diversity; the need for opportunities for self-exploration and self-definition; the need for meaningful participation in school and community; the need for positive social interaction; the need for physical activity; the need for competence and achievement; and, the need for structure and clear limits, could be ranked as important or extremely important for middle school students.

These critical needs must be met through instructional strategies and through unique organizational patterns found in the middle school. To understand these organizational patterns and effective instructional strategies, a middle school educator must receive specialized training.

This importance was also expressed by interviewees. When asked if students' developmental needs were being addressed, teachers' responses varied as follows: some are being met; need more opportunities; needs met to a point; they are really being ignored right now; there is always room for improvement; need to be trained; being met to some degree; on scale of 1 to 10 , maybe a 3 or 4 . The administrators' responses were more positive in nature: 
65-70\% of the time; to a large extent, as best we can right now; yes. Interviewees made reference to the different needs through comments such as: some opportunity for exploration and some physical activity needed. Examples of meaningful participation in school and community were cited such as an activity program and student government, which provided community service opportunities. The need for positive social interaction was being approached through after school activities, student government, extracurricular activities, and advisory.

Responses to areas for improvement included: minimal experiences that are multi-graded; kids need to feel a part of the community; emphasis is on amount of work and cranking it out; kids need leadership starting at the top; school could do more as far as trying to get kids involved; still too much sitting; need to increase content of advisory; need to replace interschool sports with intramurals; need to add advisory; teachers need more staff development.

In question III, 4, the types of courses that the respondents felt would have better prepared them to work with the middle school child were listed. Common ideas ran through the responses for suggested topics: the developmental needs of the early adolescent (social, psychological, emotional, physiological); discipline and classroom management; variety of instructional strategies; interdisciplinary and/or team teaching; middle school scheduling and organization; and, middle school curriculum. In addition, the concept of field experience at the middle 
school level was a prominent one. The comments grouped

around the themes of instruction and curriculum,

developmental needs, organization, classroom management, and

field experience. Responses from teachers included:

Instruction and Curriculum

Teaching strategies and models; assessment and testing; cooperative learning; interdisciplinary teaming; more on cooperative strategies; how to obtain innovative materials; how to motivate this age group; lab classes that emphasize discovery and independent research; techniques are rarely covered at the undergraduate level; methods courses especially in areas of cooperative learning and critical thinking; more classes in using a wide variety of teaching strategies; more specialized classes in teaching literature, language arts; and social studies on the middle school level; courses should include learning theory and curriculum design; cross curriculum teaching; communication

Developmental Needs

Early adolescent development; developmental growth; social needs; physiology/psychology of adolescent development; typical 12-14 year old; intramural programs; obviously it would have helped to have courses on characteristics and/or development of the adolescent; activities; middle school child development course zeroing in on the growth changes of that age group

\section{Organization}

Scheduling and electives and curriculum; middle school organization; scheduling; advisor/advisee; block scheduling; exploratory/elective programs; teaming; CAST (multi-disciplinary team meetings)

Classroom Management

Discipline; discipline styles; how to handle discipline; time management and classroom management 


\section{Field Experience}

Field experience at the middle school level; on job training; on site training

The administrator responses to the same question were

very similar:

Instruction/Curriculum

Curriculum for middle school level; instructional strategies for middle school level; writing across the curriculum; concept integration; thinking skills; integration across the curriculum; interdisciplinary and team teaching organizations and strategies

\section{Developmental Needs}

Understanding early adolescents; school structures that encourage development; intramural programs; social activities; course work that is aimed at teaching about the developmental needs of adolescent children and how to use varied instructional strategies that can meet their academic and social levels; child development issues; developmental issues of middle school; preadolescent needs

Organization

Interdisciplinary teaming; master scheduling as part of administration and organization and interdisciplinary curriculum; middle school organization; advisor-advisee programs

Though the concept of special preparation for middle school teachers was not directly examined in the interview process, the idea did surface in the question about what, in the next five years, would you view as the needs of the middle school personnel in the River's Edge School District. References to specialized training occurred in five of the thirteen interviews. The comments included: 
All middle school personnel should be specifically trained to teach middle level students

Our leaders need to be middle school people, our teachers need to be middle school people, not high school people

A real need for middle school teachers to be middle school teachers . . part of over-all teacher training

We're going to have to get a certification in oregon that supports middle level specifically

The need for special preparation was also indirectly covered in the questions about inservice needs for the district middle level educators in the interviews. Responses such as: teaming. . staff learn how to work together successfully; team building; integrating curriculum; effective teaching practices; behavior interventions; student management; discipline types of things; instructional strategies; philosophy; cooperative learning; and the needs of the middle school child, correspond to a number of the answers on the questionnaire.

How Teacher Preparation Institutions Should Address the Needs of Middle Level Educators

In the Special Preparation section of the questionnaire, question seven asked the respondents to list the kind of training and/or preparation they felt would be appropriate for middle level educators. This open-ended question suggests options to teacher training/preparation institutions to follow in establishing a program or a plan for direction in the education of aspiring middle school personnel. Again, 
common threads ran through the numerous suggestions. One prevalent suggestion was the requirement of field experience at the middle school level. A second, was the need for specialized training in the unique developmental needs of the early adolescent. A third theme was the need for training in a variety of teaching strategies, including cooperative learning. A number of the responses echoed answers to the first question on special preparation; however, other ideas, such as the following were expressed by the teacher respondents :

\section{Instruction/Curriculum}

A teacher needs to know how to "hook" or "catch" these kids into an education. How to take all their "exploring" needs, give them a variety of options of classes and learning styles and distract and challenge students to learn; cooperative learning; working with at-risk kids; some training in theory--adolescent needs and ideal curriculum; teaching strategies that focus on all learning styles; activity-oriented strategies; learning theory; curriculum design; inservice on developing appropriate lessons/units

Developmental Needs

Characteristics of the middle school learner

\section{Organization}

Historical perspectives on movements such as CORE, interdisciplinary programs, cooperative learning, whole language

Classroom Management

Strategies for classroom management

\section{Field Experience}

Observation of model programs; peer coaching; midlevel certification to include practice and theory; much more observation time of highly successful 
teachers, mediocre teachers, and some teachers who might be struggling so one can see what works and what doesn't work; short times of practice teaching before prospective candidates are turned loose; prospective teachers should be required to work with students like "on the job" training; classes, workshops, observations, and in-class work with mentor teachers; classroom experiences or practicums

Administrator responses included:

\section{Instruction/Curriculum}

Knowing how to teach to all levels in the classroom and how to modify and adapt lessons and curriculum to a heterogeneous group is paramount, this is hard work and not easy; not enough teachers working with middle schools know how to reach all the kids, as a result, students are bored or are not achieving; curriculum for middle school level; instructional strategies for middle school level; courses including methodology, research on effective middle schools, strategies; interdisciplinary curriculum; integration of learning and thinking skills; variety of teaching strategies; teaching the "whole" child; curriculum development related to characteristics of the middle level student

\section{Developmental Needs}

Child development course work; teachers at this

level need to understand the unique needs of this age group, once this is accomplished, then teachers need to know what strategies to use to help students be successful academically; child development issues; preadolescent needs; understanding the transescent; how to be an effective homeroom advisor

\section{Organization}

Middle school educators need help in learning how to work together as a dynamic, flexible team that can cooperatively meet the changing needs of these youngsters; middle school organization; interdisciplinary and team teaching organization

\section{Classroom Management}

Effective classroom and building-wide discipline 
Characteristics/Components of a Model Teacher Preparation Program for Middle School Teachers

Question eight, in section III (Special Preparation) of the questionnaire asked the respondents to list the types of classes that they would include if they could create a model preparation program for middle level teachers. The most common responses are classes on: the developmental needs and characteristics of early adolescents (social, emotional, physiological, and psychological), listed by $64 \%$ of the respondents; teaching strategies and methodology (including cooperative learning), listed by $56 \%$ of the respondents; middle school organization (including interdisciplinary teaching, teaming, block schedules, CORE), listed by 448 of the respondents; middle school curriculum, listed by $28 \%$ of the respondents, and discipline and classroom management, also listed by $28 \%$ of the respondents. Once again, the idea of field experience, any where from one day to one semester, was suggested by $33 \%$ of the respondents. Again many of the answers reflected those on previous questions, but some of the more striking are listed below:

\section{Teachers:}

Teaching methods for this age group for all curriculums and field experiences at this age level

Experiential peer teacher inservice that would allow classroom participants to work with a teacher in a learning environment

Teaching by themes; structure of a middle school; child development; planning for the whole child

Helping kids learn how to get organized and study; discipline; motivation; building self-esteem 
Practica galore! All working with kids at this level; short term (one week) and long term (one month or more) in a variety of settings, for a variety of purposes, even just for single day experiences

As much field experience as possible (and early on)--allow prospective teachers opportunities to make sure they want to be working with kids; practical curriculum project classes so the projects can be used later; study skills classes-how to teach these things like writing summaries and taking notes; teaming student teachers with caring, enthusiastic mentors

Psychology of the middle school student; counseling techniques; teaming; how to track kids' personal and school life and behavior needs; activities-full range of games, physical, academic, social; diversity of techniques that work (finding yours)

Administrators:

Classes on scheduling; interdisciplinary team teaching; training on special needs of middle school aged children; working with and staffing a middle school program; advisory/counseling middle school kids; organization classes at $k-6$ and 9-12 levels, so the teacher understands the entire range

Child development; preadolescent needs; middle school organization; advisor/advisee programs; interdisciplinary and team teaching organization and strategies; at least a one-semester internship in a middle school (not a high school or elementary school

Why Special Training/Preparation in Teaching at the Middle School Level is Desirable/Crucial

Another section of the questionnaire asked teachers and administrators to describe why they believed it should be desirable and/or crucial for educators who work at the middle level to receive special training/preparation to work with this age group (question seven, Section III, Special 
Preparation). The following are responses that were listed by the teachers:

\section{Instruction/Curriculum}

There is a definite transition from elementary styles of education to high school teaching styles; also, besides being just a change time, it is a time when these kids are differenct now; they need a curriculum developed for them

\section{Developmental Needs}

Teachers often unprepared for $\mid$ kids' intellectual abilities and limits; the preadolescent is a unique child unlike primary or high school; special needs of early adolescents should be explained to teachers planning to work with these students; they are at a time of their life when they are "exploring" their options in life, their power, their independence, their relationships with adults and peers, their abilities and aptitudes, and even their hormones; this age group goes through so many emotional, physical, intellectual changes which need to be addressed in every day activities; in transition period from children to young adults; social factors influencing young people today are so much more serious than they we:re twenty-five years ago; we must understand "where kids are coming from" in order to help them

\section{Developmental Needs}

I believe some teachers are adaptable and enthusiastic enough to meet the special needs of middle schoolers; but not everyone . . . I feel better teachers are needed in middle school than experience dictates are there; more prestige is associated with credential

\section{Organization}

If we are to be a true middle school, then we should not be run life a junior high, or high school, or elementary school; things should be different with a different philosophy

\section{Classroom Management}

So class and school run snoothly; more education, less disruption 


\section{Field Experience}

The more you know ahead of time, the less you have to figure out on the job and the sooner you can be more effective; because it is vital that beginning teachers learn a variety of successful styles and strategies used by highly competent teachers so that they can create their own style from a large number of models

Administrators also expressed reasons why this special preparation/training should be desirable/crucial. All of their responses fell into the category of developmental needs :

We have been short changing students by our expectation that they are either secondary or elementary without realizing the uniqueness of the transescent and designing programs aimed at the uniqueness; there are very few programs that are specifically aimed to train teachers for the middle school level; teaching adolescents is the most challenging job in education, and it should have high priority for teacher preparation; special preparation could ease some of the stresses that come with "on the job" training; there are unique needs at this age; there is also a body of knowledge that pertains to this group; middle school success is the critical point for further success in school; appreciation for preadolescent youngsters and understanding the approaches that work with them.

Summary

In this study, two middle schools in a suburban school district were sample with 30 teacher respondent questionnaires that proved to be usable, as well as 10 administrator questionnaires from the same district. Ten teachers and 3 administrators were interviewed as a follow up procedure to the survey to gather information. Finally, archival records, district documents, the data collected from the 40 questionnaires and 13 interviews provided 
information for analysis for the five research questions of this study. Bases upon the data gathered from these sources, it is possible to draw some conclusions. 


\section{CHAPTER V}

SUMMARY, CONCLUSIONS, AND RECOMMENDATIONS

This chapter presents a summary of the study, concerning the necessity of preparation and certification for middle school educators. It also discusses other avenues of preparation in addition to preservice, undergraduate and graduate course work. Specifically, it reviews inservice and staff development opportunities as well.

\section{Summary}

This study was conducted to examine the degree to which middle level educators in the River's Edge School District believed that some form of special preparation was necessary for teachers/administrators working at the middle school level. In the questionnaire, the respondents were specifically asked about the types of preparation they had received as well as the kinds of classes and/or training they would include in a model program designed to prepare teachers for working at the middle school level. In addition to the concept of specialized training, the respondents were asked if they believed that a separate certification should be mandatory for middle school educators.

Questionnaires were distributed to teachers in two middle schools in a small suburban school district. Each 
school had a population of less than 500 students. The economic level of the two school attendance areas ranged from lower middle to upper class and the student bodies were predominantly white. A total of 49 questionnaires were distributed to staff. Thirty of the questionnaires were returned and used by the researcher.

Analysis of the biographical data showed that the most frequent respondent was a CORE teacher (teaching language arts and social studies), with an average age between 40-49 years, who was more likely to be female than male. Forty percent of the respondents had taught over 20 years, $47 \%$ held bachelor's degrees and $53 \%$ held master's degrees. The majority of the teachers held elementary certification.

Ten administrators from the same district were selected to participate in the study. Analysis of the biographical data of the administrators showed that the most frequent respondent was a principal, with an average age between 40-49 years, who was more likely to be male than female. Sixty-two percent of the respondents had 11-15 years of administrative experience, $69 \%$ held master's degrees and $31 \%$ held doctorates.

A follow-up interview process focused more specifically on the school district's experience with the middle school concept and how that was perceived by a representative sample of 10 teachers and 3 administrators. The interviewees were questioned about what they felt an ideal middle school program consisted of; how their school's program compared to their ideal; how students' developmental needs were being met 
in their schools; what opportunities for inservice on middle school concepts had they had an opportunity to experience through their district and what opportunities they would like provided for them; how they saw a district school improvement grant affecting their schools and their own classrooms; and, finally, what they perceived to be the needs of the middle school personnel in the district and how those needs might best be met.

Analysis of the demographic data of the 10 teachers who were interviewed indicated that the most frequent participant was a CORE teacher (teaching language arts and literature), $70 \%$ of whom were 40 years old or older, $80 \%$ of whom had taught 10 years or longer, $70 z$ holding master's degrees, $30 \%$ being elementary certified, 408 secondary certified, 308 holding specialist certificates, $60 \%$ were female, and $40 \%$ were male. Fifty percent of the teachers $(\underline{n}=5)$ had taught for 10 years or more at the middle school level and $50 \%$ had less than 10 years middle school experience. All of the administrators were in the 40-49 year age category and held master's degrees. The administrators were a fairly inexperienced group at the middle school level, all having five years or less of administrative and middle school experience. Two administrators were female and one male. The two females were assistant principals at two different middle schools in the district while the male interviewee was the principal at the same school as one of the two female assistants. 
The survey focused on special preparation that the respondents may have received before beginning to work with middle school students. Responses from teachers indicated that $80 \%(\underline{n}=24)$ did not receive any form of special preparation prior to their certification. Of those that did receive prior training, the majority reported that they received this training at the undergraduate level. Responses from administrators were somewhat different. Fifty percent $(\underline{\mathrm{n}}=5$ ) of the administrators reported receiving no prior special preparation. Of the $50 \%$ who did receive prior training, $808(\underline{n}=4)$ received that training at the graduate level.

Further analysis of the types of preparation that the teacher respondents received, indicated that it was minimal at best. Three of the respondents listed student teaching at the middle school/junior high school level as their preparation, which did not include any course work. Two respondents indicated some course work, but were not specific about what this entailed. The final respondent listed a single course in middle school training.

The training experienced by 5 of the 10 administrators was somewhat more intense; however, three respondents indicated that their course work was geared specifically to the junior high school and was received in the early 1970s. only one respondent indicated receiving training on early adolescent development and on the philosophy of middle schools. In more detail, the study looked at the degree of training the respondents had in eight different middle school 
concept areas: advisor/advisee; interdisciplinary team teaching; intramural program; CORE program; activities program; block scheduling; variety of teaching strategies; and exploratory/elective program. It also examined at what level the training was received, at the undergraduate level, the graduate level, at a formal inservice level, or on the job training. Responses from teachers in the eight different concepts, showed that in six of the eight areas over $50 \%$ $(\underline{\mathrm{n}}=15)$ of the participants received no training at the undergraduate, graduate, or formal inservice levels. In the other two categories, $50 z$ and $40 \%(\underline{n}=12)$ of the teacher respondents received no training. In the administrative responses to the same categories, again six of the eight categories showed that all 10 of the administrators received no training at the undergraduate, graduate, or formal inservice levels. In the remaining two categories, $90 \%$ $(\underline{n}=9)$ of the administrators received no training. Conversely, the responses of both the teachers and the administrators to training on the job indicated that this was the arena in which they received training in middle school concept areas.

To provide a quality education for students, it is necessary to understand and meet the needs of the children we serve. Respondents were asked to rank the importance of seven developmental needs of early adolescents. These needs are: the need for diversity, self-exploration/selfdefinition, school/community participation, positive social interaction with peers/adults, physical activity, 
competence/achievement, and structure/clear limits. The majority of both teachers and administrators ranked all seven developmental needs as important or extremely important. Prospective middle school educators should be provided training in these developmental needs and they should understand the impact of such needs on middle school instructional practices.

The open response sections of the questionnaire asked the respondents to: (a) list the types of courses or special training that would have better prepared them for teaching at the middle school level, (b) list the kind of training/preparation that would be appropriate if middle level training would be required, and (c) list the types of classes they would include in a model preparation program for middle level teachers. The detailed answers to these questions are found in chapter IV.

Common responses to all three questions included courses on: the developmental needs of early adolescents; a variety of instructional strategies, such as cooperative learning; as well as, field experience at the middle school level. In addition, a second set of common responses was found to the questions about what would have better prepared the respondents, and about the components of model preparation programs. The common themes here were courses on: middle school organization; middle school curriculum; and, discipline and classroom management.

Both groups of respondents were asked if they felt special preparation for middle level educators was 
unnecessary, desirable, or crucial. For purposes of analysis, the responses to the categories desirable and crucial were collapsed and a chi-square test was attempted; however, because the sample was small, inferential statistical tests could not be performed with any accuracy. one hundred percent of the administrator respondents $(\underline{n}=10)$ indicated that they felt special preparation was either desirable or crucial. Ninety-seven percent $(\underline{n}=29)$ of the teacher respondents answered in a like manner. Combining the responses of both groups, $73 \%(\underline{n}=29)$ of the respondents felt that special certification should be required of teachers and $63 \%(\underline{n}=25)$ felt it should be required of administrators and counselors. It appears that in a state where no special preparation is required, and very few opportunities exist for such preparation, practitioners at the middle school level who were surveyed indicate that it is an issue that at the least warrants more extensive investigation.

The interview process reinforced some areas of the questionnaire as well as focusing on district issues. In discussing a successful middle school program, the interviewees $(\underline{n}=13)$ mentioned teaming (548); integrated curriculum (38\%); developmental needs of early adolescents (468); exploratory opportunities (778); advisory (158); and, making the program relevant to a middle school student's life (15\%). When asked how they felt their school's program matched their description, $92 \%$ had negative responses (i.e., not at all, not yet, does not match up) and only 18 
felt their school's program did correspond to their concept of a successful program. In analyzing their responses, all eight of the middle school concept areas listed in the questionnaire (advisor/advisee, interdisciplinary teaching, an intramural program, a CORE program, block scheduling, a variety of teaching strategies, and an exploratory/elective program) were mentioned.

In response to the question about whether their students' developmental needs were being met, $62 \%$ of those interviewed felt they were being met to some degree, one person (1\%) felt they were being addressed, and $31 \%$ felt they were being ignored. Those with positive responses mentioned the following ways in which these developmental needs were being recognized through opportunities for: exploration, physical activity, student government, advisory programs, community service, integrated curriculum, and a student activity program. Their responses correlated to five of the seven developmental needs listed in the questionnaire (selfexploration, school/community participation, positive social interaction, physical activity, clear structure and limits). only the needs for diversity and competence/achievement were not discussed.

When asked what they felt the training needs of district middle school personnel were, the following themes emerged: teaming (38\%), integrating curriculum (31\%), effective teaching strategies/practices (31\%), middle school concept/philosophy (15\%), student management (31\%), and the developmental needs of the middle school child (15\%). All of 
those training needs were also listed by respondents in the questionnaire.

One aspect of the interview did not directly correspond with any of the items on the questionnaire. At the time of the interviews, the district was involved in a school improvement and staff development grant in coordination with a statewide school reform referendum. The interviewees were asked to describe any special opportunities that they felt might arise as a part of being involved in this grant. Their responses focused on the following themes: site-based decision-making (31\%), restructuring/rescheduling the instructional day (54\%), addressing the new legislation (318), the teaming process (23\%), and instructional practices (15\%). Though not directly linked, these answers did relate to four of the ideas (teaching strategies, working with atrisk students, organizational patterns, curriculum) listed in the questionnaire about training/preparation needs of middle school personnel.

Finally, when questioned about the future needs of middle school personnel in the district, the responses of those interviewed centered around three areas: a specialized training/preparation program for those aspiring educators who wish to work in middle level educational institutions (38\%), effective inservice programs (46\%), and the opportunity for site-based decision-making (46\%). Combining the responses regarding training (special preparation/inservice), 858 of those interviewed felt that this was an important need, which corresponds to the 978 of those surveyed who felt that a 
unique type of training/preparation program should be available to middle level educators.

\section{Conclusions}

The conclusions drawn from the study focus on the five research questions that were designed to guide it, along with comparisons to related research.

Question 1: What are the unique preparation needs of aspiring middle level teachers as perceived by teachers and administrators of the River's Edge School District?

Respondents to the survey in this study received the majority of their training in middle school concept areas (advisor/advisee, interdisciplinary teaching, intramural program, CORE program, activities program, block scheduling, variety of teaching strategies, exploratory/elective program) through formal inservice opportunities and/or on the job. These concept areas were not a part of their training at the undergraduate or graduate level. This of course may be attributable to the age of the participants and the relative short history of special preparation for middle school educators. The respondents also overwhelmingly stated that the following developmental needs of early adolescents were important and/or very important: the need for diversity, the need for self-exploration/ self-definition, the need for school/community participation, the need for positive social interaction with peers/adults, the need for physical activity, the need for competence/achievement, and the need for structure/clear limits. Understanding these 
developmental needs and the middle school concept areas is critical for educators working with young adolescents. These are the unique preparation needs of aspiring middle level educators as also argued by Dorman (1984).

When asked in the survey to list the types of courses or special training the respondents felt would have better prepared them to teach at the middle level, their answers focused on unique training they did not receive as part of their elementary or secondary programs. Some responses grouped around understanding the 10-to-14-year-old: developmental needs, early adolescent development, adolescent development; typical 12-14-year-old, physical/emotional development of early adolescents, psychology of middle schoolers, middle school child development course zeroing in on the growth changes of that age group, understanding the unique needs of the mid-level child, and in-depth understanding of the transescent. In keeping with the research of the Carnegie Council on Adolescent Development (1989), other answers highlighted a need for field experience at the middle school level: practical teaching experience opportunities, "hands-on" working with students as part of education classes each year in college, on-site training, and mentoring opportunities.

Another focus was on training in the teaching process: teaching strategies and models; cooperative learning; interdisciplinary teaming; how to obtain innovative materials; self-image development activities; how to motivate this age group; advisor/advisee; variety of teaching 
strategies; methods courses especially in areas of cooperative learning and critical thinking; more specialized classes in teaching literature, language arts, and social studies on the middle school level; and different techniques to teach the same material. An additional area of the teaching process that received numerous comments was student discipline/ behavior management. One specific answer summed up the general consensus about classroom management: "One of the most crucial would be a class on classroom management that would be a comprehensive course. Discipline problems alone will drive most tender young teachers out of the classroom."

This unique preparation need was echoed by respondents during the interview process. Interviewees expressed the need for understanding the teaming process because they had never teamed before. They listed such things as setting common standards, how to communicate effectively, how to plan integrated curriculum units, creating opportunities for parents to be involved, understanding the nature of the students they work with daily. One administrator commented: "We need to do more teaming . . to have a school of 750 kids and not be teaming, I mean, it's ridiculous! All you have is a junior high, and you're losing kids." The need for understanding the advisor/advisee concept was also expressed by one of the administrators:

I'm concerned that, because some of our teachers aren't as comfortable addressing developmental needs of middle schoolers that we go far enough with that. I think one of the things we need to add, and there's a great deal of controversy around this, is advisory . . I think we're losing 
some kids through the cracks and I think maybe the the answer is in advisories . . . But I think we're going to have to be real careful how we move into that because we've got staff convinced that it won't work and mostly because they don't feel comfortable doing it.

One of the teachers talked about needing to know more about different teaching methods:

The cooperative teaching ideas are good ... Simulations, things that teachers can take immediately to the classroom and put into use that are so-called nontraditional. The traditional methods everybody has down pat. But we need a larger repertoire of things . . simulations, activities, in science more hands-on

The Oregon Middle Level Association (OMLA) is another proponent of specialized preparation. They have been lobbying TSPC to look at middle level certification. In the Summer 1994, the state licensing agency had decided to allow for a greater degree in flexibility for middle school teachers who were assigned to interdisciplinary teams. These teachers would be able to teach more than one subject and not be misassigned if they were endorsed in one or more subjects in the integrated course. During 1995, TSPC will be received a recommendation from a committee studying licensure design that requested that the state create four levels of licensure: birth to grade 4; grade 3 to grade 6; grade 5 to grade 9; and grade 9 to grade 12. This scenario would provide for middle school endorsement as well as allowing for some overlap in grades (Wiper, 1995). This could be viewed as the first small step in the right 
direction of providing certification/licensure for middle school personnel in oregon.

Question 2: How did the River's Edge School District, with three schools containing students ages 10 to 14 , implement a middle school program? How did the district involve staff and parents in this process? How could the district assess the effectiveness of its progress toward this endeavor?

A review of historical information from the initial middle school study (1980-1981) conducted by the River's Edge School District documented the process the district employed as it began its implementation of a "true" middle school program. The district wanted to move from a fifth and sixth grade self-contained program and a seventh and eighth grade junior high program that had previously existed.

The first step the district took was to establish a committee composed of community members, teachers, students, and administrators. The committee's charge was to develop the process for achieving an exemplary middle school program. Through literature review, school site visits, and participation in workshops, the committee arrived at the conclusion that a middle school program should: be flexible in structure (space, time, curriculum, grouping); provide activities to release energies; have a shift in routine to avoid monotony; include an allowance for wide variation in student abilities and learning styles; allow for opportunities for student choice of subjects; encourage student participation in establishing classroom regulations; 
establish consistent student behavior expectations; include student government; help in decision-making skills; support staff as they deal with student behavior and academic needs; and, promote parent understanding of students' developmental needs and characteristics.

The philosophy statement they crafted was to provide a rigorous educational experience for students which would promote the development of the total child while providing an atmosphere for flexible learning styles; responding to individual needs; developing positive self-concepts; developing standards for mastery of basic skills; encouraging an attitude which reinforces the joy of learning; meeting the physical and developmental needs of the preadolescent; teaching responsibility for one's own actions; providing equal educational experiences and opportunities; and, providing an ongoing program of evaluation. The committee additionally outlined three program goals and four specific recommendations to meet the organizational and academic standards that it had outlined. (Details of these goals and recommendations can be found in chapter IV.)

Finally, the group set up a time line to achieve their plan with the first established review date scheduled for the summer of 1982 . A report was presented to the school board at that time which included an update on the progress in the areas of the program goals and recommendations, as well as the new focus areas for the 1982-1983 school year.

What actually occurred from that time until the next study would surface in 1990 proved to be a fragmented effort 
by each school to accomplish the outlined program goals at their own site through their own unique intexpretation of the process. Some quality examples of the components of effective middle school programs could be found in each of the district's three middle schools; however, each school also lacked some of the essential program elements. Once again, in 1990, the River's Edge School District evaluated the middle school programs at its three school sites. The 1990-1991 study committee was composed of middle school principals, teachers, counselors, parents, and central office administrators. Again, the committee initiated its work with an extensive literature review, school site visits, and participation in workshops and conferences. One important aspect in this research was overlooked however. The committee failed to research the district archives and did not review the extensive process conducted by the original (1980-1981) middle school study committee.

The 1990-1991 committee crafted a mission statement which included these elements: the district recognized the unique intellectual, social/emotional, and physical needs of middle school students; the district would provide a challenging and developmentally appropriate educational program for the early adolescent; and, the middle school program would be designed to prepare students to be contributing members of local and global communities. This new mission statement was centered in the belief that all students could be successful learners. Complementing the mission statement, the committee listed 12 belief statements 
that highlighted the organizational and program components of an ideal middle school setting. (Detailed description of this information is found in chapter IV.) There were striking similarities between the belief statements of the 1990-1991 committee and the program goals and recommendations of the 1980-1981 committee. Both efforts detailed programs that contained the essential elements of effective middle level schools as outlined in the literature review in chapter II. It is clear that both studies provided the opportunity to establish a level of expertise about middle level schooling for the participants of the process. Subsequently then, has the district created model middle level schools? Has the district effectively assessed its progress toward this goal?

The River's Edge School District continues to maintain three separate and unique middle school facilities as well as three separate and unique middle school programs. One of the three facilities is very closely approaching a model program status. The key to its success is found in the dedication and expertise of the two administrators who are leading this charge and the dedicated staff who understand the nature of the early adolescent. The principal received formal education in the middle school phenomenon at the graduate level. The assistant principal facilitated a formal middle school study process in a large urban district in the state prior to joining the River's Edge District. This building provides ongoing inservice opportunities on middle school concepts for its staff. Its program has evolved over a four- 
year period, there have been few staff changes, and the staff has been able to view firsthand the success of the program with one group of students who entered as sixth graders and exited as eighth graders during the 1993-1994 school year. The staff realize that their program is a work in progress, and they continually review literature and visit other programs in their efforts to fine tune their own. The second school, the newest facility of the three as well as the largest (almost 800 students), continues to struggle with its development as an effective middle school. This building has had three principals in its short four-year history, as well as considerable staff turnover, and this has definitely hindered its progress. It appears that the staff is eager to provide an age appropriate program for its students, and attempts at pilot programs of interdisciplinary teaching, interdisciplinary teaming at one grade level, and the re-establishment of an advisor/advisee program, are meeting with approval and success. If stability in leadership and staff can be achieved, this school is heading in the right direction.

The last middle school, the oldest facility and the smallest (less than 400 students), provides the biggest challenge to the district. The staff are a veteran group and few new faces and views permeate this building. It appears that this program is caught in a traditional paradigm and the leadership struggles with this issue. The majority of the staff remember the national excellence award the school received in 1986, and they maintain that they are the experts 
in the field. The award was received for academic achievement of the students, not for recognition as a quality middle school program. The only semblance of middle school organization lies in a three-period block (Language Arts, Literature, Social Studies) at the sixth grade level and a two-period block (Language Arts, Literature) at the seventh and eighth grade level.

It is time for the River's Edge School District to conduct a formal assessment of its middle school programs. It might be most effective if the assessment were to be conducted by an outside agency. The district is known statewide for its exemplary primary school programs. It certainly has the talent and the means to produce the same quality in its middle school programs. This assessment process should minimally include a survey of administrators, teachers, classified employees, parents, and students. The survey should provide an opportunity for input about what good elements/procedures currently exist in the district and what areas are in definite need of improvement. The survey should address organizational, curricular, instructional, and developmental issues (NMSA, 1989). The district should then take the time and the effort to evaluate the information gleaned from the survey; it should establish a program outline that responds to the information and to the needs of the middle school students, teachers, and parents; it should develop an implementation time line; and, it should provide central office and building level leadership that will ensure that this plan is followed. The plan should serve as an 
outline for the schools to follow. All three programs do not, in fact should not, be identical. The programs should, however, contain common elements--those of an effective middle level school.

Question 3: How should these needs be addressed by teacher preparation institutions? How can the River's Edge School District address the needs for inservice and staff development?

The respondents to this study listed a variety of ways that teacher preparation institutions should address the unique needs of aspiring middle level teachers. Many of these were congruent with those enumerated by NMSA (1989) and those detailed in Turning Points (Carnegie Council on Adolescent Development, 1989). The three prevalent themes listed by both teachers and administrators were: requirement of field experience at the middle school level, the need for specialized training in the unique developmental needs of the early adolescent, and the need for training in a variety of teaching strategies. Some specific ideas about field experiences listed on the questionnaire were: lots of hands-on experiences, student teaching in middle school, getting into classrooms before the last year, observations and in-class work with mentor teachers, peer coaching, and observation of model programs. Comments about training in the unique developmental needs of early adolescents included course work in: early adolescent development (social, emotional, intellectual); characteristics of the middle school learner; psychology of middle schoolers; and teachers 
at this level need to understand the unique needs of this age group. Finally, typical answers which related to the need for training in a variety of teaching strategies were: teaching strategies that focused on all learning styles and activity-oriented lessons, needing knowledge of what strategies to use to help students to be successful academically, knowledge of how to teach to all levels in the classroom and how to modify and adapt lessons and curriculum to a heterogeneous group as paramount, courses including methodology, and instructional strategies for middle school level.

The University of Georgia program exposes its students to early field experience at the beginning of their junior year (MCEwin \& Alexander, 1989). Students select two fields of specialization. The certification program consists of four phases, all of which are field based. In addition to methods courses in their two fields of specialization, students participate in the following classes: Introduction to the Middle School, Adolescent Psychology, Teaching of Reading, Teaching in the Middle School, Teaching Reading in the Content Fields, The Middle School Curriculum, Introduction to the Education of Exceptional Children, and student teaching (Alexander \& MCEwin, 1988).

The University of Northern Colorado program combines work in the professional teacher education courses (Educational Psychology, Law in the Classroom, Educational Technology, Multi-Culturalism, Foundations of Education, Human Interactions, the Exceptional Child, Field Experiences) 
along with required courses in the area of middle school teacher education (Orientation to Education; Orientation to Middle School; two reading classes, one in developmental reading and one in teaching reading in the content fields; a psychology class on adolescent development; two methods classes in the content fields which students have chosen to emphasize) (McEwin \& Alexander, 1989). Field experiences play a major part in the program at the University of Northern Colorado. In fact, this opportunity exists on campus in the university's Laboratory school, although it is not limited to this facility (Alexander \& McEwin, 1988). There are two programs in the state of oregon that attempt to address the special preparation needs of middle school teachers. First, The Elementary Endorsement Program for Middle School Teachers at Western Oregon State College is approved by TSPC. This indicates that the topic of middle level preparation is being acknowledged by the state teacher licensing agency. This program consists of two summer sessions plus a practicum during the school year following the first summer session. The courses offered in this program are: Contemporary Teaching Strategies; whole Language Strategies--Intermediate; Elementary School Curriculum; Personalizing Classroom Climate; Practicum: Performance Assessment; Children with Learning Problems; Teaching Math and Science Middle School; Foundations of Literacy, K-12; The Social Arts--Middle School. Although this program ultimately leads to elementary certification, 
its components allow for some specialization in middle school studies.

The second program, at willamette University, provides a Master of Arts in Teaching. Their literature about the program states that it was created because middle level educational programs are distinctively different from either the elementary or high school models. The creators of the program felt that there was a need to recruit and to prepare teachers who were specifically teaching in the middle grades. They have created a program that is philosophically and structurally representative of a middle level education model.

Their program has been designed and implemented by the entire faculty team. Its courses and learning activities have been integrated and scheduled as a flexible block, and planned and implemented by teams of two or more faculty members. The instructional strategies employed by faculty were designed to address a variety of learning styles and individual differences. In addition, a variety of traditional and alternative assessment techniques are employed. Each faculty member is given a guide group of 8-10 students who are to remain together throughout the program.

The program is based on the concept of the importance of providing close ties between the theories examined in the university classroom and the reality and hands-on experiences of the middle school classroom. In the first semester, students spend two and one half days a week observing and participating in their assigned classrooms. Upon completion 
of the program, they will have also spent 20 weeks of student teaching in a middle school. They complete course work in Middle Level Issues and Middle Level Methods. Educators currently teaching in middle schools teach the methods courses. Topics covered in the two courses are essential to effective middle level teaching such as cooperative learning, integrated curriculum, teaming, advisory programs, early adolescent development, and philosophy and structure of middle schools. Students who complete the willamette program receive a certificate in middle level education from the university, but TSPC grants them either a secondary or elementary oregon Teaching License. The state now has two special preparation programs, but they are both graduate programs, and the state licensing agency continues to issue only elementary and secondary licenses.

Since the River's Edge School District employs teachers who are certified at either the elementary or the secondary level, the district needs to meet the unique preparation needs of its middle level employees through staff development activities and inservice programs. As outlined in chapter IV, district employees feel that they have been provided with very few opportunities for their professional development that relate specifically to the unique characteristics of middle level educators. Interviewees expressed frustration with the types of inservice opportunities as well as with the effectiveness of the efforts, the lack of organization, and the deficiency in follow through on the district's part. Some examples of comments about strategies: 
- I think that there's a real need for people who have had years of experience with middle school kids having the opportunity to share strategies

- . the first year I was here we had an inservice on cooperative learning . . . and to me, that should have been something we did with all the middle school teachers versus I think two or three from each building.

- . the middle school study . . as far as it went. I think that some of the work that we did there, gathering research, and looking into things that we were currently doing well, and ways that certain buildings within the district were doing a certain part of it well, and sharing those ideas. I think that was a good start, but I think that we didn't carry through on a lot of those suggestions.

One of the obvious concerns expressed was that few things were done at the district level and even fewer were structured, organized, and comprehensive. One teacher commented that the efforts lacked "staying power." The historical perspective outlined in chapter IV supports these staff reports. Three attempts at middle school studies and one grant proposal for staff development and school improvement proved to be replications of efforts with little success.

The National Staff Development Council standards appear to be what the River's Edge School District needs to review and adapt for their use if they are going to be serious about providing effective opportunities for their middle school staff to improve and to be given the chance to feel efficacious in their work (Holland, 1994).

Question 4: What do the teachers/administrators of the River's Edge School District recognize as the characteristics 
or components of a model teacher preparation program for middle school teachers?

Respondents in this study listed a variety of suggestions for what could be considered a model preparation program. Details of those responses are found in Chapter IV. However, there were responses that were prevalent and those reflected classes on: the developmental needs and characteristics of early adolescents (social, emotional, physiological, psychological); appropriate teaching strategies and methodology (including such strategies as cooperative learning, simulations, hands-on/active learning); middle school organization (including interdisciplinary teaching, teaming, block scheduling, CORE, advisory programs); middle school curriculum (with a heavy emphasis on the relevance and the integration of the curriculum); and field experience (from one day to one semester, in a variety of settings, and with experienced, effective mentor teachers). The literature is in agreement with all of the components suggested by the respondents; however, it is more specific about opportunities for field experience. The research states that field experience should come very early in the program, be frequent in nature, and culminate with a year-long, fifth year, teaching internship (Scales \& McEwin, $1994)$.

The NMSA has worked toward special preparation for middle level educators. They have presented a set of guidelines to NCATE that outline a Middle Level Undergraduate Teacher Education (NMSA, 1989). These guidelines were 
completely outlined in Chapter II of this study. They were considered basic components for a program: having an identifiable middle school teacher education program; preparing teachers who will have an understanding of the physical, social, emotional, intellectual and moral development of young adolescents; having courses in middle level philosophy, curriculum and instruction; preparing teachers in at least two unrelated fields, as well as one methods course for teaching at the middle level; providing field experience (observing, participating and teaching, ranging from individual to group settings) and a 10-week student teaching experience. These guidelines should be the spring board from which a model program should be built and they echo the elements listed by respondents in this study. It is important to realize that both the suggestions of the participants of this study and the recommendations of the NMSA are the framework for ideal preparation programs. Much more detail in program content, as well as more emphasis on the middle school as a valuable educational institution, need to occur before an exemplary program will emerge. As Scales (1992), reported in his study of middle level teacher preparation it is not only the opportunity for special preparation, it is the quality of the preparation program that is important. These programs need to be the best, the most successful in the country if we are to replicate them and expect to produce highly effective middle school teachers. 
Question 5: Do the teachers of the Fiver's Edge School District believe that there should be special preparation/certification for middle level educators incorporated into the teacher education program in the state of Oregon? For what reasons?

The responses from the participants in this study overwhelmingly support special preparation and/or certification for people who work with middle school students. A question in the Special Preparation section of the survey asked the respondents to express why they felt special training/preparation in teaching at the middle school level was desirable or crucial. The majority of the responses from all respondents focused around the unique needs of the early adolescent and the fact that those needs are not being addressed with present training programs that are elementary or secondary focused.

The 13 people interviewed reinforced the concept that working with middle level students was a unique experience and elementary and/or secondary training was not adequate preparation. One teacher, a veteran with over 30 years at the middle school level, was working with an intern from a local teacher training institution. She discussed her concern over lack of specialized training in relation to her intern's experience:

I'm a little bit concerned because the intern that I have at this time is interested in the sixth, seventh, and eighth grade level, and yet he finds that he's sort of in never, never land as far as his assignment is concerned. There's the high school group and there's the elementary group, and he's tending to find that because he's getting an elementary certificate, a lot of what's going on is 
not applicable to him. There's not a program even yet that is focusing on the middle learner.

A second teacher, certified to teach at the secondary level, accepted a middle school position in the district when she was hired because there were no high school positions open. She hoped to eventually be transferred to the high school level and cited the idea that there was more prestige felt accompanying the work at the high school level. However, after five years in a middle school classroom, she would never leave that age level. She still senses the feeling that middle school teachers do not receive proper recognition. She stated:

- . . the challenges that are faced by middle school teachers are really overlooked, and the needs of the middle school kids are severely overlooked. People pay lip service to it all the time--Oh, my gosh, you're a middle school teacher. Man, that must take an incredible amount of energy. How do you deal with those kids? They're just wacko at that age--1 mean everybody seems to have that kind of idea about it. But there's absolutely nothing that then says how do we address this age group and really make it so that . . . it is a good time for them, that reaches out to them and says you do have specific needs. You're not mini high school kids.

This teacher elaborated further by adding:

-. when you go through teacher training, there's elementary and there's secondary, and there is no particular area that addresses middle school . . . And it is a different beast. It's not high school, and it's not elementary. It is so different that it needs to be treated that way.

An administrator who touted the need for special training for the middle school level came from the Midwest where this practice is a reality. He received specialized 
training on the middle school concept at the graduate level. This principal is finding it difficult to adjust to working with professionals that have not had special training in the middle school concept. He felt it was critical in the next five years to establish formal training options if the middle school program was to become viable and successful.

The survey respondents and those interviewed by the researcher strongly believe that special training should be available to teachers in the state of Oregon. Overwhelmingly they stated that they were not adequately prepared to work with students at this level. Survey responses showed the preponderance of their training was received through formal inservice and/or on the job. (This could be reflective of their age and the number of years of experience they had working at this level.) They felt this practice was both unfair and frustrating for them as well as for their students. This is not an age level to be ignored and neither elementary nor secondary training met their needs. One administrator who was interviewed stated that if our local training institutions and the state of oregon were not able, willing, or ready to accept such a responsibility, then it would be up to local school districts to attempt to accomplish this necessary task.

\section{Recommendations for Further Research}

Since the results of this study are limited by the geographical area sampled, an area that further research might explore would be a larger sample locale, expanding to 
urban and rural schools and other suburban schools. Expansion of the sample could afford a better idea about the responses of middle level educators throughout the state of Oregon and could determine if the results might be connected to the suburban character of the schools sampled.

The schools in this study were specially selected for this study because the district was about to embark upon a second middle school study and the teachers had been researching the middle school concept. The administrators chosen were active participants in both local and national middle school organizations and were well-versed in middle school philosophy. Further research might opt to randomly select participants and thereby determine whether the results are connected to special selection of the participants.

The relatively small sample size of the study could also be a limiting factor. The degree of expansion of the sample size could vary anywhere from doubling it to including all middle school teachers in the state of oregon. The analysis of the data from the larger sample size could test whether the results of this study were connected to the small sample size.

The description of a model teacher preparation program could be influenced by exploring two established programs, those of the University of Georgia and the University of Northern Colorado. The other programs described in Preparing to Teach at the Middle Level, might influence the definition of what a model program might look like (Alexander \& McEwin, 1988). In addition, new programs are being created every 
year, and those programs should be explored to see how they compare to quality, well-established programs. An investigation of the two programs in the state of Oregon (Western Oregon and willamette) could identify the strengths of such preparations. In addition, a study could be conducted comparing the effectiveness of those graduating from the Western Oregon and willamette programs with those in the state who did not receive special preparation. This type of research could be expanded to the national level to investigate whether the teachers with middle school certificates have better outcomes (student learning) than those teachers who do not have middle school certification. A study that would research the correlation between how the number of years a middle school teacher has taught at this level might affect the need for more specialized training. Changes in teacher preparation in general could influence the need for more and/or less training in such areas as classroom management, assessment procedures, and/or instructional strategies.

The Oregon Middle Level Association is currently working with TSPC regarding specialized preparation and certification for middle school teachers. The association might wish to employ the use of the researcher's questionnaire in a survey of all middle level educators in the state.

Research on middle level education, especially anything related to teacher preparation, is close to nonexistent in the Western United States. A study in Oregon might incite future research in this part of the country. Middle schools 
continue to increase in this area. These schools deserve to be staffed by qualified professionals.

Finally, the River's Edge School District should review the responses of their teachers and administrators about the need for special preparation and/or training in middle level concepts and decide to seriously embark on a middle school research project that would be beneficial to all of their middle level employees and their middle level students. They should also take a historical look at the processes they have previously used in their efforts to provide quality middle school programs and see where these processes have failed. They could then take an updated view of what they currently provide in the way of middle school programs and plan effective ways to ensure that they follow through on this project and reach success in this long endeavor. As a participant observer of the process of establishing middle school programs and of providing staff development and inservice opportunities for its middle school personnel, the researcher believes that there is great need for improvement in middle school education in the River's Edge School District. The voices of the district teachers and administrators, the responses to the study's questionnaire and interview questions, and the evaluation of the district historical data indicate that the time for improvement is now. 


\section{REFERENCES}

Alexander, W. M., \& MCEwin, C. K. (1984). Training the middle level educator--Where does the solution lie? NASSP Bulletin, 68(473), 6-11.

Alexander, W. M., \& MCEwin, C. K. (Eds.). (1988). Preparing to teach at the middle school level. Columbus, $\mathrm{OH}$ : National Middle School Association.

Alexander, W. M. \& \& McEwin, C. K. (1989). Schools in the middle: Status and progress. Columbus, OH: National Middle School Association.

Andermand, E. M., \& Maehr, M. I. (1994). Motivation and schooling in the middle grades. Review of Educational Research, 64(2), 287-307.

Arth, A. A., Johnston, H. I., Lounsbury, J. H., \& Toepfer, C. F. Jr. (1985). An agenda for excellence at the middle level. Reston, $\mathrm{VA}$ : National Association of Secondary School Principals.

Becker, H. J. (1990). Curriculum and instruction in the middle-grade schools. Phi Delta Kappan, $\underline{71}(6), 450-457$.

The Carnegie Council on Adolescent Development. (1989). Turning points: Preparing American youth for the 21 st century. New York: Carnegie Corporation of New York.

Clark, S. N., \& Clark, D. C. (1993). Middle level school reform: The rhetoric and the reality. Elementary School Journal, 93(5), 447-459.

Clements, T. (1994). TSPC approves licensing change. OMLA News, $\underline{5}(1), 1$.

Compton, M. F. (1988). University of Georgia. In W. M. Alexander \& C. K. MCEwin (Eds.), preparing to teach at the middle level (pp. 11-16). Columbus, OH: National Middle School Association.

DeMedio, D., \& Mazur-Stewart, M. (1990). Attitudes toward middle grade certification: A national survey. NASSP Bulletin, $\underline{74}(525), 64-71$. 
Doda, N. (1981). Teacher to teacher. Columbus, OH: National Middle School Association.

Dorman, G. (1984). Middle grades assessment program. Chapel Hill, NC: Center for Early Adolescence.

Dorman, G., Lipsitz, J., \& Verner, P. (1985). Improving schools for young adolescents. Educationall Leadership, $\underline{42}(6), 44-49$.

Eccles, J. S., Lord, S., \& Midgley, C. (1991). What are we doing to early adolescents? The impact of educational contexts on early adolescents. American Journal of Education, 94 (4), 521-542.

Eccles, J. S., Midgley, C., Wigfield, A., Buchanan, C. M.., Reuman, D., Flanagan, C., \& MacIver, D. (1993). Development during adolescence: The impact of stageenvironment $f i t$ on young adolescents' experiences in schools and in families. American Psychologist, $48(2)$, 90-99.

Eichhorn, D. H. (1966). The middle school. New York: The Center for Applied Research in Education.

Eichhorn, D. H. (1987). The middle school (2nd ed.). Columbus, $\mathrm{OH}$ : National Middle School Assoczation.

Epstein, J. I. (1990). What matters in the micldle grades: Grade span or practices? Phi Delta Kappan $\underline{71}(6), 438-$ 444 .

Epstein, J. L., \& MacIver, D. J. (1990). Education in the middle grades: Overview of national practices and trends. Columbus, OH: National Middle School Association.

Epstein, J. L., \& Petersen, A. C. (1991). Discussion and outlook: Research on education and development across the years of adolescence. American Journal of Education, $\underline{94}(4), 643-657$.

George, P. (1982). A response to Yoder: But we do need /good middle level schools. Educational Leadership, $40(2)$, 50-51.

George, P. S. \& Lawrence, G. (1982). Handbook for middle school teaching. Glenview, IL: Scott, Foresman and Company. 
George, P. S., \& Oldaker, L. L. (1985). Evidence for the middle school. Columbus, OH: National Middle School Association.

George, P. S., \& Oldaker, L. L. (1986). A national survey of middle school effectiveness. Educational Leadership, $\underline{43}(4), 79-85$.

George, P. S., Stevenson, C., Thomason, J., \& Beane, J. (1992). The middle school and beyond. Alexandria, VA: Association for Supervision and Curriculum Development.

Gillan, R. E. (1978). A national assessment of the effects of middle school teacher certification. Unpublished doctoral dissertation, Northwestern State University of Louisiana.

Gilstrap, R. I. (1994). Preparing teachers for the middle grades at the graduate level: Reflections and dilemmas. Current issues in middle level education, $\underline{3}(1), 93-101$.

Hamburg, D. A. (1993). The opportunities of early adolescence. Teachers College Record, 94 (3), 466-471.

Hamlin, K. (1992). Schools for early adolescents (Oregon School Reform series Policy Brief \#4). Portland, OR: Portland State University/Center for Urban Research in Education.

Holland, H. (1994). Staff training gets a second look. High Strides, $\underline{7}(2), 6$.

Irvin, J. L. (Ed.). (1992). Transforming middle level education: Perspectives and possibilities. Boston: Allyn \& Bacon.

Johnston, J. H., \& Markle, G. C. (1986). What research says to the middle level practitioner. Columbus, $\mathrm{OH}$ : National Middle School Association.

Lawton, E. J. (1989). A journey through time: A chronology of middle level education resources. Columbus, $\mathrm{OH}$ : National Middle School Association.

Lipsitz, J. (1984). Successful schools for young adolescents. New Brunswick, NJ: Transaction Books.

Lounsbury, J. H. (Ed.) . (1982). This we believe. Columbus, $\mathrm{OH}$ : National Middle School Association. 
Lounsbury, J. H. (Ed.) . (1984). Perspectives: Middle school education, 1964-1984. Columbus, $\mathrm{OH}$ : National Middle School Association.

Lounsbury, J. H. (1991a). As I see it. Columbus, OH: National Middle School Association.

Lounsbury, J. H. (Ed.). (1991b) . Professional certification and preparation for the middle level. Columbus, $\mathrm{OH}$ : National Middle School Association.

Lounsbury, J. H., Marani, J. V., \& Compton, M. F. (1980). The middle school in profile: A day in the seventh grade. Columbus, OH: National Middle School Association.

Lyon, G. (1994). Case studies of the structure, dynamics, and outcomes of interdisciplinary team organization in oregon middle schools. Unpublished doctoral dissertation, Portland state University, Portland.

MacIver, D. J. (1990). Meeting the needs of young adolescents: Advisory groups, interdisciplinary teaching teams, and school transition programs. Phi Delta Kappan, $11(6), 458-464$.

MacIver, D. J., \& Epstein; J. I. (1993). Middle grades research: Not yet mature, but no longer a child. Elementary School Journal, 93(5), 519-533.

Martin, T. (1993). "Turning points" revisited: How effective middle-grades schools address developmental needs of young adolescent students. Journal of Health Education, 24 $(6)$, S24-S27.

McEwin, C. K. (1983). Middle level teacher education and certification. NASSP Bulletin, 67(463), 78-82.

McEwin, C. K. (1989). Who they are how we teach. Columbus, $\mathrm{OH}$ : National Middle School Association.

McEwin, C. K., \& Alexander, W. (1982). Toward middle level teacher education. Middle School Journal, 14(1), 3-5, 15 .

McE'win, C. K., \& Allen, M. G. (1985). Moving toward middle level teacher certification. Middle School Journal, $\underline{16}(4), 18-20$. 
McPartland, J. M. (1990). Staffing decisions in the middle grades: Balancing quality instruction and teacher/students relations. Phi Delta Rappan, 71(6), 465-469.

Merenbloom, E. Y. (1988). Developing effective middle schools through faculty participation. Columbus, $\mathrm{OH}$ : National Middle School Association.

National Association of Secondary School Principals. (1985). An agenda for excellence at the middle level. Reston, VA: Author.

National Middle School Association. (1986). Professional certification and preparation for the middle level: A position paper of the National Middle School Association. Columbus, $\mathrm{OH}$ : Author.

National Middle School Association. (1989). NCATE accepts MU Teacher Education Guidelines. Middle Ground, Fall 1989 Edition, p. 4 .

National Middle School Association. (1990, February 16-18). National Council for Accreditation of Teacher Education: Guidelines handbook and matrix. Paper presented at the National Middle School Association Thematic Conference, Atlanta, GA.

National Staff Development Council. (1994). National staff development council's standards for staff development: Middle level edition. Oxford, $\mathrm{OH}$ : Author.

Oakes, J., Hunter-Quartz, K., Gong, J., Guiton, G., \& Lipton, M. (1993). Creating middle schools: Technical, normative, and political considerations. Elementary School Journal, $\underline{93}(5), 461-479$.

Page, F. M., Page, J. A., Dickinson, T., Warkentin, R., \& Tibbles, A. D. (1992). 4,000 voices. Columbus, $\mathrm{OH}$ : National Middle School Association.

Piaget, J. (1972). Intellectual evolution from adolescence to adulthood. Human Development, 15, 1-12.

Preparing teachers for the middle grades: A position paper. (1981). Middle School Journal, 12(4), 17-19.

Price, R. H., Cioci, M., Penner, W., \& Trautlein, B. (1993). Webs of influence: School and community programs that enhance adolescent health and education. Teachers College Record, 94(3), 487-521. 
Rottier, J., \& Whooley, J. E. (1986). An instrument for evaluating middle grade instruction programs. Middle School Journal, 17(3), 20-24.

Sale, I. L. (1979). Introduction to middle school teaching. Columbus, $\mathrm{OH}$ : Merrill Publishing Company.

Scales, P. C. (1991). A portrait of young adolescents in the 1990s. Chapel Hill: The University of North Carolina at Chapel Hill/Center for Early Adolescence.

Scales, P. C. (1992). Windows of opportunity: Improving middle grades teacher preparation. Chapel Hill: The University of North Carolina at Chapel Hill/Center for Early Adolescence.

Scales, P. C., \& MCEwin, K. C. (1994). Growing pains: The making of America's middle school teachers. Columbus, OH: National: Middle School Association.

Smith, J. (1992). Effective middle school teaching: Factors that promote and maintain it. Unpublished doctoral dissertation, Portland State University, Portland.

St. Clair, R. (1984). In search of excellence at the middle level. NASSP Bulletin, 68 (473), 1-5.

Steer, D. R. (Ed.). (1980). The emerging adolescent characteristics and educational implications. Fairborn, $\mathrm{OH}$ : National Middle School Association.

Swaim, J. (1982). Foreword. In J. H. Lounsbury (Ed.), This we believe. Columbus, $\mathrm{OH}$ : National Middle School Association.

Swaim, J., \& Needham, R. (1984). In search of excellence: The national reports--Implications for middle schools. Columbus, OH: National Middle School Association.

Takanishi, R. (1993). Changing views of adolescence in contemporary society. Teachers College Record, $94(3)$, $459-465$.

Takanishi, R. (1993). The opportunities of adolescence-research, interventions, and policy: Introduction to the special issue. American Psychologist, $\underline{48}(2), 85-87$.

Thomason, J., \& Williams, B. (1982). Middle schools are for me. Educational Leadership, $\underline{40}(2), 54-58$. 
Valentine, J. W., \& Mogar, D. C. (1992). Middle level certification: An encouraging evolution. Middle School Journal, 24 (2), 36-43.

Van Hoose, J., \& Strahan, D. (1988). Young adolescent development and school practices: Promoting harmony. Columbus, $\mathrm{OH}$ : National Middle School Association.

Vars, G. F. (1985). Graduate programs for junior high/middle school teachers: Four models from universities in Ohio. Middle School Journal, 16(2), 16-18.

Walzer, P. (1994, November/December). Teacher education misses the middle: Few colleges prepare teachers to lead middle school classrooms. High Strides, $\underline{7}(2), 1,4-5$.

Wiles, J., \& Bondi, J. (1986a). The essential middle school. Tampa, FL: Wiles, Bondi \& Associates, Inc.

Wiles, J., \& Bondi, J. (1986b). Making middle schools work. Alexandria, VA: Association for Supervision and Curriculum Development.

Wiper, K. (1995, February). Redesigning teacher licensure in Oregon. Oregon Education, pp. 19-20.

Whisler, J. (1990). Young adolescents and middle level education: A review of current issues, concerns, and recommendations. Aurora, CO: Mid-continent Regional Educational Laboratory.

Yin, R. K. (1989). Case study design and methods. Newbury Park, CA: SAGE publications, Inc.

Yoder, W. H. Jr. (1982). Middle school vs. junior high misses the point. Educational Leadership, $\underline{40}(2), 5$.

Youngblood, S. R. (1989). Middle level staff development needs: A survey of middle level educators. NASSP Bulletin, 73(515), 102-105. 
APPENDIX A

MIDDLE SCHOOL STAFF QUESTIONNAIRES 
TEACHER QUESTIONNAIRE

I . SCHOOL DEMOGRAPHICS

1. Indicate below the grade levels found in your school:

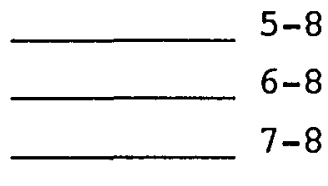

$7-8$

Other (Please specify)

2. Number of students enrolled in your school:

3. Number of full-time certified teaching staff in your school:

4. Number of certified administrative staff in your school

5. Number of certified counselor(s) in your school:

6. Number of years the school has operated as a middle school:

7. Does your school district have a middle school organization plan?

Yes No In concept only

\section{TEACHER DEMOGRAPHIC INFORMATION}

1. Age:

$20-29$

$30-39$

$40-49$

50 and over

2. Sex:

Male

Female

3. Academic Level:

(Check highest level)

Bachelor's Degree

Master's Degree

Other (Please specify) 
4. Undergraduate Major:

5. Total years of administrative experience: (Check one) $1-5$ years 11-15 years 6-10 years $16-20$ years over 20 years

6. How many years have you held your present administrative position?

years

7. How many years have you taught at the middle school or junior high level? years

8. What is the level of certification that you have in the state of Oregon? (Check one)

Principal

Vice Principal

Supervisor

9. Do you hold or have you ever held any other certification?

Yes No

If so, what is/was that certification?

III. SPECIAL PREPARATION

1. Have you had any training which directly prepared you for teaching at the middle school or junior high school level BEFORE you began teaching at this level?

Yes No

If yes, was this training at the graduate or undergraduate level?

Undergraduate Graduate

What kind of training? 
2. Please indicate below the level of training you received in each of the middle school concept areas indicate the degree of adequacy of such preparation by circling the appropriate number:

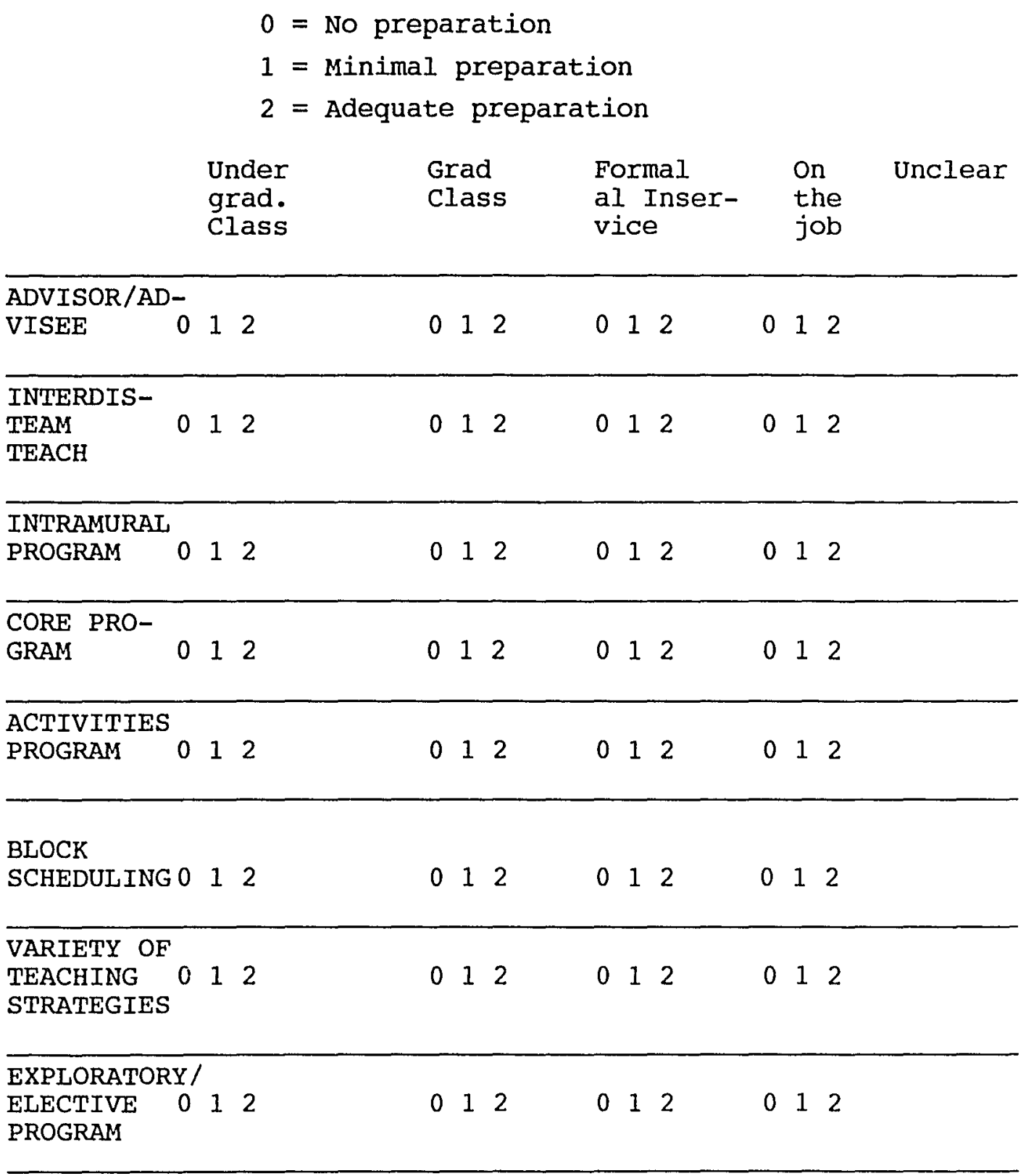


3. From the list below, rank the importance of the developmental needs of young adolescents as you perceive them:

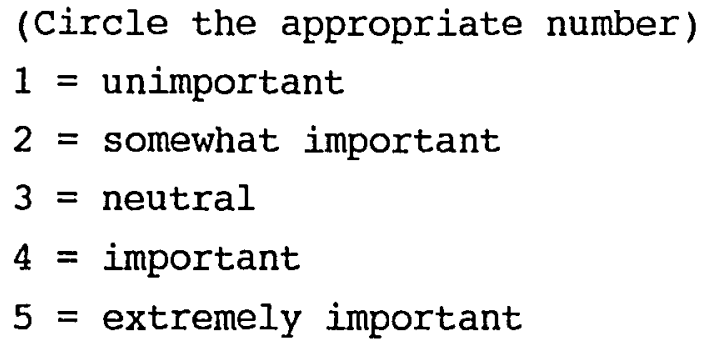

a) The need for diversity $\quad \begin{array}{llllll}1 & 2 & 3 & 4 & 5\end{array}$

b) The need for self-exploration and self-definition

$$
\begin{array}{lllll}
1 & 2 & 3 & 4 & 5
\end{array}
$$

c) The need for meaningful participation in school and $\begin{array}{llllll}\text { community } & 1 & 2 & 3 & 4 & 5\end{array}$

d) The need for positive social interaction with peers and $\begin{array}{llllll}\text { adults } & 1 & 2 & 3 & 4 & 5\end{array}$

e) The need for physical activity $1 \begin{array}{llllll} & 2 & 3 & 4 & 5\end{array}$

f) The need for competence and achievement

g) The need for structure and clear limits

$\begin{array}{lllll}1 & 2 & 3 & 4 & 5\end{array}$

$\begin{array}{lllll}1 & 2 & 3 & 4 & 5\end{array}$

4. Please list the types of courses or special training you feel would have better prepared you for teaching at the middle school level: 
5. Please list the types of instructional techniques you employ in your classroom on a regular basis:

6. Do you think special training/preparation in teaching at the middle school level is:

unnecessary desirable crucial

7. If desirable or crucial, why?

8. If desirable or crucial, what KIND training/preparation?

9. Should separate certification be required for middle level

of teachers

of administrators of counselors

10. If you could create a model preparation program for middle level teachers, what types of classes would you include?

11. Would you like the results of this survey sent to you? Yes No 


\section{ADMINISTRATOR QUESTIONNAIRE}

I. SCHOOL DEMOGRAPHICS

1. Indicate below the grade levels found in your school:
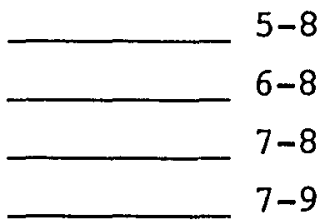

Other (Please specify)

2. Number of students enrolled in your school:

3. Number of full-time certified teaching staff in your school:

4. Number of certified administrative staff in your school:

5. Number of certified counselor(s) in your school:

6. Number of years the school has operated as a middle school:

7. Does your school district have a middle school organization plan? Yes No In concept only

\section{ADMINISTRATOR DEMOGRAPHIC INFORMATION}

1. Age:

$20-29$

$30-39$

$40-49$

50 and over

2. Sex:

Male

Female

3. Academic Level:

(Check highest level)

Master's Degree

Doctorate

Other (Please specify)

4. Undergraduate Major: 
5. Total years of administrative experience: (Check one)

$1-5$ years $6-10$ years
11-15 years

$16-20$ years

over 20 years

6. How many years have you held your present administrative position? years

7. How many years have you worked at the middle school or junior high level? years

8. What is the level of certification that you have in the state of Oregon? (Check one)

Principal

Vice-Principal

Supervisor

9. Do you hold or have you ever held any other certification?

Yes No

If so, what is/was that certification?

\section{SPECIAL PREPARATION}

1. Have you had any training which directly prepared you for working at the middle school or junior high school level BEFORE you began working at this level?

Yes No

If yes, was this training at the graduate or undergraduate level?

Undergraduate Graduate

What kind of training? 
2. Please indicate below the level of training you received in each of the middle school concept areas indicate the degree of adequacy of such preparation by circling the appropriate number:

$$
\begin{aligned}
& 0=\text { No preparation } \\
& 1=\text { Minimal preparation } \\
& 2=\text { Adequate preparation }
\end{aligned}
$$

$\begin{array}{lllll}\text { Under- } & \text { Grad. } & \text { Form- } & \text { Learn- } & \text { Un- } \\ \text { grad. } & \text { Class } & \begin{array}{l}\text { al Inser- ed on } \\ \text { vice }\end{array} & \text { the job } & \end{array}$

\begin{tabular}{lllllllllllllll}
\hline $\begin{array}{l}\text { ADVISOR/AD- } \\
\text { VISEE }\end{array}$ & 0 & 1 & 2 & 0 & 1 & 2 & 0 & 1 & 2 & 0 & 1 & 2 \\
\hline $\begin{array}{l}\text { INTERDIS. } \\
\text { TEAM } \\
\text { TEACHING }\end{array}$ & 0 & 1 & 2 & 0 & 12 & 0 & 12 & 0 & 12
\end{tabular}

\begin{tabular}{|c|c|c|c|c|}
\hline $\begin{array}{l}\text { ACTIVITIES } \\
\text { PROGRAM }\end{array}$ & $\begin{array}{lll}0 & 1 & 2\end{array}$ & $\begin{array}{lll}0 & 1 & 2\end{array}$ & $\begin{array}{lll}0 & 12\end{array}$ & $\begin{array}{lll}0 & 1 & 2\end{array}$ \\
\hline $\begin{array}{l}\text { BLOCK } \\
\text { SCHEDULING }\end{array}$ & $\begin{array}{lll}0 & 1 & 2\end{array}$ & $\begin{array}{lll}0 & 1 & 2\end{array}$ & 012 & $\begin{array}{lll}0 & 1 & 2\end{array}$ \\
\hline $\begin{array}{l}\text { VARIETY OF } \\
\text { TEACHING } \\
\text { STRATEGIES }\end{array}$ & 012 & $\begin{array}{lll}0 & 1 & 2\end{array}$ & 0112 & $\begin{array}{lll}0 & 1 & 2\end{array}$ \\
\hline $\begin{array}{l}\text { EXPLORATORY/ } \\
\text { ELECTIVE } \\
\text { PROGRAM }\end{array}$ & $\begin{array}{lll}0 & 1 & 2\end{array}$ & $\begin{array}{lll}0 & 1 & 2\end{array}$ & 0122 & $\begin{array}{lll}0 & 1 & 2\end{array}$ \\
\hline
\end{tabular}

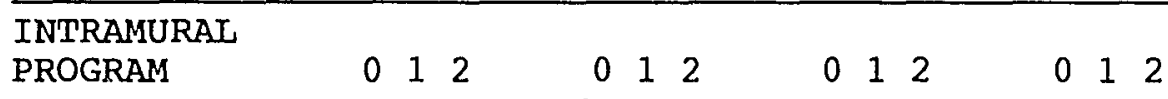

\begin{tabular}{llllllllllllllllll}
\hline CORE PRO- & 0 & 1 & 0 & 0 & 1 & 2 & 0 & 1 & 2 & 0 & 1 & 2
\end{tabular}


3. From the list below, rank the importance of the develcpmental

needs of young adolescents as you perceive them: (Circle the appropriate number)

1 = unimportant

2 = somewhat important

3 = neutral

4 = important

5 = extremely important

a) The need for diversity $\quad \begin{array}{llllll}1 & 2 & 3 & 4 & 5\end{array}$

b) The need for self-exploration

$\begin{array}{lllllll}\text { and self-definition } & 1 & 2 & 3 & 4 & 5\end{array}$

c) The need for meaningful

participation in school and community

$\begin{array}{lllll}1 & 2 & 3 & 4 & 5\end{array}$

d) The need for positive social

interaction with peers and adults

$\begin{array}{lllll}1 & 2 & 3 & 4 & 5\end{array}$

e) The need for physical activity

$\begin{array}{lllll}1 & 2 & 3 & 4 & 5\end{array}$

f) The need for competence and

$\begin{array}{lllllll}\text { achievement } & 1 & 2 & 3 & 4 & 5\end{array}$

g) The need for structure and

$\begin{array}{lllllll}\text { clear limits } & 1 & 2 & 3 & 4 & 5\end{array}$

4. Please list the types of courses or special training you feel would have better prepared you for teaching at the middle school level: 
5. Do you think special training/preparation in teaching at the middle school level is: unnecessary desirable crucial

6. If desirable or crucial, why?

7. If desirable or crucial, what KIND training/preparation?

8. Should separate certification be required for middle level

of teachers

of administrators of counselors

9. If you could create a model preparation program for middle level teachers, what types of classes would you include?

10. Would you like the results of this survey sent to you? Yes No 
APPENDIX B

DEMOGRAPHIC DATA CHARTS 


$$
\text { B-1 }
$$

Age of Respondents

\begin{tabular}{|c|c|c|c|c|c|c|}
\hline Group & & Age & $\begin{array}{l}\text { Survey } \\
\underline{\underline{f}}\end{array}$ & $\underset{\frac{q}{8}}{\text { Sample }}$ & $\begin{array}{l}\text { Interview } \\
\underline{\underline{f}}\end{array}$ & N Sample \\
\hline \multirow[t]{4}{*}{ Teach } & & -29 & 2 & 6 & 0 & 0 \\
\hline & & -39 & 6 & 60 & 1 & 10 \\
\hline & & -49 & 14 & 47 & 9 & 90 \\
\hline & 50 & $0+$ & 8 & 27 & 0 & 0 \\
\hline \multirow[t]{4}{*}{ Admin } & 20 & -29 & 0 & 0 & 0 & 0 \\
\hline & 30 & -39 & 1 & 10 & 0 & 0 \\
\hline & 40 & -49 & 9 & 90 & 3 & 100 \\
\hline & $50+$ & & 0 & 0 & 0 & 0 \\
\hline & & & $\cdot$ & B-2 & & \\
\hline \multicolumn{7}{|c|}{ Gender of Respondents } \\
\hline Group & & Gender & $\begin{array}{l}\text { Survey } \\
\underline{f}\end{array}$ & $\underset{q}{\text { Sample }}$ & $\begin{array}{c}\text { Interview } \\
\underline{f}\end{array}$ & $\underset{\substack{q \\
\text { Sample }}}{ }$ \\
\hline \multirow[t]{2}{*}{ Teacher } & ers & Male & 10 & 33 & 4 & 40 \\
\hline & & Female & 20 & 67 & 6 & 60 \\
\hline \multirow[t]{2}{*}{ Admin } & & Male & 8 & 80 & 1 & 33 \\
\hline & & Female & 2 & 20 & 2 & 67 \\
\hline
\end{tabular}


B-3

Academic Level of Respondents

\begin{tabular}{|c|c|c|c|c|c|c|}
\hline Group & $\begin{array}{l}\text { Academic } \\
\text { Level }\end{array}$ & & $\begin{array}{l}\text { Survey } s \\
\underline{f}\end{array}$ & $\underset{\frac{q}{8}}{\text { Sample }}$ & $\begin{array}{l}\text { Interview } \\
\underline{\underline{f}}\end{array}$ & Sample \\
\hline \multirow[t]{2}{*}{ Teach } & Bachelor's & & 14 & 47 & 3 & 30 \\
\hline & Master's & & 16 & 53 & 7 & 70 \\
\hline \multirow[t]{2}{*}{ Admin } & Master's & & 7 & 70 & 3 & 100 \\
\hline & Doctorate & & 3 & 30 & 0 & 0 \\
\hline \multicolumn{7}{|c|}{$\mathrm{B}-4$} \\
\hline \multicolumn{7}{|c|}{ Total Years of Experience } \\
\hline Group & Years & \multicolumn{3}{|c|}{$\begin{array}{lc}\text { Survey } & \text { Sample } \\
\underline{f} & \frac{8}{8}\end{array}$} & \multicolumn{2}{|c|}{$\begin{array}{l}\text { Interview } \underset{\underline{q}}{\underline{f}} \\
\underline{q}\end{array}$} \\
\hline \multirow[t]{5}{*}{ Teach } & $1-5$ & 3 & 10 & & 1 & 10 \\
\hline & $6-10$ & 2 & 7 & & 1 & 10 \\
\hline & $11-15$ & 10 & 33 & & 3 & 30 \\
\hline & $16-20$ & 3 & 10 & & 3 & 30 \\
\hline & $20+$ & 12 & 40 & & 2 & 20 \\
\hline \multirow[t]{5}{*}{ Admin } & $1-5$ & 3 & 30 & & 3 & 100 \\
\hline & $6-10$ & 1 & 10 & & 0 & 0 \\
\hline & $11-15$ & 6 & 60 & & 0 & 0 \\
\hline & $16-20$ & 0 & 0 & & 0 & 0 \\
\hline & $20+$ & 0 & 0 & & 0 & 0 \\
\hline
\end{tabular}




$$
\text { B-5 }
$$

Total Years of Middle School Experience

\begin{tabular}{|c|c|c|c|c|c|}
\hline \multirow[t]{2}{*}{ Group } & \multirow[t]{2}{*}{ Years } & \multicolumn{2}{|c|}{ Survey } & \multicolumn{2}{|c|}{ Interview } \\
\hline & & $\underline{\mathbf{f}}$ & 8 & $\underline{f}$ & 字 \\
\hline Teachers & $\begin{array}{r}1 \\
2 \\
3 \\
4 \\
5 \\
6 \\
7 \\
8 \\
9 \\
10 \\
11 \\
12 \\
13 \\
14 \\
15 \\
16 \\
17 \\
18 \\
19 \\
20 \\
21 \\
22 \\
23 \\
24 \\
25 \\
26 \\
27 \\
28 \\
29 \\
30 \\
31 \\
32 \\
33\end{array}$ & 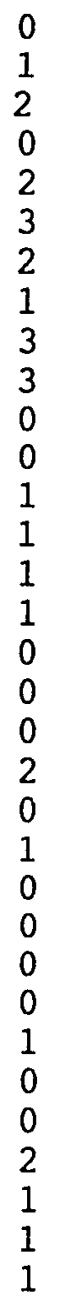 & $\begin{array}{r}0 \\
3 \\
7 \\
0 \\
7 \\
10 \\
7 \\
3 \\
10 \\
10 \\
0 \\
0 \\
3 \\
3 \\
3 \\
3 \\
0 \\
0 \\
0 \\
7 \\
0 \\
3 \\
0 \\
0 \\
0 \\
0 \\
3 \\
0 \\
0 \\
7 \\
3 \\
3 \\
3\end{array}$ & $\begin{array}{l}0 \\
0\end{array}$ & $\begin{array}{r}0 \\
0 \\
20 \\
0 \\
0 \\
10 \\
10 \\
0 \\
10 \\
10 \\
0 \\
0 \\
10 \\
0 \\
10 \\
10 \\
0 \\
0 \\
0 \\
0 \\
0 \\
0 \\
0 \\
0 \\
0 \\
0 \\
0 \\
0 \\
0 \\
10 \\
0 \\
0 \\
0\end{array}$ \\
\hline
\end{tabular}




$$
\text { B-6 }
$$

Total Years of Middle School Experience

\begin{tabular}{|c|c|c|c|c|c|}
\hline \multirow[t]{2}{*}{ Group } & \multirow[t]{2}{*}{ Years } & \multicolumn{2}{|c|}{ Survey } & \multicolumn{2}{|c|}{ Interview } \\
\hline & & $\underline{f}$ & $z$ & $\underline{f}$ & 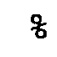 \\
\hline Admin & $\begin{array}{r}1 \\
2 \\
3 \\
4 \\
5 \\
6 \\
7 \\
8 \\
9 \\
10 \\
11 \\
12 \\
13 \\
14 \\
15 \\
16 \\
17 \\
18 \\
19 \\
20 \\
21\end{array}$ & $\begin{array}{l}1 \\
0 \\
2 \\
1 \\
1\end{array}$ & $\begin{array}{r}10 \\
0 \\
20 \\
10 \\
0 \\
10 \\
10 \\
0 \\
0 \\
0 \\
10 \\
10 \\
0 \\
0 \\
0 \\
10 \\
0 \\
0 \\
0 \\
0 \\
10\end{array}$ & $\begin{array}{l}1 \\
0 \\
1 \\
0 \\
0 \\
1 \\
0 \\
0 \\
0 \\
0 \\
0 \\
0 \\
0 \\
0 \\
0 \\
0 \\
0 \\
0 \\
0 \\
0 \\
0 \\
0 \\
0 \\
0 \\
0 \\
0\end{array}$ & $\begin{array}{r}33 \\
0 \\
33 \\
0 \\
33 \\
0 \\
0 \\
0 \\
0 \\
0 \\
0 \\
0 \\
0 \\
0 \\
0 \\
0 \\
0 \\
0 \\
0 \\
0 \\
0\end{array}$ \\
\hline
\end{tabular}




$$
\text { B-7 }
$$

Distribution of Respondents by Subject Area Taught

\begin{tabular}{|c|c|c|c|c|c|c|c|}
\hline Subject Area & & & & & $\overline{\mathrm{EVI}}$ & & \\
\hline & $\underline{f}$ & $q$ & & $\underline{f}$ & & $q$ & \\
\hline Language Arts / & & & & & & & \\
\hline Literature & 24 & 60 & & 4 & & 40 & \\
\hline Math & 7 & 23 & & 1 & & 10 & \\
\hline Science & 3 & 10 & & 2 & & 20 & \\
\hline $\begin{array}{l}\text { Physical Education/ } \\
\text { Health }\end{array}$ & 3 & 10 & & 1 & & 10 & \\
\hline Social Studies & 13 & 43 & & 0 & & 0 & \\
\hline Art & 1 & 3 & & 0 & & 0 & \\
\hline Special Education & 1 & 3 & & 1 & & 10 & \\
\hline Counselor & 1 & 3 & & 1 & & 10 & \\
\hline Media Specialist & 1 & 3 & & 0 & & 0 & \\
\hline & & $3-8$ & & & & & \\
\hline & & ation & Level. & & & & \\
\hline Certification & & & & & & er & \\
\hline & $\underline{f}$ & & $q$ & & $\underline{\underline{f}}$ & & $z$ \\
\hline Elementary & 17 & & 57 & & 3 & & 30 \\
\hline Secondary & 8 & & 27 & & 4 & & 40 \\
\hline Specialist & 10 & & 33 & & 3 & & 30 \\
\hline
\end{tabular}

